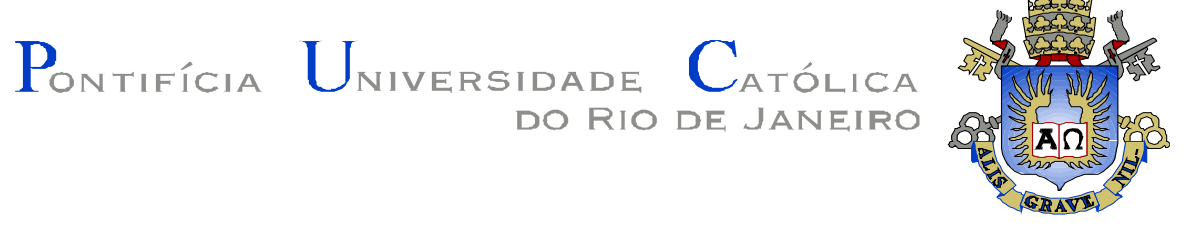

Pedro Diniz Bernardo

\title{
Indução de Humor por Realidade Virtual
}

Dissertação de mestrado

Dissertação apresentada como requisito parcial para obtenção do grau de Mestre pelo Programa de PósGraduação em Psicologia (Psicologia Clínica e Neurociências) da PUC-Rio.

Orientador: Prof. Daniel Correa Mograbi

Rio de Janeiro

Março de 2019 
Pontifícia Universidade C $a$ tóllica

Pedro Diniz Bernardo

\title{
Indução de Humor por Realidade Virtual
}

Dissertação de mestrado

Dissertação apresentada como requisito parcial para obtenção do grau de Mestre pelo Programa de PósGraduação em Psicologia (Psicologia Clínica e Neurociências) da PUC-Rio. Aprovada pela Comissão Examinadora.

\author{
Prof. Daniel Correa Mograbi \\ Orientador \\ Departamento de Psicologia - PUC-Rio
}

Prof.a Marcele Regine de Carvalho

Departamento de Psicologia - UFRJ

Prof. Jesus Landeira-Fernandez

Departamento de Psicologia - PUC-Rio

Rio de Janeiro, 29 de março de 2019 
Todos os direitos reservados. E proibida a reprodução total ou parcial do trabalho sem a autorização da universidade, do autor e do orientador.

Pedro Diniz Bernardo

Graduou-se em Psicologia pela Pontifícia Universidade Católica do Rio de Janeiro em 2015.

Ficha Catalográfica

Bernardo, Pedro Diniz

Indução de humor por realidade virtual / Pedro Diniz Bernardo; orientador: Daniel Correa Mograbi. - 2019.

104 f. ; $30 \mathrm{~cm}$

Dissertação (mestrado)-Pontifícia Universidade Católica do Rio de Janeiro, Departamento de Psicologia, 2019.

Inclui bibliografia

1. Psicologia - Teses. 2. Indução de humor. 3. Emoção. 4. Respostas fisiológicas. 5. Realidade virtual. 6. Consciência. I. Mograbi, Daniel Correa. II. Pontifícia Universidade Católica do Rio de Janeiro. Departamento de Psicologia. III. Título. 


\section{RESUMO}

Bernardo, Diniz Pedro; Mograbi, Daniel Correa (Orientador). Indução de Humor na Realidade Virtual. Rio de Janeiro, 2019. 104p. Dissertação de Mestrado - Departamento de Psicologia, Pontifícia Universidade Católica do Rio de Janeiro.

A Realidade Virtual tem seu uso sendo disseminado em diversas áreas de conhecimento, incluindo o campo da Psicologia. Assim, vem sendo utilizada como método terapêutico e também em pesquisas científicas. Um desses usos no campo experimental se dá em Procedimentos de Indução de Humor, nos quais o indivíduo é inserido no ambiente virtual por meio de um equipamento eletrônico como mediador. Essa dissertação apresenta dois artigos vinculados a essa temática. $\mathrm{O}$ primeiro se trata de uma revisão sistemática realizada para explorar a forma em que a Realidade Virtual é utilizada em indução de humor. Nesta revisão encontramos evidências da eficácia da técnica, além de identificarmos o equipamento de Óculos de Realidade Virtual como o mais utilizado, a população universitária como amostra mais comum e a atividade eletrodérmica como medida fisiológica mais frequentemente utilizada para avaliação da indução. $O$ segundo artigo apresenta um estudo empírico com a intenção de investigar a Realidade Virtual na indução de humor e melhora na capacidade interoceptiva. As análises indicaram efeito de interação entre tempo e grupo para atividade eletrodérmica. Tamanhos de efeito moderados a grandes foram observados para maior reatividade emocional negativa e melhor interocepção, sugerindo que com uma amostra maior esses efeitos poderiam ser significativos. Os resultados de frequência cardíaca não apresentaram diferenças significativas. Os resultados apresentados da atividade eletrodérmica indicam sucesso na indução de emoção. $\mathrm{O}$ presente estudo se mostra relevante por trazer novos procedimentos e tecnologias para auxiliar nas pesquisas em psicologia, com a Realidade Virtual se mostrando eficaz em estudos de difícil aplicação. O caráter clínico do estudo é reforçado por sua a intenção em melhorar a capacidade cognitiva da interocepção, apresentando indícios da possibilidade de seu uso em tratamentos clínicos, ajudando o indivíduo em eventos com conteúdo emocional, onde a capacidade de 
identificar e discernir suas emoções e sensações corporais possibilitaria gerar respostas mais adaptativas.

\section{Palavras-chave}

Indução de humor; emoção; respostas fisiológicas, realidade virtual; consciência. 


\section{ABSTRACT}

Bernardo, Pedro Diniz; Mograbi, Daniel Correa (Advisor). Mood

Induction in Virtual Reality Environment. Rio de Janeiro, 2019. 104p. Dissertação de Mestrado - Departamento de Psicologia, Pontifícia Universidade Católica do Rio de Janeiro.

Virtual Reality has been disseminated in several areas of knowledge, including the field of Psychology, for example being used as a therapeutic method and in scientific research. One of these uses as an experimental tool is as a Mood Induction Procedure, in which the individual experiences a virtual environment mediated through electronic equipment. This dissertation presents two articles related to this theme. The first is a systematic review carried out to explore ways in which Virtual Reality can be used as a mood induction procedure. In this review we found evidence for the efficacy of the method, in addition to identifying the Headmounted Display equipment as the most used, college students as the most common sample and electrodermal activity as the most frequently used physiological measure. The second article presents an empirical study investigating Virtual Reality as a mood inductor and how it can be used to promote emotional reactivity and improve interoception. The analyses indicated significant increases for electrodermal activity in an emotional condition elicited by Virtual Reality. Moderate to large effect sizes were observed for negative emotional reactivity and for interoception, which could be significant with a larger sample. Heart rate results did not show significant differences. The presented results of the electrodermal activity indicate successful mood induction. This study is relevant for presenting new procedures and technologies to assist in research in psychology, with Virtual Reality being a potential experimental tool. The clinical character of the study is reinforced by the promising results of the pilot study in relation to interoception, suggesting that Virtual Reality may be employed in clinical treatments, helping subjects to identify and discern their emotions and sensations in emotional situations, which would allow the development of more adaptive responses. 


\section{Keywords}

Mood induction; emotion; physiological response; virtual reality; awareness. 


\section{Agradecimentos}

Agradeço ao meu orientador Prof. Daniel Mograbi, pela confiança e dedicação, por se fazer presente quando necessário e sempre estar atento às demandas de orientação. Sua participação foi imprescindível na conclusão desta etapa.

Agradeço aos membros da banca, pelo auxílio na estruturação e lapidação deste trabalho.

Agradeço aos Professores do programa de Pós-Graduação e também os funcionários do departamento, pelos ensinamentos e auxílio concedidos ao longo dessa jornada. Em especial, à Professora Norma Franco, pelo apoio e confiança na disciplina de estágio em docência.

Agradeço ao Departamento de Informática, em especial ao Renato Cherullo, pela disponibilidade em prestar auxílio com os equipamentos

Agradeço a PUC-Rio, por me auxiliare ao longo do curso e assim, possibilitando a conclusão deste trabalho.

Agradeço aos amigos do Mograbilab, pela união, pelo auxílio e pela comunhão do cotidiano. O suporte fornecido foi de grande importância para meu crescimento profissional e pessoal.

Agradeço aos meus amigos e a minha família, pelo apoio e pelo incentivo diário, sendo importante base para minha formação.

O Presente trabalho foi realizado com apoio da Coordenação e Aperfeiçoamento de Pessoal Nível Superior - Brasil (CAPES) - Código de Financiamento 001 


\section{Lista de Figuras}

\section{Artigo 1}

Figura 1 - Procedimento de seleção de artigos para a revisão 28

\section{Artigo 2}

Figura 1 - Modelo gráfico do procedimento de testagem 75

Figura 2 - Gráfico das médias de Frequência Cardíaca ...................... 77

Figura 3 - Gráfico das médias de Atividade eletrodérmica ................... 78

Figura 4 - Gráfico das médias de Reatividade Emocional Negativa ...... 78

Figura 5 - Gráfico das médias de Reatividade Emocional Positiva ........ 79

Figura 6 - Gráfico das médias de Reatividade Emocional Total ........... 79

Figura 7 - Gráfico das médias de Interocepção .................................. 80

Figura 8 - Gráfico da média de Presença ..................................... 80 


\section{Lista de Tabelas}

\section{Artigo 1}

Tabela 1 - Termos utilizados para busca nas bases de dados

Tabela 2 - Resultados descritos da revisão sistemática 29

\section{Artigo 2}

Tabela 1 - Dados sociodemográficos e clínicos 77 


\section{Lista de Abreviações}

AV - Ambiente Virtual
BDI - Inventário de Depressão de Beck

CAVE - Caverna Virtual

HAM-A - Questionário de Ansiedade de Hamilton

HBD - Detecção de batimentos cardíacos

HMD - Óculos de Realidade Virtual

IEC - Instituto Estadual do Cérebro Paulo Niemeyer

IPQ - Questionário de Presença Igroup

MAIA-VB2 - Avaliação Multidimensional da Consciência Interoceptiva

QRE - Questionário de Regulação Emocional

RV - Realidade Virtual

SAM - Escala de Auto avaliação Manikin

STAI - Inventário de Traço-Estado de Ansiedade

TAS-20 - Escala de Alexitimia de Toronto

VAS - Escala Análoga Visual

WEIRD - Western, Educated, Industrialized, Rich and Democratic amostras com população occidental, escolarizada, com acesso à indústria, grande poder aquisitivo e de países democráticos 


\section{Sumário}

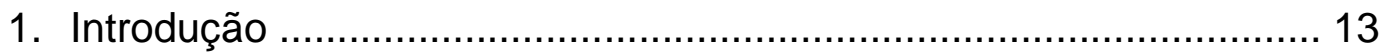

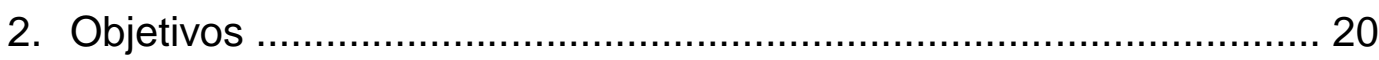

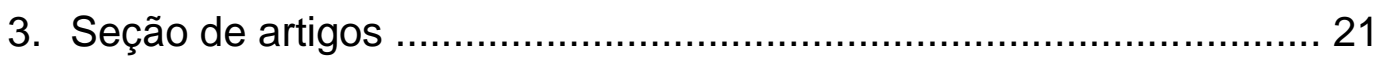

Artigo 1: Indução de humor por realidade virtual: Uma revisão sistemática dos achados recentes.................................................................... 22

Artigo 2: Indução de humor por realidade virtual na promoção de autoconsciência - Um estudo piloto.................................................... 66

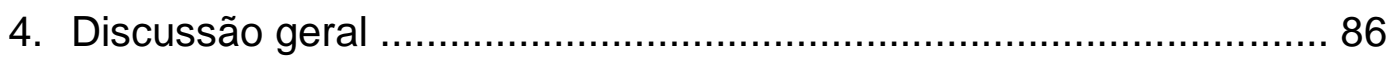

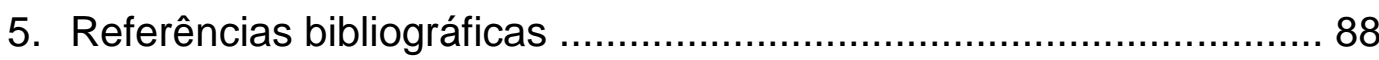

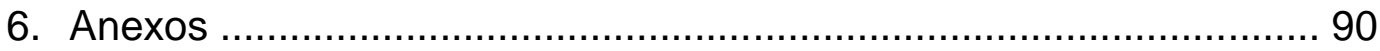




\section{Introdução}

1.1. Emoção

Simbolizando um movimento de dentro para fora, do latim movere (mover), a palavra emoção é utilizada para nomear nossos estados internos. A emoção vem sido estudada pela Filosofia desde a antiguidade. Já na segunda metade do século XIX iniciou o período onde os processos cognitivos ganham foco nos interesses científicos. (Barreto \& Ponte e Silva, 2010). Surgindo quando presenciamos um episódio importante, as emoções podem aparecer automaticamente ou mesmo quando pensamos sobre tal episódio. Assim, as emoções abrangem uma gama de respostas, tais como reações fisiológicas, comportamentais e subjetivas que irão ter impacto nos eventos do cotidiano (Gross, 2002). Grande parte dos teóricos incluem reação muscular, expressão comportamental, cognição e afeto subjetivo na definição dos elementos da emoção (Reeve, 2014). O indivíduo nesse episódio emocional pode ou não ter consciência da emoção gerada e, estar ciente, pode ser determinante na característica dessa emoção (Miguel, 2015).

\subsection{Consciência das emoções}

Cada indivíduo experimenta emoções em sua própria maneira. Assim, há aqueles que possuem a capacidade de diferenciar uma gama de diferentes emoções básicas vivenciadas, e há aqueles que as agrupam em positivas ou negativas, sem uma maior capacidade de distinção (Barrett, Gross, Christensen \& Benvenuto, 2001). Tendo um papel essencial no cotidiano, as emoções permitem ao indivíduo avaliar os eventos vivenciados, comparando-os com sua motivação e metas, e assim permitindo que uma resposta seja direcionada ao evento em forma de ação. O processo citado acima explicaria o papel adaptativo da emoção, pois possibilita a criação de gostos pessoais, de motivações e desejos que norteariam a vida do indivíduo. Os sentimentos seriam a experiência subjetiva das emoções, fazendo parte do processo cognitivo. Diferenciam-se das respostas emocionais automáticas por estas terem cunho fisiológico, preparando o corpo do indivíduo para ação frente à situação. A consciência do sentimento sobre um evento emocional, unida ao histórico de experiências anteriores, promove a capacidade de o indivíduo realizar uma ação-resposta, de maneira a facilitar e enriquecer suas 
vivências. Porém, a consciência de um sentimento sobre uma emoção negativa pode gerar comportamentos disfuncionais. Dito isto, a consciência das emoções no reconhecimento de sentimentos negativos pode levar o indivíduo a buscar ajuda clínica ou a ignorá-los e buscar suporte em respostas não adaptativas (e.g. abuso de substâncias; Chhatwal \& Lane, 2016). Ainda que o estado emocional de um indivíduo se modifique, há certa estabilidade nas experiências emocionais, onde uma emoção específica tende a se repetir mesmo em situações não similares. Tal afirmação reforça o impacto da personalidade na experiência emocional, que teria maior responsabilidade na estabilidade das emoções que o ambiente (Lucas \& Baird, 2004).

A patologia que afeta a consciência das emoções se chama Alexitimia, podendo ser traduzida do grego como "sem palavras para o sentimento", é um termo criado por Sifneos (1972) para descrever pacientes com dificuldades de nomear emoções e sentimentos. Possui três pilares: dificuldade em expressar sentimentos e diferenciar de sensações corporais, baixa capacidade de imaginação e pensamento operacional. Apesar de ser testada clinicamente, não se trata de uma doença em si, mas uma desordem psiquiátrica relacionada a outras questões médica, ainda que haja evidências de sua independência que possibilitaria a categorização em disfunção afetivo-cognitiva, associada à condição patológica e por danos na vida social (Freire, 2010).

\subsection{Medidas de Avaliação Emocional}

A mensuração quantitativa das emoções pode ser complicada pela individualidade dos sentimentos apresentados no estado de humor de um indivíduo. Dentre os diversos métodos de avaliação, a resposta emocional pode ser avaliada pela fisiologia, por meio de atividade eletrodérmica, frequência cardíaca, neuroimagem. A avaliação pela subjetividade se dá pela utilização dos questionários e escalas de autorrelato. Já a avaliação comportamental é aferida por expressão facial, voz e movimentos de aproximação ou evitação (Mauss, \& Robinson, 2009).

Há um século, as respostas autônomas já eram tema de estudo no tema das emoções, ainda que não haja consenso da relação das emoções e organização do sistema nervoso autônomo. Os autores podem ter teorias opostas (Kreibig, 2010). Alguns autores afirmam que não é possível relacionar emoções e respostas fisiológicas específicas com exatidão, sendo apenas possível de relacionar algumas respostas com 
afeto negativo e positivo, também indicando a existência de moderadores entre emoção e fisiologia (Feldman-Barrett, 2006). Um posicionamento equilibrado é sugerido em uma meta-análise sobre respostas fisiológicas na emoção, apresentando graus de especificidade autonômica na emoção, tendo possíveis atividades autonômicas específicas em situações contextuais, porém com maiores evidências encontradas em padrões de valência afetiva. Ainda, as limitações da meta-análise acabam por reduzir a capacidade de generalização (Cacioppo, Berntson, Larsen, Poehlmann, \& Ito, 2000). Apresentando oposição aos pensamentos de Feldman-Barrett, há também o pensamento de que a não especificidade dos padrões fisiológicos na emoção teriam papel na a adaptação humana. A diferenciação das respostas do sistema nervoso autônomo se

relaciona com os distintos objetivos das emoções e nortearia o comportamento (Stemmler, 2009). Na revisão de Kreibig (2010) sobre estudos que induziram humor por diversos métodos, como o uso de clipes de filmes, imagens, expressões faciais e músicas, a frequência cardíaca apresentou aumento em emoções negativas, como raiva, medo, nojo por contaminação e tristeza com choro, e positivas, como prazer e alegria. Quanto à tristeza aguda, tristeza sem choro, nojo por mutilação e afeição, a frequência cardíaca apresentou queda. Quanto a atividade eletrodérmica, as emoções de tristeza aguda, tristeza sem choro e alívio apresentaram redução. As outras emoções listadas apresentaram aumento, que pode ter como causa a preparação motora da emoção (Kreibig, 2010).

\subsection{Interocepção}

Interocepção pode ser definida como a capacidade de percepção das sensações corporais (ref). É diferenciada da exterocepção, a percepção dos acontecimentos externos ao corpo e da propriocepção, a percepção da posição ocupada pelo corpo no espaço. A interocepção possui três pilares: precisão, sensibilidade e consciência (ref). A precisão interoceptiva é caracterizada por ser pragmática, podendo discriminar e medir um comportamento específico. A sensibilidade interoceptiva envolve a subjetividade e engajamento do indivíduo nas sensações corporais. A consciência interoceptiva tem caráter metacognitivo, avaliando a relação da precisão e sensibilidade percebidas com as medidas e comportamentos reais (Garfinkel, Seth, Barrett, Suzuki, \& Critchley, 2015). Tem como subdivisões principais a sensitividade interoceptiva, sendo caracterizada pela detecção objetiva das sensações viscerais, comumente avaliadas por tarefas de detecção 
de batimento cardíaco (HBD) e interocepção metacognitiva, caracterizada por crenças reflexivas sobre suas sensações corporais (Yoris et al, 2015).

A interocepção vem ganhando foco nas pesquisas científicas durante os últimos anos, com estudos de neuroimagem destacando o papel do córtex cingulado insular e anterior para auto percepção (ref). Autores como Damásio (2003) indicaram conexões entre auto percepção e percepção interoceptiva. Este autor indicou também a ligação entre cognição e tomada de decisão com interocepção. Há evidencias ainda da relação entre comprometimento da interocepção e transtornos psiquiátricos, como ansiedade e depressão (Payne et al, 2015). Estímulos recebidos por indivíduos com alta sensitividade interoceptiva comumente são classificados como bastante excitatórios, intensos e também estressantes em comparação com as classificações dadas por indivíduos com baixa sensitividade.

Ainda, aparentemente há relações entre interocepção e emoções experienciadas no cotidiano (Sedeño et al, 2014). Podemos considerar que a consciência dos estados corporais de um indivíduo está relacionada com a regulação emocional, já que este processo está frequentemente ligado à atenção e consciência do estado emocional. A teoria de que estímulos emocionais gerariam atividades fisiológicas especificas foi sugerida por William James (1894), propondo também que a percepção das atividades corporais levaria à experiência emocional. Damásio (1999) afirma que cognição e comportamento seriam influenciados por estados emocionais evocados por marcadores somáticos, isto é, representações de ativações corporais com papel fundamental na produção de sentimentos, o componente subjetivo das emoções (Füstös, 2012).

\subsection{Regulação Emocional}

O cotidiano atual é permeado de estímulos que podem gerar emoções. Assim, a constante presença de emoções necessita de estratégias para a manutenção do equilíbrio emocional, como a Regulação Emocional, que são processos que auxiliam o indivíduo a suportar a intensidade de emoções, sejam confortáveis ou desconfortáveis (Cruvinel \& Boruchovitch, 2010). A regulação emocional é muitas vezes caracterizada como a capacidade de controlar a experiência e a expressão emocional, tendo como consequência a redução da ativação emocional. Em contrapartida, há o enfoque na 
capacidade de monitorar e avaliar a experiência emocional, apontando a importância do desenvolvimento da consciência das emoções. Considerando o contraste de controlar e avaliar as emoções experimentadas, algumas tentativas de regulação para evitar emoções indesejadas podem ser não adaptativas, e assim, estar relacionadas à existência de transtornos psicológicos. Tentativas de controlar a expressão emocional podem levar ao aumento da atividade fisiológica e também a desregulação emocional. Formas de regulação adaptativas envolveriam a capacidade de manipular a intensidade e duração de uma emoção e não a extinguir, e assim, o indivíduo conseguiria avaliar e tomar controle sobre seu comportamento mediante o evento emocional (Gratz \& Roemer, 2004).

Emoções demandam respostas comportamentais e fisiológicas ao evento que as disparou. A flexibilidade das ações-respostas possíveis em um evento de conteúdo emocional é o que possibilita a regulação emocional. A regulação emocional vai além de evitar emoções negativas, alcançando toda valência de emoções. Comumente, as estratégias de regulação ocorrem de forma consciente, mas podem ocorrer inconscientemente. Assim, a regulação emocional não é necessariamente boa ou má, apenas auxilia um indivíduo a vivenciar uma experiência emocional que se apresenta muito intensa, e, assim, permitindo o indivíduo a manipular sua duração e intensidade (Gross, 2002). Os processos de regulação de emoção são definidos em grupos. Tais processos podem ocorrer antes da geração de emoção (focada nos antecedentes) ou depois da geração de emoção (focada nas respostas). Seleção da Situação: uma situação pode ser escolhida para evitar estímulos os quais o indivíduo não queira lidar. Modificação da Situação: alterar o impacto emocional de uma situação através de manipulação da mesma. Realocação da Atenção: pode escolher um aspecto ao qual o indivíduo foca. Ainda há possibilidade de reduzir o impacto emocional ainda que o indivíduo já tenha selecionado, modificado e atendido uma situação. Reavaliação Cognitiva trata dos significados que serão ligados à situação, que assim permite ocorrer tendências de resposta emocional seja fisiológica, experimental ou comportamental. Modulação da Resposta: seria influenciar as tendências de respostas que foram induzidas (Gross, 1998). 


\subsection{Realidade Virtual}

A Realidade Virtual é composta por softwares e hardwares que permitem a criação de aplicações, com as simulações sendo apresentadas por um computador conectado a um equipamento eletrônico específico para realizar a interação humanomundo virtual. Seu funcionamento ocorre com o hardware recebendo comandos de controle, sendo gerenciados pelo software, que então se transformam em um mundo virtual multissensorial. O mundo virtual pode representar tanto algo já existente no mundo real, criar um mundo imaginário ou mesmo ser usado para representar acontecimentos ou objetos reais que normalmente não temos acesso (Riva, 2009). Certos componentes são necessários para o funcionamento da realidade virtual, aqui listados: o sistema de renderização gráfica, que apresenta o ambiente virtual. $\mathrm{O}$ software para criação e manutenção dos objetos virtuais, dá forma aos objetos e acontecimentos no ambiente virtual. O Input, que seriam as informações de comando dadas pelo usuário para a RV. O Output, que seriam os fatores multissensoriais gerados na RV que fazem parte da imersão (Burdea \& Coiffet, 2003). Listando os equipamentos de utilização da $\mathrm{RV}$, temos: os Óculos de $R V$, sendo um equipamento de máxima imersão, onde o usuário seria inserido no ambiente, tendo seus movimentos sincronizados para serem fielmente representados no ambiente virtual. CAVE (Cave Automatic Virtual Environment), consistindo de uma sala com enormes telas que projetariam o ambiente virtual e permitindo o uso coletivo da RV. A Telepresença, onde o usuário tem acesso a um ambiente à distância, realizando operações de modo remoto. Na Realidade Aumentada, o mundo real é complementado com objetos virtuais sendo acessados por meio de um equipamento eletrônico, como o celular. RV por Computadores é possível com imersão subjetiva, que seria melhorada por visão estereoscópica e manipulada por mouse ou controles. No tocante ao uso da RV no campo da Psicologia, é comum o uso no tratamento de transtornos de ansiedade, onde os pacientes aprendem a manejar as situações que seriam gatilho de seu problema. Isso seria possível pela RV oferecer um ambiente mais seguro e controlável do que as situações reais, onde o paciente enfrentaria o estímulo fóbico com intensidades variadas até se dessensibilizar. A RV apresenta uma interação humano-computador que permite a interação com um ambiente computadorizado de maneira natural, servindo como um meio tão eficaz em induzir emoções quanto à realidade, que é possível por meio da sensação de presença. Podendo explorar e interagir com o ambiente possuindo maior 
segurança das consequências, tendo em vista que não ocorrerão danos reais, assim o paciente pode experimentar da RV de forma mais completa, ainda que respondendo emocionalmente ao estímulo (Riva, 2009).

\subsection{Realidade Virtual na Psicologia}

Apresentando um ambiente tridimensional interativo que permite constante troca entre o usuário e o mundo virtual, as possibilidades ilimitadas desse novo paradigma trazem o usuário como um ser que recebe informações e atua sobre o ambiente em que está imerso e se sente presente. A sensação de presença se dá pelas interações sensoriais e motoras e o grau de realismo do ambiente virtual. Com um olhar histórico, as técnicas de imagem mental tem sido base para muitas metodologias terapêuticas, seguindo da interpretação dos sonhos até reestruturação cognitiva, com o intuito atuar sobre as representações mentais da realidade de um indivíduo. A RV pode ser considerada um avanço dessas técnicas, dando forma ao imaginário e incluindo os outros sentidos ao foco imagético. A RV pode atuar como um complemento para as terapias comportamentais, expondo o indivíduo ao estímulo que causa a disfunção e assim, trabalhar para que a resposta seja diferente das disfuncionais (Vincelli, 1999). Imergir o usuário em um ambiente virtual que o mesmo se sinta presente como no ambiente real possui custos reduzidos em comparação com outras formas de tratamento clínico. O sucesso do uso da RV na psicologia pode ser proveniente da capacidade de recriar um mundo tridimensional em laboratório, em conjunto com o potencial da RV em trabalhar com faculdades cognitivas como memória e imaginação, que seriam limitadas apenas pela capacidade do usuário. $\mathrm{O}$ ambiente virtual permitiria superar tais limites, gerando realidades mais vívidas do que as da memória e imaginação (Glantz, Durlach, Barnett \& Aviles (1997). O enorme potencial de criação dá a RV a flexibilidade de servir como intervenção psicológica em diversas questões e transtornos, apresentando um estímulo ao mesmo tempo em que realiza monitoramento das respostas (Vincelli, 1999). 


\section{Objetivos}

Tendo como base os conceitos apresentados acima e por meio de dois artigos que serão apresentados abaixo, esta dissertação tem como objetivos:

- Investigar a eficácia da Realidade Virtual como procedimento de indução de humor

- Investigar a capacidade da Realidade Virtual em promover autoconsciência 
3. Seção de Artigos 
Indução De Humor Por Realidade Virtual: Uma Revisão Sistemática Dos Achados Recentes

\footnotetext{
Pedro Diniz Bernardo*a, Amrita Bains ${ }^{\mathrm{b}}$, Sophia Westwood ${ }^{\mathrm{b}}$, Daniel C. Mograbi ${ }^{\mathrm{a}, \mathrm{c}}$, a Pontifícia Universidade Católica do Rio de Janeiro, Departamento de Psicologia, 22451 100, Gávea, Rio de Janeiro, Brasil b Aston University, Department of Life and Health Sciences, Aston Triangle, Birmingham, United Kingdom. c King's College London, Institute of Psychiatry, Psychology \& Neuroscience, De Crespigny Park, SE58AF, London, United Kingdom
} 


\section{Resumo}

Esta revisão sistemática reúne pesquisas que utilizaram Realidade Virtual (RV) como paradigma de indução de humor. Quatro bases de dados foram usadas (Web of Science, Science Direct, PsycInfo e PubMed), com 1752 artigos identificados inicialmente. Após a exclusão de artigos repetidos, leitura de títulos e resumos, 85 artigos foram lidos na íntegra, concluindo com um total de 61 artigos adequados aos critérios de inclusão (artigos escritos em inglês, que utilizam indução experimental de humor, com medidas de avaliação de emoções, sem foco terapêutico e publicados entre os anos de 2008 e 2018). Como resultado, foi visto que grande parte das pesquisas foi realizada com participantes universitários. As emoções mais induzidas foram ansiedade, relaxamento, medo e alegria, respectivamente. Quanto aos equipamentos de RV, os mais utilizados foram os óculos de RV (HeadMounted Display), CAVE (Cave Automatic Virtual Environment - ambiente virtual automático em forma de caverna, em tradução livre), videogames e computadores, respectivamente. Grande parte das pesquisas (95\%) utilizou medidas subjetivas para a verificação de indução de humor, enquanto algumas pesquisas $(57 \%)$ também utilizaram medidas fisiológicas. Os achados sugerem que a RV é uma ferramenta efetiva na indução de humor em laboratório. Esses achados são discutidos em relação a lacunas na literatura, propondo uma base para futuras pesquisas neste campo.

\section{Palavras-chave:}

Humor; indução; emoção; realidade virtual. 


\section{Abstract}

This systematic review compiles studies that have used virtual reality (VR) as an emotion induction paradigm. Four databases were used (Web of Science, Science Direct, PsycInfo and PubMed), with 1752 articles initially identified. After the exclusion of duplicates, screening by title and abstract reading, 85 papers were fully read, with a total of 61 articles fitting the inclusion criteria (articles written in english, that used an experimental mood induction method, with manipulation checks, having no focus on therapeutic interventions and published between 2008 and 2018). In most studies, participants were college students, with the most common emotions elicited being anxiety, relaxation, fear and joy. The VR equipment employed included the HeadMounted Display, the Cave Automatic Virtual Environment, videogames and computers, with almost all studies using subjective measures of emotion and approximately half of them including also physiological measures. The findings suggest that VR is an effective tool to induce emotion in lab settings. These findings are discussed in relation to gaps in the literature, suggesting a blueprint for future research in this field.

\section{Keywords:}

Mood; induction; emotion; virtual reality. 


\section{Introdução}

A Psicologia das emoções é um campo tradicional da psicologia (James, 1894), porém, em décadas recentes, avanços metodológicos permitiram um aprofundamento na exploração científica deste tópico (Davidson, 2003). Por exemplo, a Realidade Virtual (RV) tem se tornado um novo ponto crescente na psicologia. RV é o termo utilizado para descrever a simulação gerada por computador de uma imagem tridimensional ou ambiente que possibilita interação de um participante que aparenta ser físico ou real. As interações envolvem a capacidade de manipular objetos ou realizar uma série de ações usando um equipamento eletrônico especial, por exemplo, óculos com telas ou luvas com sensores. A ilusão de realidade é criada pela estimulação dos sentidos dos participantes, incluindo visão, audição, sentido vestibular e em certos casos, tato e propriocepção (Chirico et al., 2016).

Há uma grande variedade de aplicações da RV, que incluem filmes e videogames imersivos, bem como no esporte e medicina. Entretanto, existem também aplicações no mundo da psicologia, que podem resultar em implicações práticas úteis e sérias. A RV pode apresentar novas e excitantes descobertas para as pesquisas em psicologia, que podem ter impacto e melhorar a vida de pessoas. Por exemplo, o uso da RV como ferramenta em terapias, sendo comumente utilizada em tratamentos de pacientes com transtorno de ansiedade, como fobia social (Peperkorn et al., 2015). Na terapia por exposição em RV, o paciente é gradualmente exposto ao estímulo fóbico, permitindo maior controle por parte do terapeuta dos níveis de exposição. Pesquisas mostram que a RV é eficaz em tratamentos para transtornos de ansiedade (Gorini et al., 2009).

Ainda que os Ambientes Virtuais (AV) tenham sido incorporados em uma variedade de settings clínicos e regulares para a melhora da saúde mental, muitas outras áreas da saúde podem ser exploradas usando essa tecnologia inovadora (Riva et al., 2007). Um exemplo é representado pelo gerenciamento do estresse, um dos grandes problemas mentais das sociedades ocidentais, que está relacionado a diversas patologias (McEwen, \& Stellar, 1993). Mesmo considerando este potencial, não há literaturas prévias que investigam AV como procedimentos de indução de humor.

A emoção tem sido investigada em laboratório usando uma variedade de procedimentos de indução de humor. Em uma revisão de induções experimentais de 
estados emocionais e suas eficácias, conduzida por Gerrards-Hesse e colaboradores (1994), cinco grupos de procedimentos de indução de humor foram diferenciados de acordo com o estímulo utilizado para influenciar os participantes. Foi sugerido que procedimentos que usam filmes/estórias foram os mais eficazes, produzindo tanto euforia quanto depressão em participantes saudáveis. Assim, a efetividade dos procedimentos de indução de humor diferencia indução de euforia e depressão. No tocante a indução de euforia, comparações de experiência emocional subjetiva entre grupos foram não significativas em $30 \%$ dos casos, e quanto a indução de depressão, $14 \%$ das vezes.

Ainda, aparenta ser mais fácil tornar depressivo o humor de um participante do que fazê-lo sentir-se eufórico (Gerrards-Hesse, 1994). Com o desenvolvimento de novas tecnologias, pesquisadores atualmente visam a explorar a capacidade de AVs que permitam a estimulação de reações similares aquelas em situações reais. Pesquisas começaram a comparar dados subjetivos em conjunto a técnicas de neuroimagem para entender se a RV pode evocar emoções em humanos (Felnhofer et al., 2015), como visto nos estudos de Ahs e colaboradores (2015), Rodriguez e colaboradores (2015) e Wrzesien e colaboradores (2015).

Não há revisão de literatura prévia que investigue o papel da RV na indução de humor. A razão para tal seria que as pesquisas neste campo ainda se encontram em seus primeiros passos. Assim, essa revisão de literatura sistemática é necessária para resumir evidências existentes na utilização da RV em indução de humor em participantes saudáveis. O propósito primário desta revisão de literatura sistemática é examinar a eficácia da RV em indução de humor, explorando também as metodologias frequentemente usadas em pesquisas, tanto para induzir e medir emoções, bem como a eficácia da RV em induzir emoções específicas. 


\section{Método}

Quatro bases de dados foram utilizadas na busca por artigos: Web of Science, Science Direct, PsycInfo and PubMed. Termos relevantes, incluindo truncamentos e variações, foram usados para captar artigos adequados.

Os termos selecionados foram:

- Emotion* Induction

- Mood Induction

- Emotion* Valence

- Mood
- Virtual Reality

- VR

- Virtual Environment

Emotion* Induction AND Virtual Reality

Mood Induction AND VR

Emotion* Valence AND Virtual Reality

Mood AND Virtual Environment

Esta revisão sistemática teve foco em estudos que induziram emoções em participantes saudáveis. Outros critérios de inclusão foram: a pesquisa teria que ser experimental; ter utilizado ao menos um método de avaliação de emoção (autorrelato ou fisiologia ou comportamento). Apenas pesquisas escritas em inglês foram incluídas e todos os artigos selecionados foram publicados entre 2008 e 2018. Pesquisas com participantes que foram diagnosticados e que utilizavam a RV como forma de terapia foram excluídos.

1752 artigos foram encontrados utilizando os termos de busca. Alguns dos artigos foram excluídos devido à falta de aderência do tema principal desta revisão. Os artigos foram filtrados pela leitura de título e resumo. Duplicatas encontradas em cada base de dados também foram removidas. Assim, um total de 86 artigos foi lido na íntegra. 24 artigos foram excluídos, culminando em 61 artigos elegíveis para esta revisão. 


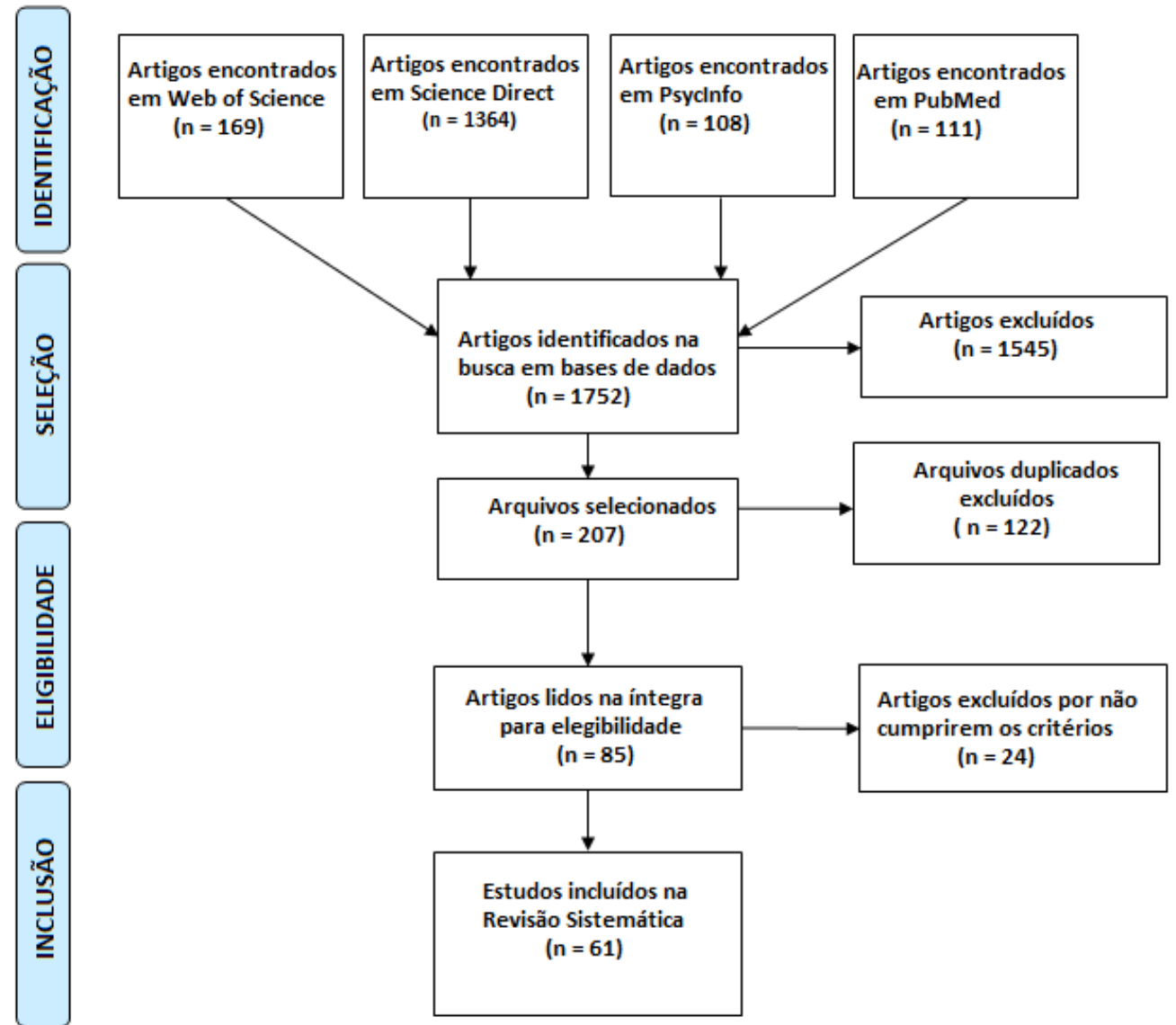

Figura 1: Método de busca de artigos realizado, organizados no modelo PRISMA (Moher D, Liberati A, Tetzlaff J, Altman DG, The PRISMA Group, 2009). 


\begin{tabular}{|c|c|c|c|c|c|c|c|}
\hline AUTOR & TÍTULO & PARTICIPANTES & $\begin{array}{c}\text { TIPO DE } \\
\text { EMOÇÃO }\end{array}$ & $\begin{array}{l}\text { DESFECHO DOS } \\
\text { ESTUDOS }\end{array}$ & EQUIPAMENTO & $\begin{array}{c}\text { MEDIDAS } \\
\text { SUBJETIVAS }\end{array}$ & $\begin{array}{c}\text { MEDIDAS } \\
\text { FISIOLÓGICAS }\end{array}$ \\
\hline $\begin{array}{l}\text { Ahs et al } \\
2015\end{array}$ & $\begin{array}{l}\text { Spatial proximity } \\
\text { amplifies valence in } \\
\text { emotional memory } \\
\text { and defensive } \\
\text { approach-avoidance }\end{array}$ & $\begin{array}{c}\text { Experimento 1: } 6 \\
\text { homens e 6 } \\
\text { mulheres (22.3); } \\
\text { Experimento 2: } 11 \\
\text { mulheres e 10 } \\
\text { homens (20.30); } \\
\text { Experimento 3: } 18 \\
\text { mulheres e 12 } \\
\text { homens (25.1); } \\
\text { Experimento 4: } 18 \\
\text { mulheres e 12 } \\
\text { homens (25.1) }\end{array}$ & Medo & $\begin{array}{c}\text { No experimento 1: } \\
\text { os participantes } \\
\text { apresentaram maior } \\
\text { resposta de susto } \\
\text { quando próximo ao } \\
\text { estímulo; No } \\
\text { experimento 2: } \\
\text { Houve sucesso na } \\
\text { tarefa de } \\
\text { aprendizagem do } \\
\text { medo; No } \\
\text { experimento 3: os } \\
\text { participantes } \\
\text { apresentaram } \\
\text { dificuldades na } \\
\text { extinção do medo } \\
\text { quando próximos } \\
\text { ao estímulo; No } \\
\text { experimento 4: foi } \\
\text { visto que estímulos } \\
\text { com recompensas } \\
\text { inibem estímulos } \\
\text { sem recompensas }\end{array}$ & $\begin{array}{c}\text { Óculos de } \\
\text { Realidade Virtual }\end{array}$ & Não realizado & $\begin{array}{l}\text { Atividade } \\
\text { eletrodérmica; } \\
\text { Eletromiografia }\end{array}$ \\
\hline
\end{tabular}




\begin{tabular}{|c|c|c|c|c|c|c|c|}
\hline $\begin{array}{l}\text { Ahs et al } \\
2015\end{array}$ & $\begin{array}{l}\text { Medial prefrontal } \\
\text { pathways for the } \\
\text { contextual regulation } \\
\text { of extinguished fear } \\
\text { in humans }\end{array}$ & $\begin{array}{c}22 \text { mulheres e } 21 \\
\text { homens (28.7) }\end{array}$ & Medo & $\begin{array}{c}\text { Controle contextual } \\
\text { do medo foi obteve } \\
\text { sucesso no } \\
\text { paradigma de } \\
\text { Realidade Virtual }\end{array}$ & $\begin{array}{l}\text { Óculos de } \\
\text { Realidade Virtual }\end{array}$ & $\begin{array}{l}\text { Visual Analogue } \\
\text { Scale (VAS) }\end{array}$ & $\begin{array}{l}\text { Atividade } \\
\text { eletrodérmica; } \\
\text { Neuroimagem } \\
\text { (fMRI) }\end{array}$ \\
\hline $\begin{array}{l}\text { Anderson et } \\
\text { al } 2017\end{array}$ & $\begin{array}{l}\text { Relaxation with } \\
\text { Immersive Natural } \\
\text { Scenes Presented } \\
\text { Using Virtual Reality }\end{array}$ & $\begin{array}{l}9 \text { Mulheres e } 9 \\
\text { Homens }\end{array}$ & Relaxamento & $\begin{array}{l}\text { A diminuição da } \\
\text { atividde } \\
\text { eletrodérmica foi } \\
\text { maior na simulação } \\
\text { com relaxamento } \\
\text { em comparação } \\
\text { com a simulação } \\
\text { controle }\end{array}$ & $\begin{array}{c}\text { Óculos de } \\
\text { Realidade Virtual }\end{array}$ & $\begin{array}{c}\text { Reality } \\
\text { Judgment and } \\
\text { Presence } \\
\text { Questionnaire } \\
\text { (MRJPQ); } \\
\text { Positive and } \\
\text { Negative Affect } \\
\text { Schedule } \\
\text { (PANAS); Value } \\
\text { of VR } \\
\text { Questionnaire } \\
\text { (VVR) } \\
\end{array}$ & $\begin{array}{c}\text { Atividade } \\
\text { eletrodérmica; } \\
\text { Frequência cardíaca }\end{array}$ \\
\hline $\begin{array}{l}\text { Annerstedt } \\
\text { et al } 2013\end{array}$ & $\begin{array}{c}\text { Inducing } \\
\text { physiological stress } \\
\text { recovery with sounds } \\
\text { of nature in a virtual } \\
\text { reality forest }- \\
\text { Results from a pilot } \\
\text { study }\end{array}$ & 30 homens (27.7) & $\begin{array}{c}\text { Estresse; } \\
\text { Relaxamento }\end{array}$ & $\begin{array}{c}\text { Níveis de cortisol } \\
\text { aumentaram } \\
\text { durante a condição } \\
\text { de estresse, e então } \\
\text { retornaram para a } \\
\text { linha de base; A } \\
\text { condição } \\
\text { audiovisual de } \\
\text { recuperação } \\
\text { apresentou maior } \\
\text { relaxamento, } \\
\text { enquanto a } \\
\text { condição apenas } \\
\text { visual induziu } \\
\text { desconforto }\end{array}$ & $\begin{array}{l}\text { CAVE (cave } \\
\text { automatic virtual } \\
\text { environment) }\end{array}$ & $\begin{array}{c}\text { State-Trait } \\
\text { Anxiety } \\
\text { Inventory } \\
\text { (STAI-S); Trier } \\
\text { Social Stress } \\
\text { Test (TSST) }\end{array}$ & $\begin{array}{c}\text { Frequência } \\
\text { cardíaca; } \\
\text { Frequência } \\
\text { respiratória; Análise } \\
\text { de cortisol da saliva }\end{array}$ \\
\hline
\end{tabular}




\begin{tabular}{|c|c|c|c|c|c|c|c|}
\hline $\begin{array}{l}\text { Aymerich- } \\
\text { Franch et al } \\
2010\end{array}$ & $\begin{array}{l}\text { Presence and } \\
\text { Emotions in Playing } \\
\text { a Group Game in a } \\
\text { Virtual Environment: } \\
\text { The Influence of } \\
\text { Body Participation }\end{array}$ & $\begin{array}{c}34 \text { mulheres e } 32 \\
\text { homens (22.6) }\end{array}$ & $\begin{array}{c}\text { Ativação e } \\
\text { valência afetiva }\end{array}$ & $\begin{array}{c}\text { Não foram } \\
\text { encontradas } \\
\text { diferenças } \\
\text { significativas no } \\
\text { relato emocional } \\
\text { dos participantes } \\
\text { que jogaram o } \\
\text { videogame com o } \\
\text { corpo em } \\
\text { comparação com os } \\
\text { que jogaram com } \\
\text { joystick }\end{array}$ & $\begin{array}{l}\text { CAVE (cave } \\
\text { automatic virtual } \\
\text { environment) }\end{array}$ & $\begin{array}{c}\text { Self-Assessment } \\
\text { Manikin (SAM); } \\
\text { Slater-Usoh- } \\
\text { Steed Presence } \\
\text { Questionnaire } \\
\text { (SUS) }\end{array}$ & $\begin{array}{l}\text { Atividade } \\
\text { eletrodérmica; } \\
\text { Eletromiografia }\end{array}$ \\
\hline $\begin{array}{l}\text { Baños et al } \\
2012\end{array}$ & $\begin{array}{c}\text { Positive mood } \\
\text { induction procedures } \\
\text { for virtual } \\
\text { environments } \\
\text { designed for elderly } \\
\text { people }\end{array}$ & $\begin{array}{l}14 \text { mulheres e } 4 \\
\text { homens (66.94) }\end{array}$ & $\begin{array}{c}\text { Alegria; } \\
\text { Relaxamento }\end{array}$ & $\begin{array}{l}\text { Diminuição da } \\
\text { ansiedade e tristeza } \\
\text { foi reportada após a } \\
\text { indução de humor } \\
\text { em ambos os } \\
\text { procedimentos }\end{array}$ & Computador & $\begin{array}{c}\text { General Mood } \\
\text { State (GMS); } \\
\text { Geriatric } \\
\text { Depression Scale } \\
\text { (GDS-15); } \\
\text { State-Trait } \\
\text { Anxiety } \\
\text { Inventory } \\
\text { (STAI); Visual } \\
\text { Analogue Scale } \\
\text { (VAS) }\end{array}$ & Não realizado \\
\hline $\begin{array}{l}\text { Brundage et } \\
\text { al } 2016\end{array}$ & $\begin{array}{c}\text { Utility of virtual } \\
\text { reality environments } \\
\text { to } \\
\text { examinephysiological } \\
\text { reactivity and } \\
\text { subjective distress in } \\
\text { adults who stutter }\end{array}$ & $\begin{array}{l}10 \text { homens que } \\
\text { gaguejam (26) }\end{array}$ & Ansiedade & $\begin{array}{l}\text { Emoções negativas } \\
\text { foram } \\
\text { significativamente } \\
\text { maiores na } \\
\text { simulação com } \\
\text { audiência virtual }\end{array}$ & $\begin{array}{c}\text { Óculos de } \\
\text { Realidade Virtual }\end{array}$ & $\begin{array}{c}\text { Fear of Negative } \\
\text { Evaluation } \\
\text { (FNE); Modified } \\
\text { Erickson Scale } \\
\text { (S-24); Overall } \\
\text { Assessment of } \\
\text { the Speaker's } \\
\text { Experience of } \\
\text { Stuttering } \\
\text { (OASES); State- } \\
\text { Trait Anxiety } \\
\text { Inventory-Trait } \\
\text { (STAI-T); }\end{array}$ & $\begin{array}{c}\text { Atividade } \\
\text { eletrodérmica; } \\
\text { Frequência cardíaca }\end{array}$ \\
\hline
\end{tabular}




\begin{tabular}{|c|c|c|c|c|c|c|c|}
\hline & & & & & & $\begin{array}{c}\text { Stuttering } \\
\text { Severity } \\
\text { Instrument-4 } \\
\text { (SSI-4); } \\
\text { Subjective Units } \\
\text { of Distress Scale } \\
\text { (SUDS) }\end{array}$ & \\
\hline $\begin{array}{l}\text { Canazei et } \\
\text { al } 2017\end{array}$ & $\begin{array}{l}\text { Artificial skylight } \\
\text { effects in a } \\
\text { windowless office } \\
\text { environment }\end{array}$ & $\begin{array}{c}55 \text { mulheres e } 45 \\
\text { homens }\end{array}$ & $\begin{array}{c}\text { Ativação e } \\
\text { valência afetiva }\end{array}$ & $\begin{array}{l}\text { Estados positivos } \\
\text { de humor foram } \\
\text { significativamente } \\
\text { maiores na } \\
\text { condição } \\
\text { experimental, } \\
\text { porém o humor } \\
\text { negativo aumentou } \\
\text { ao longo do tempo }\end{array}$ & Painel Artificial & $\begin{array}{c}\text { Emotional State } \\
\text { Adjective } \\
\text { Checklist; } \\
\text { Claustrophobic } \\
\text { Symptoms Scale; } \\
\text { Connectedness- } \\
\text { To-Nature Scale; } \\
\text { Dundee Stress } \\
\text { State } \\
\text { Questionnaire; } \\
\text { Game of Dice } \\
\text { Task; Room } \\
\text { Atmosphere } \\
\text { Questionnaire; } \\
\text { Perceived } \\
\text { Restorativeness } \\
\text { Scale; State- } \\
\text { Trait Anxiety } \\
\text { Inventory } \\
\text { (STAI); }\end{array}$ & Não realizado \\
\hline $\begin{array}{l}\text { Cartaud et } \\
\text { al } 2018\end{array}$ & $\begin{array}{c}\text { Physiological } \\
\text { Response to Facial } \\
\text { Expressions in } \\
\text { Peripersonal Space } \\
\text { Determines } \\
\text { Interpersonal } \\
\text { Distance in a Social } \\
\text { Interaction Context }\end{array}$ & $\begin{array}{c}17 \text { mulheres e } 30 \\
\text { homens }(21.7)\end{array}$ & $\begin{array}{l}\text { Felicidade; } \\
\text { Estado neutro; } \\
\text { Raiva }\end{array}$ & $\begin{array}{l}\text { Cada expressão } \\
\text { facial (felicidade, } \\
\text { raiva e estado } \\
\text { neutro) induziu } \\
\text { atividade } \\
\text { eletrodérmica de } \\
\text { modo diferente; A } \\
\text { condição com a } \\
\text { expressão facial de }\end{array}$ & Projeção de tela & $\begin{array}{c}\text { Interpersonal } \\
\text { Comfort } \\
\text { Distance } \\
\text { Judgment Task; } \\
\text { Reachability } \\
\text { Judgment Task; } \\
\text { Self-Assessment } \\
\text { Manikin (SAM); } \\
\text { State-Trait }\end{array}$ & $\begin{array}{c}\text { Atividade } \\
\text { eletrodérmica }\end{array}$ \\
\hline
\end{tabular}




\begin{tabular}{|c|c|c|c|c|c|c|c|}
\hline & & & & $\begin{array}{l}\text { raiva apresentou } \\
\text { crescimento } \\
\text { significativo nas } \\
\text { respostas } \\
\text { fisiológicas }\end{array}$ & & $\begin{array}{l}\text { Anxiety } \\
\text { Inventory } \\
\text { (STAI-YB) }\end{array}$ & \\
\hline $\begin{array}{c}\text { Chirico et al } \\
2018\end{array}$ & $\begin{array}{l}\text { Designing Awe in } \\
\text { Virtual Reality: An } \\
\text { Experimental Study }\end{array}$ & $\begin{array}{c}18 \text { mulheres }(23.33) \\
\text { e } 18 \text { homens } \\
(23.67)\end{array}$ & $\begin{array}{c}\text { Deslumbramento } \\
\text { em ambientes } \\
\text { naturais }\end{array}$ & $\begin{array}{c}\text { A simulação de } \\
\text { montanhas nevadas } \\
\text { apresentou alta } \\
\text { indução de } \\
\text { deslumbramento }\end{array}$ & $\begin{array}{c}\text { Óculos de } \\
\text { Realidade Virtual }\end{array}$ & $\begin{array}{c}\text { Awe Intensity } \\
\text { Subjective Scale; } \\
\text { Global Perceived } \\
\text { Awe Subjective } \\
\text { Scale; Positive } \\
\text { And Negative } \\
\text { Affect Scale } \\
\text { (PANAS); } \\
\text { Vastness And } \\
\text { Need For } \\
\text { Accommodation } \\
\text { Original Scale }\end{array}$ & Não realizado \\
\hline $\begin{array}{l}\text { Chittaro et } \\
\text { al } 2014\end{array}$ & $\begin{array}{l}\text { Affective computing } \\
\text { vs. affective placebo: } \\
\text { Study of a } \\
\text { biofeedback- } \\
\text { controlled game for } \\
\text { relaxation training }\end{array}$ & $\begin{array}{c}9 \text { mulheres e } 26 \\
\text { homens }\end{array}$ & Relaxamento & $\begin{array}{c}\text { A atividade } \\
\text { eletrodérmica foi } \\
\text { significativamente } \\
\text { maior na indução de } \\
\text { relaxamento em } \\
\text { comparação com a } \\
\text { atividade placebo }\end{array}$ & Videogame & $\begin{array}{c}\text { Difficulty Of } \\
\text { Relaxation } \\
\text { Training } \\
\text { Original } \\
\text { Questionnaire; } \\
\text { Perceived } \\
\text { Quality Of The } \\
\text { Feedback } \\
\text { Original } \\
\text { Questionnaire }\end{array}$ & $\begin{array}{c}\text { Atividade } \\
\text { eletrodérmica; } \\
\text { Frequência cardíaca }\end{array}$ \\
\hline $\begin{array}{l}\text { Chittaro et } \\
\text { al } 2014\end{array}$ & $\begin{array}{l}\text { Anxiety Induction in } \\
\text { Virtual } \\
\text { Environments: An } \\
\text { Experimental } \\
\text { Comparison of Three } \\
\text { General Techniques }\end{array}$ & $\begin{array}{c}24 \text { mulheres e } 84 \\
\text { homens }(24.1)\end{array}$ & Ansiedade & $\begin{array}{l}\text { Os resultados do } \\
\text { STAI foram } \\
\text { consistentes com as } \\
\text { medidas } \\
\text { fisiológicas }\end{array}$ & $\begin{array}{c}\text { Óculos de } \\
\text { Realidade Virtual }\end{array}$ & $\begin{array}{l}\text { State-Trait } \\
\text { Anxiety } \\
\text { Inventory } \\
\text { (STAI-Y) }\end{array}$ & $\begin{array}{l}\text { Atividade } \\
\text { eletrodérmica }\end{array}$ \\
\hline
\end{tabular}




\begin{tabular}{|c|c|c|c|c|c|c|c|}
\hline $\begin{array}{l}\text { Chittaro et } \\
\text { al } 2017\end{array}$ & $\begin{array}{l}\text { Mortality Salience in } \\
\text { Virtual Reality } \\
\text { Experiences and its } \\
\text { Effects on Users' } \\
\text { Attitudes towards } \\
\text { Risk }\end{array}$ & $\begin{array}{l}95 \text { mulheres e } 10 \\
\text { homens }\end{array}$ & Tristeza & $\begin{array}{l}\text { A checagem de } \\
\text { manipulação } \\
\text { apresentou } \\
\text { diferenças } \\
\text { significativas nas } \\
\text { condições com } \\
\text { ambiente } \\
\text { experimental }\end{array}$ & $\begin{array}{c}\text { Óculos de } \\
\text { Realidade Virtual }\end{array}$ & \begin{tabular}{|c} 
Delay task \\
questionnaire; \\
Demographic \\
Questionnaire; \\
Five-Facet \\
Mindfulness \\
Questionnaire \\
(FFMQ); Locus \\
of Control of \\
Behavior Scale \\
(LCB); Name- \\
Letter Task \\
(NLT); Risk \\
Assessment \\
Survey (RAS); \\
Temperament \\
and Character \\
Inventory (TCI); \\
Word Fragment \\
Completion Task \\
(WFCT)
\end{tabular} & $\begin{array}{c}\text { Frequência } \\
\text { cardíaca; Volume } \\
\text { do pulso sanguíneo }\end{array}$ \\
\hline $\begin{array}{l}\text { Crescentini } \\
\text { et al } 2016\end{array}$ & $\begin{array}{l}\text { Psychological and } \\
\text { physiological } \\
\text { responses to stressful } \\
\text { situations in } \\
\text { immersive virtual } \\
\text { reality: Differences } \\
\text { between users who } \\
\text { practice mindfulness } \\
\text { meditation and } \\
\text { controls }\end{array}$ & $\begin{array}{l}41 \text { participantes } \\
(43.33)\end{array}$ & $\begin{array}{l}\text { Ansiedade; } \\
\text { Estresse }\end{array}$ & $\begin{array}{l}\text { A condição de alto } \\
\text { estresse induziu } \\
\text { maior estresse e } \\
\text { ansiedade que a } \\
\text { condição de pouco } \\
\text { estresse }\end{array}$ & $\begin{array}{c}\text { Óculos de } \\
\text { Realidade Virtual }\end{array}$ & $\begin{array}{c}\text { Five Facet } \\
\text { Mindfulness } \\
\text { Questionnaire } \\
\text { (FFMQ); } \\
\text { Freiburg } \\
\text { Mindfulness } \\
\text { Inventory (FMI); } \\
\text { Mindful } \\
\text { Attention } \\
\text { Awareness Scale } \\
\text { (MAAS); State- } \\
\text { Trait Anxiety } \\
\text { Inventory } \\
\text { (STAI); Visual } \\
\text { Analogue Scale }\end{array}$ & $\begin{array}{l}\text { Atividade } \\
\text { eletrodérmica; } \\
\text { Eletromiografia; } \\
\text { Frequência } \\
\text { cardíaca; } \\
\text { Frequência } \\
\text { respiratória; } \\
\text { Volume do pulso } \\
\text { sanguíneo }\end{array}$ \\
\hline
\end{tabular}




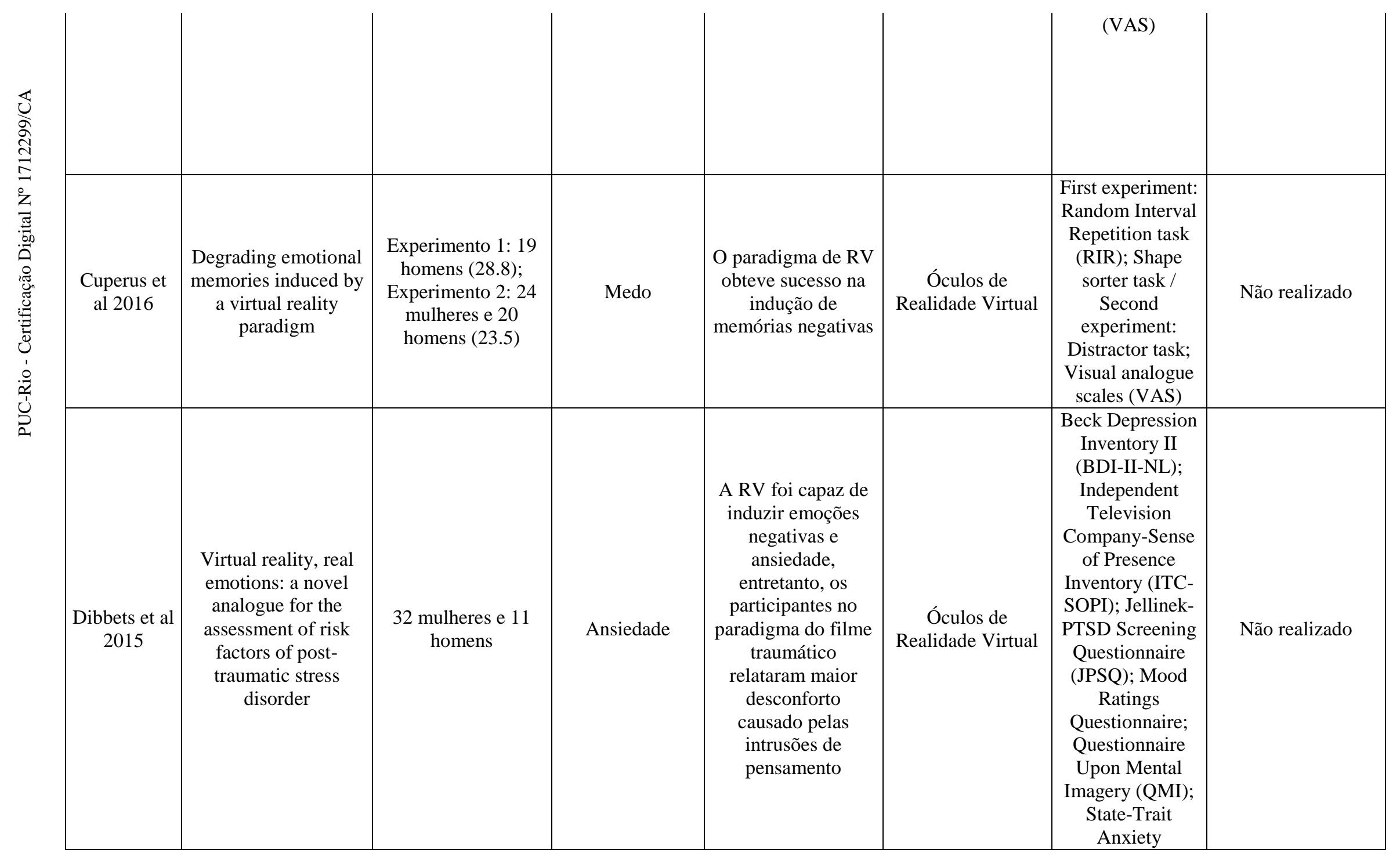




\begin{tabular}{|c|c|c|c|c|c|c|c|}
\hline & & & & & & $\begin{array}{l}\text { Inventory } \\
\text { (STAI-DY) }\end{array}$ & \\
\hline $\begin{array}{l}\text { Felnhofer et } \\
\text { al } 2015\end{array}$ & $\begin{array}{l}\text { Is virtual reality } \\
\text { emotionally } \\
\text { arousing? } \\
\text { Investigating five } \\
\text { emotion inducing } \\
\text { virtual park } \\
\text { scenarios }\end{array}$ & $\begin{array}{c}61 \text { mulheres e } 59 \\
\text { homens }(24,89)\end{array}$ & $\begin{array}{c}\text { Alegria; } \\
\text { Tristeza; Raiva; } \\
\text { Ansiedade; } \\
\text { Tédio }\end{array}$ & $\begin{array}{l}\text { Quatro das cinco } \\
\text { emoções foram } \\
\text { induzidas, com } \\
\text { exceção de tristeza }\end{array}$ & $\begin{array}{c}\text { Óculos de } \\
\text { Realidade Virtual }\end{array}$ & $\begin{array}{c}\text { Differential } \\
\text { Emotions Scale } \\
\text { (DES); } \\
\text { Differential } \\
\text { Emotions } \\
\text { Theory; } \\
\text { Manipulation } \\
\text { Check; } \\
\text { Modifzierte } \\
\text { Differentielle } \\
\text { Affekt Skala } \\
\text { (mDAS) }\end{array}$ & $\begin{array}{c}\text { Atividade } \\
\text { eletrodérmica; } \\
\text { Frequência cardíaca }\end{array}$ \\
\hline $\begin{array}{l}\text { Fich et al } \\
2014\end{array}$ & $\begin{array}{l}\text { Can architectural } \\
\text { design alter the } \\
\text { physiological } \\
\text { reaction to } \\
\text { psychosocial stress? } \\
\text { A virtual TSST } \\
\text { experiment }\end{array}$ & 49 homens (23.9) & Estresse & $\begin{array}{c}\text { Os níveis de } \\
\text { cortisol da saliva } \\
\text { aumentaram } \\
\text { durante o teste e } \\
\text { tiveram pico } \\
\text { máximo logo após; } \\
\text { Frequência cardíaca } \\
\text { também apresentou } \\
\text { aumento; A indução } \\
\text { foi considerada } \\
\text { bem-sucedida, } \\
\text { como indicado } \\
\text { pelas medidas }\end{array}$ & $\begin{array}{l}\text { CAVE (cave } \\
\text { automatic virtual } \\
\text { environment) }\end{array}$ & $\begin{array}{l}\text { Trier Social } \\
\text { Stress Test } \\
\text { (TSST) }\end{array}$ & $\begin{array}{l}\text { Heart rate; Saliva } \\
\text { cortisol analysis }\end{array}$ \\
\hline
\end{tabular}




\begin{tabular}{|c|c|c|c|c|c|c|c|}
\hline $\begin{array}{c}\text { Gordon et al } \\
2011\end{array}$ & $\begin{array}{l}\text { Interactive gaming } \\
\text { reduces experimental } \\
\text { pain with or without } \\
\text { a head mounted } \\
\text { display }\end{array}$ & 19 homens (19) & Relaxamento & $\begin{array}{c}\text { A condição que } \\
\text { usou o Óculos foi a } \\
\text { única que } \\
\text { apresentou redução } \\
\text { na dor de modo } \\
\text { significativo; A } \\
\text { condição sem } \\
\text { Óculos reduziu a } \\
\text { dor, mas não } \\
\text { apresentou } \\
\text { significância em } \\
\text { comparação com as } \\
\text { linhas de base } \\
\end{array}$ & $\begin{array}{c}\text { Óculos de } \\
\text { Realidade Virtual }\end{array}$ & $\begin{array}{l}\text { Beck Depression } \\
\text { Inventory (BDI) }\end{array}$ & Não realizado \\
\hline $\begin{array}{l}\text { Hildebrandt } \\
\text { et al } 2016\end{array}$ & $\begin{array}{l}\text { Cognitive flexibility, } \\
\text { heart rate variability, } \\
\text { and resilience predict } \\
\text { fine-grained } \\
\text { regulation of arousal } \\
\text { during prolonged } \\
\text { threat }\end{array}$ & $\begin{array}{c}172 \text { mulheres e } 128 \\
\text { homens }(40.65)\end{array}$ & $\begin{array}{c}\text { Medo; } \\
\text { Relaxamento }\end{array}$ & $\begin{array}{c}\text { Participantes que } \\
\text { apresentaram } \\
\text { melhor flexibilidade } \\
\text { cognitiva possuíram } \\
\text { maior controle } \\
\text { sobre os efeitos } \\
\text { fisiológicos da } \\
\text { emoção induzida; } \\
\text { Participantes que } \\
\text { apresentaram maior } \\
\text { resiliência } \\
\text { possuíram maior } \\
\text { controle sobre os } \\
\text { efeitos subjetivos } \\
\text { da emoção induzida }\end{array}$ & $\begin{array}{c}\text { Óculos de } \\
\text { Realidade Virtual }\end{array}$ & $\begin{array}{c}\text { Ego-Resilience } \\
\text { Scale (ER89); } \\
\text { Task-Switching } \\
\text { Task }\end{array}$ & $\begin{array}{c}\text { Atividade } \\
\text { eletrodérmica; } \\
\text { Frequência cardíaca }\end{array}$ \\
\hline $\begin{array}{l}\text { Jackson et } \\
\text { al } 2015\end{array}$ & $\begin{array}{l}\text { EEVEE: the } \\
\text { Empathy-Enhancing } \\
\text { Virtual Evolving } \\
\text { Environment }\end{array}$ & $\begin{array}{l}\text { Experimento } 1 \text { a-b: } \\
10 \text { mulheres e } 9 \\
\text { homens (22.6) }\end{array}$ & $\begin{array}{l}\text { Experimento 1a- } \\
\text { b: Dor; Nojo; } \\
\text { Raiva; Medo }\end{array}$ & $\begin{array}{c}\text { Experimento 1a-b: } \\
\text { Sim, mas nojo foi } \\
\text { detectado pelos } \\
\text { participantes nas } \\
\text { condiç̃os de } \\
\text { simulação de raiva } \\
\text { e dor enquanto } \\
\text { medo foi a emoção }\end{array}$ & $\begin{array}{c}\text { Óculos de } \\
\text { Realidade Virtual }\end{array}$ & $\begin{array}{c}\text { Facial Action } \\
\text { Coding System } \\
\text { (FACS); Visual } \\
\text { Analogue Scales } \\
\text { (VAS) }\end{array}$ & Não realizado \\
\hline
\end{tabular}




\begin{tabular}{|c|c|c|c|c|c|c|c|}
\hline & & & & melhor detectada & & & \\
\hline $\begin{array}{l}\text { Jonsson et } \\
\text { al } 2010\end{array}$ & $\begin{array}{l}\text { Cardiovascular and } \\
\text { cortisol reactivity and } \\
\text { habituation to a } \\
\text { virtual reality version } \\
\text { of the Trier Social } \\
\text { Stress Test: A pilot } \\
\text { study } \\
\end{array}$ & 10 homens (28.3) & Estresse & $\begin{array}{c}\text { Compared to the } \\
\text { baseline data, saliva } \\
\text { cortisol level was } \\
\text { shown to almost } \\
\text { doubled }\end{array}$ & $\begin{array}{l}\text { CAVE (cave } \\
\text { automatic virtual } \\
\text { environment) }\end{array}$ & $\begin{array}{c}\text { Trier Social } \\
\text { Stress Test } \\
\text { (TSST); } \\
\text { Spielberger state } \\
\text { and trait anxiety } \\
\text { inventory (STAI) }\end{array}$ & $\begin{array}{l}\text { Análise de cortisol } \\
\quad \text { da saliva; } \\
\text { Frequência cardíaca }\end{array}$ \\
\hline $\begin{array}{c}\text { Kwon et al } \\
2013\end{array}$ & $\begin{array}{l}\text { How level of realism } \\
\text { influences anxiety in } \\
\text { virtual reality } \\
\text { environments for a } \\
\text { job interview }\end{array}$ & $\begin{array}{c}\text { 31mulheres e } 29 \\
\text { homens (25.95) }\end{array}$ & Ansiedade & $\begin{array}{c}\text { BFNE encontrou } \\
\text { medidas médias nas } \\
\text { quatro condições de } \\
\text { entrevista-teste } \\
\text { (Foto humana, } \\
\text { Cartum em 3d, 3d } \\
\text { realístico e } \\
\text { entrevistador real); } \\
\text { A condição de 3d } \\
\text { realístico } \\
\text { apresentou maior } \\
\text { presença, indicando } \\
\text { a influência da } \\
\text { qualidade gráfica na } \\
\text { imersão }\end{array}$ & $\begin{array}{c}\text { Óculos de } \\
\text { Realidade Virtual }\end{array}$ & $\begin{array}{c}\text { Brief Fear of } \\
\text { Negative } \\
\text { Evaluation Scale } \\
\text { (BFNE); } \\
\text { Liebowitz social } \\
\text { anxiety scale } \\
\text { (LSAS); } \\
\text { Measure of } \\
\text { Anxiety in } \\
\text { Selection } \\
\text { Interviews } \\
\text { (MASI); Temple } \\
\text { Presence } \\
\text { Inventory (TPI) }\end{array}$ & $\begin{array}{c}\text { Atividade } \\
\text { eletrodérmica; } \\
\text { Frequência } \\
\text { cardíaca; Resposta } \\
\text { de sobressalto da } \\
\text { pálpebra }\end{array}$ \\
\hline $\begin{array}{l}\text { lin et al } \\
2017\end{array}$ & $\begin{array}{c}\text { Fear in Virtual } \\
\text { Reality (VR): Fear } \\
\text { elements, coping } \\
\text { reactions, immediate } \\
\text { and next-day } \\
\text { fright responses } \\
\text { toward a survival }\end{array}$ & $\begin{array}{c}92 \text { mulheres e } 53 \\
\text { homens (22.57) }\end{array}$ & Medo & $\begin{array}{l}\text { Participantes } \\
\text { reportaram as ações } \\
\text { plausíveis como } \\
\text { mais temidas do } \\
\text { que as pistas do } \\
\text { ambiente virtual }\end{array}$ & $\begin{array}{c}\text { Óculos de } \\
\text { Realidade Virtual }\end{array}$ & $\begin{array}{c}\text { Brief Sensation } \\
\text { Seeking Scale } \\
\text { (BSSS); Coping } \\
\text { Inventory } \\
\text { (COPE); Fear } \\
\text { Assessment } \\
\text { Original scale; }\end{array}$ & Não realizado \\
\hline
\end{tabular}




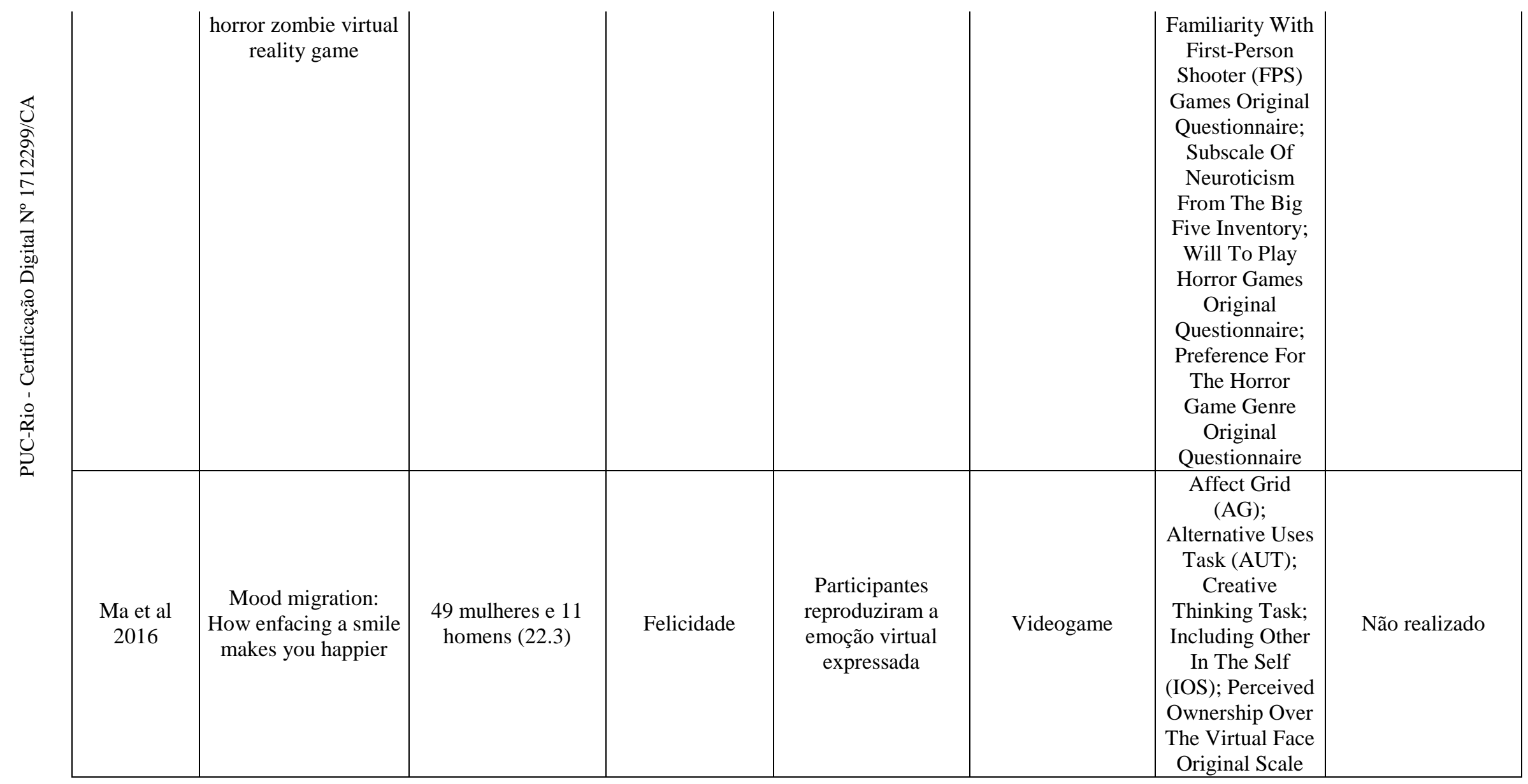




\begin{tabular}{|c|c|c|c|c|c|c|c|}
\hline $\begin{array}{l}\text { Madsen et } \\
\text { al } 2016\end{array}$ & $\begin{array}{c}\text { The differential } \\
\text { effects of agency on } \\
\text { fear induction using a } \\
\text { horror-themed video } \\
\text { game }\end{array}$ & 53 homens & Medo & $\begin{array}{c}\text { Diferenças } \\
\text { significativas não } \\
\text { foram encontradas } \\
\text { entre os grupos } \\
\text { experimentais na } \\
\text { indução de medo }\end{array}$ & Videogame & $\begin{array}{l}\text { Five Emotion } \\
\text { Likert Scale }\end{array}$ & $\begin{array}{l}\text { Atividade } \\
\text { eletrodérmica, } \\
\text { Frequência } \\
\text { cardíaca; } \\
\text { Frequência } \\
\text { respiratória }\end{array}$ \\
\hline $\begin{array}{l}\text { Maiano et al } \\
2011\end{array}$ & $\begin{array}{c}\text { Affective, anxiety } \\
\text { and behavioral } \\
\text { effects of an aversive } \\
\text { stimulation during a } \\
\text { simulated navigation } \\
\text { task within a virtual } \\
\text { environment: A pilot } \\
\text { study }\end{array}$ & $\begin{array}{l}4 \text { mulheres e } 10 \\
\text { homens }(23.50)\end{array}$ & Ansiedade & $\begin{array}{c}\text { Em comparação } \\
\text { com as sessooses } \\
\text { neutras, ansiedade } \\
\text { significativamente } \\
\text { alta foi observada } \\
\text { na condição de } \\
\text { corredor em } \\
\text { chamas, que } \\
\text { possuía sons de } \\
\text { alerta e fumaça }\end{array}$ & $\begin{array}{l}\text { CAVE (cave } \\
\text { automatic virtual } \\
\text { environment) }\end{array}$ & $\begin{array}{l}\text { Beck Anxiety } \\
\text { Inventory (BAI); } \\
\text { Positive And } \\
\text { Negative } \\
\text { Affective Scale } \\
\text { (PANAS); State- } \\
\text { Trait Anxiety } \\
\text { Inventory } \\
\text { (STAI-Y) }\end{array}$ & Não realizado \\
\hline $\begin{array}{l}\text { Marschner } \\
\text { et al2015 }\end{array}$ & $\begin{array}{l}\text { Social } \\
\text { communication with } \\
\text { virtual agents: The } \\
\text { effects of body and } \\
\text { gaze direction on } \\
\text { attention and } \\
\text { emotional responding } \\
\text { in human observers }\end{array}$ & $\begin{array}{c}20 \text { mulheres e } 20 \\
\text { homens }(23.4)\end{array}$ & $\begin{array}{l}\text { Felicidade; } \\
\text { Estado neutro; } \\
\text { Raiva }\end{array}$ & $\begin{array}{c}\text { Foi visto que a } \\
\text { emoção estaria } \\
\text { relacionada com a } \\
\text { direção corporal e } \\
\text { direção do olhar; } \\
\text { Expressões faciais } \\
\text { felizes foram } \\
\text { reportadas como } \\
\text { mais agradáveis, } \\
\text { seguidas por } \\
\text { expressões neutras e } \\
\text { então expressões de } \\
\text { raiva, } \\
\text { respectivamente; As } \\
\text { expressões faciais } \\
\text { de raiva foram } \\
\text { reportadas como } \\
\text { mais ativadoras que } \\
\text { as outras } \\
\end{array}$ & Computador & $\begin{array}{l}\text { Self-Assessment- } \\
\text { Manikin (SAM) }\end{array}$ & $\begin{array}{l}\text { Eletromiografia; } \\
\text { Eye tracking }\end{array}$ \\
\hline
\end{tabular}




\begin{tabular}{|c|c|c|c|c|c|c|c|}
\hline $\begin{array}{l}\text { Matthias et } \\
\text { al } 2012\end{array}$ & $\begin{array}{l}\text { Adaptive Generation } \\
\text { of Emotional Impact } \\
\text { Using Enhanced } \\
\text { Virtual Environments }\end{array}$ & $\begin{array}{l}12 \text { mulheres e } 18 \\
\text { homens }(28.9)\end{array}$ & $\begin{array}{c}\text { Confiança; } \\
\text { Surpresa; } \\
\text { Antecipação; } \\
\text { Alegria; Medo; } \\
\text { Tristeza; Nojo; } \\
\text { Raiva }\end{array}$ & $\begin{array}{c}\text { Resultados } \\
\text { discretos foram } \\
\text { encontrados na lista } \\
\text { de emoções; Nojo e } \\
\text { raiva apresentaram } \\
\text { resultados fracos, } \\
\text { considerando o } \\
\text { conteúdo das } \\
\text { imagens }\end{array}$ & $\begin{array}{l}\text { Virtual } \\
\text { environment } \\
\text { display }\end{array}$ & $\begin{array}{c}\text { International } \\
\text { Affective Picture } \\
\text { System (IAPS); } \\
\text { Interactive } \\
\text { Tendencies } \\
\text { Questionnaire } \\
\text { (ITQ); Presence } \\
\text { Questionnaire } \\
\text { (PQ); Self- } \\
\text { Assessment } \\
\text { Manikin (SAM); } \\
\text { Simulator } \\
\text { Sickness } \\
\text { Questionnaire } \\
\text { (SSQ) }\end{array}$ & $\begin{array}{l}\text { Atividade } \\
\text { eletrodérmica; } \\
\text { Frequência } \\
\text { respoiratória; } \\
\text { Volume do pulso } \\
\text { sanguíneo }\end{array}$ \\
\hline $\begin{array}{l}\text { McCall et al } \\
2016\end{array}$ & $\begin{array}{l}\text { Introducing the } \\
\text { Wunderkammer as a } \\
\text { tool for emotion } \\
\text { research: } \\
\text { Unconstrained gaze } \\
\text { and movement } \\
\text { patterns in three } \\
\text { emotionally } \\
\text { evocative virtual } \\
\text { worlds }\end{array}$ & $\begin{array}{c}191 \text { mulheres e } 133 \\
\text { homens (41) }\end{array}$ & $\begin{array}{c}\text { Ativação e } \\
\text { valência afetiva }\end{array}$ & $\begin{array}{l}\text { Os resultados da } \\
\text { ativação e valência } \\
\text { emocional foram } \\
\text { suportados pelas } \\
\text { hipóteses }\end{array}$ & $\begin{array}{c}\text { Óculos de } \\
\text { Realidade Virtual }\end{array}$ & $\begin{array}{c}\text { Cognitive } \\
\text { Emotion } \\
\text { Regulation } \\
\text { Questionnaire } \\
\text { (CERQ); Coping } \\
\text { Inventory } \\
\text { (COPE); Ego } \\
\text { Resilience Scale } \\
\text { (ER-89); VR } \\
\text { Experience } \\
\text { Original } \\
\text { Questionnaire }\end{array}$ & $\begin{array}{l}\text { Captura de } \\
\text { movimento }\end{array}$ \\
\hline $\begin{array}{l}\text { Mira et al } \\
2016\end{array}$ & $\begin{array}{c}\text { Access to } \\
\text { autobiographical } \\
\text { memory as an } \\
\text { emotion regulation } \\
\text { strategy and its } \\
\text { relation to } \\
\text { dispositional } \\
\text { mindfulness }\end{array}$ & $\begin{array}{l}46 \text { mulheres } 14 \\
\text { homens }(22.9)\end{array}$ & Tristeza & $\begin{array}{l}\text { Resultados } \\
\text { apresentaram } \\
\text { aumento } \\
\text { significativo na } \\
\text { tristeza }\end{array}$ & $\begin{array}{c}\text { Óculos de } \\
\text { Realidade Virtual }\end{array}$ & $\begin{array}{c}\text { Autobiographical } \\
\text { memory test } \\
\text { (AMT); Beck } \\
\text { Depression } \\
\text { Inventory (BDI- } \\
\text { II); Five Facet } \\
\text { Mindfulness } \\
\text { Questionnaire } \\
\text { (FFMQ); Visual }\end{array}$ & Não realizado \\
\hline
\end{tabular}




\begin{tabular}{|c|c|c|c|c|c|c|c|}
\hline & & & & & & $\begin{array}{l}\text { Analogue Scale } \\
\text { (VAS) }\end{array}$ & \\
\hline $\begin{array}{l}\text { Moghimi et } \\
\text { al } 2016\end{array}$ & $\begin{array}{l}\text { Influencing Human } \\
\text { Affective Responses } \\
\text { to Dynamic Virtual } \\
\text { Environments }\end{array}$ & $\begin{array}{l}48 \text { mulheres } 54 \\
\text { homens (23.23) }\end{array}$ & $\begin{array}{c}\text { Ativação e } \\
\text { valência afetiva }\end{array}$ & $\begin{array}{l}\text { Foi visto que a RV } \\
\text { pode manipular e } \\
\text { prever emoções }\end{array}$ & $\begin{array}{c}\text { Óculos de } \\
\text { Realidade Virtual }\end{array}$ & $\begin{array}{l}\text { Circumplex Of } \\
\text { Affect; Self- } \\
\text { Assessment } \\
\text { Manikin (SAM) }\end{array}$ & Não realizado \\
\hline $\begin{array}{l}\text { Molet et al } \\
2013\end{array}$ & $\begin{array}{l}\text { Conditioned place } \\
\text { preference and } \\
\text { aversion for music in } \\
\text { a virtual reality } \\
\text { environment }\end{array}$ & $\begin{array}{c}8 \text { mulheres e } 8 \\
\text { homens (em ambos } \\
\text { os experimentos) }\end{array}$ & $\begin{array}{c}\text { Ativação e } \\
\text { valência afetiva }\end{array}$ & $\begin{array}{c}\text { No primeiro } \\
\text { experimento, os } \\
\text { participantes } \\
\text { escolheram visitar a } \\
\text { casa associada com } \\
\text { a música consoante } \\
\text { em primeiro lugar } \\
\text { em comparação } \\
\text { com a casa } \\
\text { associada a white } \\
\text { noise; No segundo } \\
\text { experimento, os } \\
\text { participantes } \\
\text { escolheram } \\
\text { primeiro a casa com } \\
\text { white noise em } \\
\text { comparação a casa } \\
\text { com música } \\
\text { dissonante }\end{array}$ & Videogame & Não realizado & Não realizado \\
\hline
\end{tabular}




\begin{tabular}{|c|c|c|c|c|c|c|c|}
\hline $\begin{array}{l}\text { Mousas et al } \\
2018\end{array}$ & $\begin{array}{l}\text { The effects of } \\
\text { appearance and } \\
\text { motion of virtual } \\
\text { characters on } \\
\text { emotional reactivity }\end{array}$ & $\begin{array}{c}16 \text { mulheres e } 56 \\
\text { homens }(23.24)\end{array}$ & $\begin{array}{c}\text { Ativação e } \\
\text { valência afetiva }\end{array}$ & $\begin{array}{l}\text { A condição com o } \\
\text { zumbi masculino de } \\
\text { alta amplitude } \\
\text { motora apresentou } \\
\text { as maiores } \\
\text { excitações e } \\
\text { valências negativas, } \\
\text { seguida pela } \\
\text { condição de zumbi } \\
\text { masculino com } \\
\text { baixa amplitude } \\
\text { motora, a condição } \\
\text { homem com alta } \\
\text { amplitude motora e } \\
\text { então a condição } \\
\text { homem com baixa } \\
\text { amplitude motora }\end{array}$ & $\begin{array}{l}\text { Óculos de } \\
\text { Realidade Virtual }\end{array}$ & $\begin{array}{c}\text { Emotion } \\
\text { Reactivity Scale }\end{array}$ & Não realizado \\
\hline $\begin{array}{l}\text { Muhlberger } \\
\text { et al } 2008\end{array}$ & $\begin{array}{l}\text { Darkness-enhanced } \\
\text { startle responses in } \\
\text { ecologically valid } \\
\text { environments: A } \\
\text { virtual tunnel driving } \\
\text { experiment }\end{array}$ & $\begin{array}{l}19 \text { mulheres e } 7 \\
\text { homens }(22.31)\end{array}$ & Medo & $\begin{array}{l}\text { Foi visto que estado } \\
\text { de ansiedade estava } \\
\text { associada com } \\
\text { reações de susto } \\
\text { aumentadas com } \\
\text { escuridão }\end{array}$ & $\begin{array}{l}\text { Óculos de } \\
\text { Realidade Virtual }\end{array}$ & $\begin{array}{c}\text { Fear of Tunnel } \\
\text { Questionnaire } \\
\text { (TAF); State- } \\
\text { Trait Anxiety } \\
\text { Inventory } \\
\text { (STAI); Igroup } \\
\text { Presence } \\
\text { Questionnaire } \\
\text { (IPQ); Emotional } \\
\text { Valence Original } \\
\text { Scale } \\
\end{array}$ & $\begin{array}{l}\text { Resposta de } \\
\text { sobressalto das } \\
\text { pálpebras }\end{array}$ \\
\hline $\begin{array}{l}\text { Munyan et } \\
\text { al } 2016\end{array}$ & $\begin{array}{c}\text { Olfactory Stimuli } \\
\text { Increase Presence in } \\
\text { Virtual Environments }\end{array}$ & $\begin{array}{c}21 \text { mulheres e } 39 \\
\text { homens }(20.48)\end{array}$ & Ansiedade & $\begin{array}{l}\text { A ansiedade obteve } \\
\text { classificações mais } \\
\text { significativas no } \\
\text { primeiro teste }\end{array}$ & $\begin{array}{l}\text { Óculos de } \\
\text { Realidade Virtual }\end{array}$ & $\begin{array}{l}\text { Igroup Presence } \\
\text { Questionnaire } \\
\text { (IPQ); } \\
\text { Immersive } \\
\text { Tendencies } \\
\text { Questionnaire } \\
\text { (ITQ); Presence } \\
\text { Rating Scale }\end{array}$ & $\begin{array}{l}\text { Atividade } \\
\text { eletrodérmica }\end{array}$ \\
\hline
\end{tabular}




\begin{tabular}{|c|c|c|c|c|c|c|c|}
\hline & & & & & & \begin{tabular}{|c} 
(PRS); Presence \\
Visual-Analogue \\
Scale (PVAS); \\
Quick Smell \\
Identification \\
Test (QSIT); \\
Simulator \\
Sickness \\
Questionnaire \\
(SSQ); State- \\
Trait Anxiety \\
Inventory \\
(STAI) \\
\end{tabular} & \\
\hline $\begin{array}{l}\text { Murray et al } \\
2016\end{array}$ & $\begin{array}{l}\text { The effects of the } \\
\text { presence of others } \\
\text { during a rowing } \\
\text { exercise in a virtual } \\
\text { reality environment }\end{array}$ & 62 mulheres (20.20) & $\begin{array}{c}\text { Ativação e } \\
\text { valência afetiva }\end{array}$ & $\begin{array}{c}\text { Não foram } \\
\text { encontradas } \\
\text { diferenças } \\
\text { significativas entre } \\
\text { os grupos; Não } \\
\text { foram encontradas } \\
\text { diferenças } \\
\text { significativas nas } \\
\text { subescalas de afeto } \\
\text { positivo, } \\
\text { tranquilidade, } \\
\text { fadiga ou afeto } \\
\text { negativo na escala } \\
\text { de afeto e atividade } \\
\text { física }\end{array}$ & Projeção de tela & \begin{tabular}{|c} 
Exercise \\
Benefits/Barrier \\
Scale (EBBS); \\
Exercise \\
Thoughts \\
Questionnaire \\
(ETQ); Feeling \\
Scale (FS); \\
Intrinsic \\
Motivation \\
Inventory (IMI); \\
International \\
Physical Activity \\
Questionnaire - \\
Short Form \\
(IPAQ-SF); \\
Physical Activity \\
Affect Scale \\
(PAAS); \\
Physical Activity \\
Enjoyment Scale \\
(PACES)
\end{tabular} & Frequência cardíaca \\
\hline
\end{tabular}




\begin{tabular}{|c|c|c|c|c|c|c|c|}
\hline $\begin{array}{c}\text { Nazry et al } \\
2016\end{array}$ & $\begin{array}{l}\text { Mood and Learning } \\
\text { in Navigation-based } \\
\text { Serious Games }\end{array}$ & $\begin{array}{c}\text { Experimento 1: } 18 \\
\text { mulheres e 18 } \\
\text { homens (29,9); } \\
\text { Experimento 2: } 8 \\
\text { mulheres e 8 } \\
\text { homens (25.88) }\end{array}$ & $\begin{array}{c}\text { Alegria; } \\
\text { Relaxamento }\end{array}$ & $\begin{array}{c}\text { A agradabilidade } \\
\text { dos participantes } \\
\text { aumentou } \\
\text { significativamente } \\
\text { após a tarefa e o } \\
\text { escore de felicidade } \\
\text { também apresentou } \\
\text { aumento; No } \\
\text { segundo } \\
\text { experimento, o } \\
\text { humor dos } \\
\text { participantes } \\
\text { aumentou } \\
\text { significativamente }\end{array}$ & Videogame & $\begin{array}{c}\text { Reduced Brief } \\
\text { Mood } \\
\text { Introspection } \\
\text { Scale (BMIS); } \\
\text { Spatial And } \\
\text { Navigation Test }\end{array}$ & Não realizado \\
\hline $\begin{array}{l}\text { Nogueira et } \\
\text { al } 2015\end{array}$ & $\begin{array}{l}\text { Modelling human } \\
\text { emotion in interactive } \\
\text { environments: } \\
\text { Physiological } \\
\text { ensemble and } \\
\text { grounded approaches } \\
\text { for synthetic agents }\end{array}$ & $\begin{array}{l}12 \text { participantes } \\
(24.83)\end{array}$ & $\begin{array}{c}\text { Ativação e } \\
\text { valência afetiva }\end{array}$ & $\begin{array}{c}\text { O paradigma foi } \\
\text { capaz de predizer } \\
\text { precisamente os } \\
\text { estados emocionais } \\
\text { em ambas as } \\
\text { condições } \\
\text { experimentais }\end{array}$ & Computador & $\begin{array}{c}\text { International } \\
\text { Affective Picture } \\
\text { System (IAPS) }\end{array}$ & $\begin{array}{c}\text { Atividade } \\
\text { eletrodérmica; } \\
\text { Eletromiografia; } \\
\text { Frequência cardíaca }\end{array}$ \\
\hline $\begin{array}{l}\text { Pallavicini } \\
\text { et al } 2013\end{array}$ & $\begin{array}{l}\text { Is virtual reality } \\
\text { always an effective } \\
\text { stressors for exposure } \\
\text { treatments? some } \\
\text { insights from a } \\
\text { controlled trial }\end{array}$ & $\begin{array}{l}41 \text { participantes } \\
(21.15)\end{array}$ & Ansiedade & $\begin{array}{c}\text { Escores de } \\
\text { ansiedade } \\
\text { significativos foram } \\
\text { encontrados pelo } \\
\text { Post Media } \\
\text { Questionnaire; } \\
\text { Entretanto, a } \\
\text { condição de RV } \\
\text { associada com as } \\
\text { interrupções } \\
\text { apresentaram menor } \\
\text { efetividade na } \\
\text { indução de } \\
\text { ansiedade }\end{array}$ & $\begin{array}{c}\text { Óculos de } \\
\text { Realidade Virtual }\end{array}$ & $\begin{array}{c}\text { Post Media } \\
\text { Questionnaire } \\
\text { (PMQ); Slater- } \\
\text { Usoh-Steed } \\
\text { Presence } \\
\text { Questionnaire } \\
\text { (SUS) }\end{array}$ & $\begin{array}{l}\text { Eletromiografia; } \\
\text { Frequência } \\
\text { cardíaca; } \\
\text { Frequência } \\
\text { respiratória }\end{array}$ \\
\hline
\end{tabular}




\begin{tabular}{|c|c|c|c|c|c|c|c|}
\hline $\begin{array}{l}\text { Peperkorn } \\
\text { et al } 2015\end{array}$ & $\begin{array}{l}\text { Temporal dynamics } \\
\text { in the relation } \\
\text { between presence and } \\
\text { fear in virtual reality }\end{array}$ & 22 mulheres (25.18) & Medo & $\begin{array}{l}\text { Classificações de } \\
\text { medo foram } \\
\text { maiores em grupos } \\
\text { com a condição } \\
\text { estereotípica em } \\
\text { comparação com o } \\
\text { grupo na condição } \\
\text { monoscópica; As } \\
\text { classificações de } \\
\text { medo diminuíram } \\
\text { ao longo do tempo }\end{array}$ & $\begin{array}{c}\text { CAVE (cave } \\
\text { automatic virtual } \\
\text { environment) }\end{array}$ & $\begin{array}{c}\text { Fear of Spiders } \\
\text { Questionnaire } \\
\text { (FSQ); Igroup } \\
\text { Presence } \\
\text { Questionnaire } \\
\text { (IPQ); } \\
\text { Subjective Units } \\
\text { of Discomfort } \\
\text { Scale (SUDS) }\end{array}$ & $\begin{array}{c}\text { Atividade } \\
\text { eletrodérmica; } \\
\text { Frequência cardíaca }\end{array}$ \\
\hline $\begin{array}{l}\text { Rodriguez } \\
\text { et al } 2015\end{array}$ & $\begin{array}{l}\text { Assessing brain } \\
\text { activations associated } \\
\text { with emotional } \\
\text { regulation during } \\
\text { virtual reality mood } \\
\text { induction procedures }\end{array}$ & $\begin{array}{l}13 \text { mulheres e } 14 \\
\text { homens }(23.36)\end{array}$ & Tristeza & $\begin{array}{c}\text { As medidas } \\
\text { subjetivas não } \\
\text { encontraram } \\
\text { evidencia para a } \\
\text { indução de tristeza, } \\
\text { mas a indução de } \\
\text { emoções negativas } \\
\text { foi confirmada pelo } \\
\text { eletroencefalograma }\end{array}$ & $\begin{array}{c}\text { CAVE (cave } \\
\text { automatic virtual } \\
\text { environment) }\end{array}$ & $\begin{array}{c}\text { International } \\
\text { Affective Picture } \\
\text { System (IAPS); } \\
\text { Positive and } \\
\text { Negative Affect } \\
\text { Schedule } \\
\text { (PANAS); } \\
\text { Velten Self- } \\
\text { Statements; } \\
\text { Visual Analogue } \\
\text { Scale (VAS) }\end{array}$ & Eletroencefalografia \\
\hline $\begin{array}{l}\text { Ruggiero et } \\
\quad \text { al } 2016\end{array}$ & $\begin{array}{l}\text { The effect of facial } \\
\text { expressions on } \\
\text { peripersonal and } \\
\text { interpersonal spaces }\end{array}$ & $\begin{array}{l}17 \text { mulheres e } 17 \\
\text { homens }(23)\end{array}$ & $\begin{array}{l}\text { Felicidade; } \\
\text { Estado neutro; } \\
\text { Raiva }\end{array}$ & $\begin{array}{l}\text { Participantes se } \\
\text { distanciaram mais } \\
\text { no ambiente } \\
\text { raivoso; Ambos } \\
\text { ambientes foram } \\
\text { sensíveis à valência } \\
\text { emocional } \\
\end{array}$ & $\begin{array}{l}\text { Óculos de } \\
\text { Realidade Virtual }\end{array}$ & $\begin{array}{c}\text { Interpersonal } \\
\text { reactivity index } \\
\text { (IRI); Karolinska } \\
\text { Directed } \\
\text { Emotional Faces } \\
(\mathrm{KDEF})\end{array}$ & Não realizado \\
\hline $\begin{array}{l}\text { Schweizer } \\
\text { et al } 2017\end{array}$ & $\begin{array}{l}\text { The impact of pre- } \\
\text { existing anxiety on } \\
\text { affective and } \\
\text { cognitive processing } \\
\text { of a Virtual Reality } \\
\text { analogue trauma }\end{array}$ & $\begin{array}{c}66 \text { mulheres e } 14 \\
\text { homens }(21.86)\end{array}$ & Ansiedade & $\begin{array}{c}\text { A ansiedade } \\
\text { aumentou } \\
\text { significativamente } \\
\text { nas classificações } \\
\text { subjetivas } \\
\text { comparando com a } \\
\text { linha de base, o que }\end{array}$ & $\begin{array}{l}\text { Óculos de } \\
\text { Realidade Virtual }\end{array}$ & $\begin{array}{l}\text { Beck Depression } \\
\text { Inventory (BDI- } \\
\text { II); Difficulties } \\
\text { in Emotion } \\
\text { Regulation Scale } \\
\text { (DERS); } \\
\text { Intrusive }\end{array}$ & $\begin{array}{l}\text { Atividade } \\
\text { eletrodérmica }\end{array}$ \\
\hline
\end{tabular}




\begin{tabular}{|c|c|c|c|c|c|c|c|}
\hline & & & & $\begin{array}{l}\text { indicou sucesso na } \\
\text { indução }\end{array}$ & & $\begin{array}{c}\text { Memory } \\
\text { Questionnaire; } \\
\text { State-Trait } \\
\text { Anxiety } \\
\text { Inventory } \\
\text { (STAI-T); } \\
\text { Subjective } \\
\text { Anxiety Scale; } \\
\text { Subjective } \\
\text { presence scale }\end{array}$ & \\
\hline $\begin{array}{l}\text { Seinfeld et } \\
\text { al } 2016\end{array}$ & $\begin{array}{c}\text { Influence of Music } \\
\text { on Anxiety Induced } \\
\text { by Fear of Heights in } \\
\text { Virtual Reality }\end{array}$ & 40 participantes & Ansiedade & $\begin{array}{l}\text { No cenário sem } \\
\text { música a ansiedade } \\
\text { aumentou } \\
\text { significativamente e } \\
\text { no cenário com } \\
\text { música a ansiedade } \\
\text { se manteve com as } \\
\text { mesmas } \\
\text { classificações }\end{array}$ & $\begin{array}{c}\text { CAVE (cave } \\
\text { automatic virtual } \\
\text { environment) }\end{array}$ & $\begin{array}{l}\text { The State Trait } \\
\text { Anxiety } \\
\text { Inventory-Form } \\
\text { Y (STAI-Y); } \\
\text { Subjective Units } \\
\text { of Discomfort } \\
\text { (SUDS); } \\
\text { Autonomic } \\
\text { Perception } \\
\text { Questionnaire } \\
\text { (APQ); Virtual } \\
\text { Reality } \\
\text { Experience } \\
\text { Questionnaire }\end{array}$ & $\begin{array}{c}\text { Atividade } \\
\text { eletrodérmica; } \\
\text { Frequência cardíaca }\end{array}$ \\
\hline $\begin{array}{l}\text { Serrano et al } \\
2016\end{array}$ & $\begin{array}{l}\text { Virtual reality and } \\
\text { stimulation of touch } \\
\text { and smell for } \\
\text { inducing relaxation: } \\
\text { A randomized } \\
\text { controlled trial }\end{array}$ & $\begin{array}{c}84 \text { mulheres e } 52 \\
\text { homens }(27.05)\end{array}$ & Relaxamento & $\begin{array}{c}\text { Aumento no } \\
\text { relaxamento } \\
\text { ocorreu quando } \\
\text { houve diminuição } \\
\text { da Ativação }\end{array}$ & $\begin{array}{c}\text { CAVE (cave } \\
\text { automatic virtual } \\
\text { environment) }\end{array}$ & $\begin{array}{c}\text { Clinical } \\
\text { Assessment } \\
\text { Questionnaire; } \\
\text { Beck Depression } \\
\text { Inventory II } \\
\text { (BDI-II); State- } \\
\text { Trait Anxiety } \\
\text { Inventory } \\
\text { (STAI); Visual } \\
\text { Analogue Scale } \\
\text { (VAS); Self- } \\
\text { Assessment }\end{array}$ & Não realizado \\
\hline
\end{tabular}




\begin{tabular}{|c|c|c|c|c|c|c|c|}
\hline & & & & & & $\begin{array}{l}\text { Manikin (SAM); } \\
\text { International } \\
\text { Affective } \\
\text { Pictures System } \\
\text { (IAPS) }\end{array}$ & \\
\hline $\begin{array}{c}\text { Sharar et al } \\
2016\end{array}$ & $\begin{array}{l}\text { Circumplex Model of } \\
\text { Affect: A Measure of } \\
\text { Pleasure and Arousal } \\
\text { During Virtual } \\
\text { Reality Distraction } \\
\text { Analgesia }\end{array}$ & $\begin{array}{c}37 \text { mulheres e } 37 \\
\text { homens (mean age } \\
\text { of } 29 \text { ) }\end{array}$ & Alegria & $\begin{array}{l}\text { Sensação analgésica } \\
\text { subjetiva foi } \\
\text { reportada na } \\
\text { distração em RV }\end{array}$ & $\begin{array}{l}\text { Óculos de } \\
\text { Realidade Virtual }\end{array}$ & $\begin{array}{c}\text { Circumplex } \\
\text { Model of Affect; } \\
\text { Graphic Rating } \\
\text { Scales (GRSs) }\end{array}$ & Não realizado \\
\hline $\begin{array}{c}\text { Shiban et al } \\
2016\end{array}$ & $\begin{array}{l}\text { Trier Social Stress } \\
\text { Test in vivo and in } \\
\text { virtual reality: } \\
\text { Dissociation of } \\
\text { response domains }\end{array}$ & 45 homens (23.76) & Estresse & $\begin{array}{l}\text { As classificações de } \\
\text { estresse mostraram } \\
\text { um grande efeito de } \\
\text { fase e condição na } \\
\text { manipulação } \\
\text { experimental }\end{array}$ & $\begin{array}{l}\text { Óculos de } \\
\text { Realidade Virtual }\end{array}$ & $\begin{array}{c}\text { Autobiographical } \\
\text { Memory Test } \\
\text { (AMT); Beck } \\
\text { Depression } \\
\text { Inventory (BDI- } \\
\text { II); Five Facet } \\
\text { Mindfulness } \\
\text { Questionnaire } \\
\text { (FFMQ); Visual } \\
\text { Analogue Scale } \\
\text { (VAS) }\end{array}$ & $\begin{array}{l}\text { Análise de cortisol } \\
\text { da saliva; Atividade } \\
\text { eletrodérmica; } \\
\text { Frequência } \\
\text { cardíaca; }\end{array}$ \\
\hline $\begin{array}{l}\text { Shin et al } \\
2018\end{array}$ & $\begin{array}{c}\text { Empathy and } \\
\text { embodied experience } \\
\text { in virtual } \\
\text { environment: To } \\
\text { what extent can } \\
\text { virtual reality } \\
\text { stimulate empathy } \\
\text { and embodied } \\
\text { experience? }\end{array}$ & $\begin{array}{c}100 \text { mulheres e } 100 \\
\text { homens }(31.17)\end{array}$ & Empatia & $\begin{array}{c}\text { A imersão } \\
\text { propiciou uma } \\
\text { grande sensação de } \\
\text { presença; A imersão } \\
\text { foi relatada como } \\
\text { menos influente que } \\
\text { características de } \\
\text { participantes } \\
\text { idiossincráticos }\end{array}$ & $\begin{array}{c}\text { Óculos de } \\
\text { Realidade Virtual }\end{array}$ & $\begin{array}{c}\text { Empathy And } \\
\text { Embodiment } \\
\text { Questionnaire; } \\
\text { Flow } \\
\text { Questionnaire; } \\
\text { Presence } \\
\text { Subscale }\end{array}$ & Não realizado \\
\hline
\end{tabular}




\begin{tabular}{|c|c|c|c|c|c|c|c|}
\hline $\begin{array}{l}\text { Siamonava } \\
\text { et al } 2018\end{array}$ & $\begin{array}{l}\text { Effects of spatial } \\
\text { colors on guests' } \\
\text { perceptions of a hotel } \\
\text { room }\end{array}$ & $\begin{array}{c}76 \text { mulheres e } 63 \\
\text { homens }\end{array}$ & $\begin{array}{c}\text { Ativação e } \\
\text { valência afetiva; } \\
\text { Relaxamento }\end{array}$ & $\begin{array}{l}\text { Na simulação do } \\
\text { hotel azul, foram } \\
\text { relatadas mais } \\
\text { relaxantes que os } \\
\text { hotéis vermelhos, } \\
\text { mas não houve } \\
\text { diferença } \\
\text { significativa; As } \\
\text { cores azuis foram } \\
\text { associadas com } \\
\text { leveis baixos de } \\
\text { Ativação. }\end{array}$ & $\begin{array}{c}\text { Óculos de } \\
\text { Realidade Virtual }\end{array}$ & $\begin{array}{c}\text { PAD model; } \\
\text { Presence } \\
\text { Questionnaire; } \\
\text { Semantic Scale }\end{array}$ & Não realizado \\
\hline $\begin{array}{l}\text { Strien et al } \\
2013\end{array}$ & $\begin{array}{l}\text { Emotional eating and } \\
\text { food intake after } \\
\text { sadness and joy }\end{array}$ & 60 mulheres & Alegria; tristeza & $\begin{array}{c}\text { Foi encontrado um } \\
\text { efeito do tempo em } \\
\text { ambas condições } \\
\text { triste e feliz na } \\
\text { escala análoga } \\
\text { visual (VAS) para } \\
\text { alegria }\end{array}$ & Projeção de tela & $\begin{array}{c}\text { Beck Depression } \\
\text { Inventory(BDI); } \\
\text { Dutch Eating } \\
\text { Behavior } \\
\text { Questionnaire } \\
\text { (DEBQ-E: } \\
\text { DEBQ } \\
\text { Emotional } \\
\text { Eating } \\
\text { Subscale); } \\
\text { Eating Attitudes } \\
\text { Test (EAT- 26); } \\
\text { Visual Analogue } \\
\text { Scale(VAS) }\end{array}$ & Não realizado \\
\hline $\begin{array}{l}\text { Thimmesch- } \\
\text { Gill et al } \\
2017\end{array}$ & $\begin{array}{l}\text { Perceiving emotions } \\
\text { in robot body } \\
\text { language: Acute } \\
\text { stress heightens } \\
\text { sensitivity to } \\
\text { negativity while } \\
\text { attenuating } \\
\text { sensitivity to arousal }\end{array}$ & $\begin{array}{c}\text { Experimento 1: } 16 \\
\text { mulheres e } 1 \\
\text { homem (21.27); } \\
\text { Experimento 2: } 56 \\
\text { mulheres e } 40 \\
\text { homens (21.15) }\end{array}$ & $\begin{array}{c}\text { Ativação e } \\
\text { valência afetiva }\end{array}$ & $\begin{array}{l}\text { A valência dos } \\
\text { participantes } \\
\text { diminuiu ao longo } \\
\text { do tempo, com um } \\
\text { aumento após a } \\
\text { indução de estresse; } \\
\text { A ativação dos } \\
\text { participantes } \\
\text { cresceu ao longo do } \\
\text { tempo com }\end{array}$ & $\begin{array}{c}\text { Óculos de } \\
\text { Realidade Virtual }\end{array}$ & $\begin{array}{c}\text { Brief Symptom } \\
\text { Inventory (BSI); } \\
\text { Maastricht Acute } \\
\text { Stress Test } \\
\text { (MAST); Self- } \\
\text { Assessment } \\
\text { Manikin (SAM) }\end{array}$ & Não realizado \\
\hline
\end{tabular}




\begin{tabular}{|c|c|c|c|c|c|c|c|}
\hline & & & & $\begin{array}{l}\text { diminuição no final } \\
\text { da indução de } \\
\text { estresse }\end{array}$ & & & \\
\hline $\begin{array}{l}\text { Toet et al } \\
2009\end{array}$ & $\begin{array}{l}\text { Is a Dark Virtual } \\
\text { Environment Scary? }\end{array}$ & 52 homens (23.37) & $\begin{array}{c}\text { Estresse; } \\
\text { Relaxamento }\end{array}$ & $\begin{array}{l}\text { Medidas subjetivas } \\
\text { e objetivas mostrou } \\
\text { que os participantes } \\
\text { na condição de } \\
\text { estresse } \\
\text { apresentaram tal } \\
\text { emoção }\end{array}$ & Videogame & $\begin{array}{l}\text { Experience } \\
\text { Questionnaire; } \\
\text { Recognition test; } \\
\text { Semantic } \\
\text { Questionnaire; } \\
\text { State-Trait } \\
\text { Anxiety } \\
\text { Inventory } \\
\text { (STAI); Trier } \\
\text { Social Stress } \\
\text { Test (TSST) }\end{array}$ & $\begin{array}{l}\text { Análise de cortisol } \\
\text { da saliva; } \\
\text { Frequência cardíaca }\end{array}$ \\
\hline $\begin{array}{l}\text { Toet et al } \\
2012\end{array}$ & $\begin{array}{l}\text { Effects of signals of } \\
\text { disorder on fear of } \\
\text { crime in real and } \\
\text { virtual environments }\end{array}$ & $\begin{array}{l}54 \text { mulheres e } 66 \\
\text { homens (39) }\end{array}$ & Medo & $\begin{array}{c}\text { Preocupação com } \\
\text { segurança no } \\
\text { ambiente virtual } \\
\text { silencioso foi } \\
\text { significativamente } \\
\text { mais percebido na } \\
\text { condição de } \\
\text { desordem em } \\
\text { comparação com a } \\
\text { linha de base; O } \\
\text { ambiente real e o } \\
\text { ambiente virtual } \\
\text { com som não } \\
\text { apresentou } \\
\text { diferença da } \\
\text { preocupação nas } \\
\text { condições de }\end{array}$ & Videogame & $\begin{array}{c}\text { Neighborhood } \\
\text { Safety Original } \\
\text { Scale; Personal } \\
\text { Safety And } \\
\text { Mental State } \\
\text { Original Scale }\end{array}$ & Não realizado \\
\hline
\end{tabular}




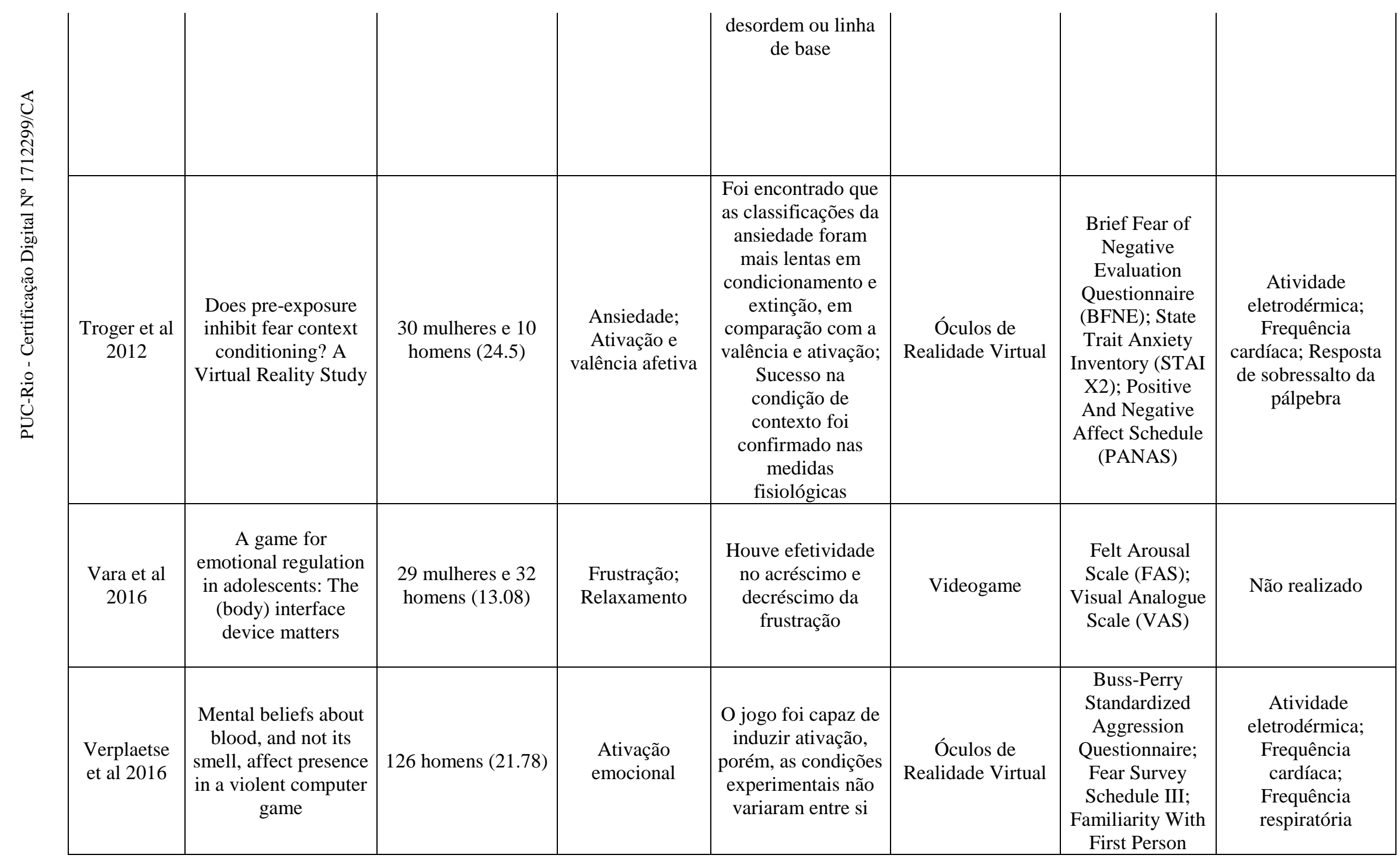




\begin{tabular}{|c|c|c|c|c|c|c|c|}
\hline & & & & & & $\begin{array}{c}\text { Shooter Games } \\
\text { Original Survey; } \\
\text { Subjective } \\
\text { Questionnaire } \\
\text { For Presence } \\
\text { Assessment; } \\
\text { Subjective } \\
\text { Assessment Of } \\
\text { Levels Of } \\
\text { Excitement, } \\
\text { Aggression, } \\
\text { Anger, And } \\
\text { Power Or } \\
\text { Dominance; } \\
\text { Sniffin' Sticks } \\
\text { Screening } 12 \\
\text { Test } \\
\end{array}$ & \\
\hline $\begin{array}{l}\text { Wrzesien et } \\
\text { al } 2015\end{array}$ & $\begin{array}{l}\text { How the physical } \\
\text { similarity of avatars } \\
\text { can influence the } \\
\text { learning of emotion } \\
\text { regulation strategies } \\
\text { in teenagers }\end{array}$ & $\begin{array}{l}11 \text { mulheres e } 11 \\
\text { homens }(13.27)\end{array}$ & $\begin{array}{l}\text { Frustração; } \\
\text { Relaxamento }\end{array}$ & $\begin{array}{c}\text { Medidas subjetivas } \\
\text { e objetivas } \\
\text { apresentam que o } \\
\text { avatar virtual } \\
\text { aumentou e } \\
\text { diminuiu a valência } \\
\text { e ativação nos } \\
\text { participantes }\end{array}$ & $\begin{array}{c}\text { Óculos de } \\
\text { Realidade Virtual }\end{array}$ & $\begin{array}{c}\text { Appeal } \\
\text { Questionnaire } \\
\text { (AQ); Emotion } \\
\text { Regulation } \\
\text { Questionnaire } \\
\text { For Children } \\
\text { And Adolescents } \\
\text { (ERQ-CA); } \\
\text { Identification } \\
\text { With The Avatar } \\
\text { Questionnaire; } \\
\text { Self-Assessment } \\
\text { Manikin (SAM); } \\
\text { Presence Self } \\
\text { Assessment } \\
\text { Manikin (P- } \\
\text { SAM); Visual } \\
\text { Analogue Scale } \\
\text { (VAS) } \\
\end{array}$ & Eletroencefalografia \\
\hline
\end{tabular}




\begin{tabular}{|c|c|c|c|c|c|c|c|}
\hline $\begin{array}{l}\text { Zhang et al } \\
2016\end{array}$ & $\begin{array}{l}\text { Enhanced emotional } \\
\text { responses during } \\
\text { social coordination } \\
\text { with a virtual partner }\end{array}$ & $\begin{array}{l}9 \text { mulheres e } 12 \\
\text { homens (25) }\end{array}$ & $\begin{array}{l}\text { Ativação } \\
\text { emocional }\end{array}$ & $\begin{array}{l}\text { Alta ativação } \\
\text { emocional foi } \\
\text { encontrada quando } \\
\text { a Companhia } \\
\text { Virtual era } \\
\text { controlada por } \\
\text { humanos } \\
\end{array}$ & Computador & Não realizado & $\begin{array}{l}\text { Atividade } \\
\text { eletrodérmica }\end{array}$ \\
\hline $\begin{array}{l}\text { Zlomusica } \\
\text { et al } 2016\end{array}$ & $\begin{array}{l}\text { The impact of } \\
\text { different emotional } \\
\text { states on the memory } \\
\text { for what, where and } \\
\text { when features of } \\
\text { specific events }\end{array}$ & $\begin{array}{c}53 \text { mulheres e } 22 \\
\text { homens (22) }\end{array}$ & $\begin{array}{l}\text { Ansiedade; } \\
\text { Estado neutro; } \\
\text { relaxamento }\end{array}$ & $\begin{array}{c}\text { A ANOVA } \\
\text { apresentou que a } \\
\text { indução emocional } \\
\text { afetou os grupos de } \\
\text { modo diferente }\end{array}$ & Computador & $\begin{array}{c}\text { Depression } \\
\text { Anxiety Stress } \\
\text { Scales (DASS); } \\
\text { Igroup Presence } \\
\text { Questionnaire } \\
\text { (IPQ); } \\
\text { Immersive } \\
\text { Tendencies } \\
\text { Questionnaire } \\
\text { (ITQ) }\end{array}$ & Não realizado \\
\hline $\begin{array}{l}\text { Zumbach et } \\
\text { al } 2015\end{array}$ & $\begin{array}{c}\text { Impact of violent } \\
\text { video game realism } \\
\text { on the self-concept of } \\
\text { aggressiveness } \\
\text { assessed with explicit } \\
\text { and implicit measures }\end{array}$ & $\begin{array}{c}33 \text { mulheres e } 36 \\
\text { homens (24.46) }\end{array}$ & Raiva & $\begin{array}{c}\text { Nas medidas } \\
\text { explícitas, os } \\
\text { participantes } \\
\text { relataram redução } \\
\text { da agressividade ao } \\
\text { longo do tempo; A } \\
\text { associação entre } \\
\text { self e } \\
\text { comportamento } \\
\text { agressivo aumentou } \\
\text { após exposição à } \\
\text { violelncia } \\
\end{array}$ & Videogame & $\begin{array}{c}\text { Aggression } \\
\text { Questionnaire } \\
\text { (BPAQ); } \\
\text { Association Test } \\
\text { On } \\
\text { Aggressiveness } \\
\text { (Agg-IAT) }\end{array}$ & Não realizado \\
\hline
\end{tabular}

Tabela 2: Descrição dos resultados 


\section{Resultados}

\subsection{Participantes}

As pesquisas apresentaram um vasto alcance de tamanho de amostras, indo de 10 (Brundage, Brinton \& Hancock, 2016) até 324 participantes (McCall et al., 2016). A maioria dos estudos utilizou amostra conveniente, com voluntários, tipicamente estudantes universitários, sendo incluídos de acordo com a disponibilidade. Grande parte das pesquisas randomizaram os participantes para as condições experimentais e controle. Sempre que a randomização não foi utilizada, participantes eram tipicamente combinados por variáveis demográficas como sexo. Pesquisas com ansiedade e estresse usaram comumente participantes do sexo masculino, considerando questões hormonais. Entretanto, participantes do sexo feminino foram a maioria entre as pesquisas revisadas.

Um estudo entre os 61 (Baños, 2012) teve amostra composta por idosos, focando no uso da RV para a promoção de bem-estar neste grupo etário. 12 dos artigos apresentaram amostra contendo participantes com média de idade acima de 25 anos. Com a exceção do estudo com idosos, nenhum outro utilizou paradigma de RV específico para se adequar as limitações dos participantes.

\subsection{Emoções Induzidas}

No total, os estudos verificaram 8 diferentes emoções, incluindo tanto humores positivos quanto negativos. As emoções foram alegria/felicidade, medo, tristeza, nojo, raiva, relaxamento, estresse e ansiedade. Algumas pesquisas não apresentaram foco em emoções específicas, investigando os efeitos dos AVs em ativação e valência afetiva $(n=13)$. Dois estudos focaram na indução emoções complexas e seu espectro, como visto em Nazry et al., (2016), com o uso de emoções positivas e Chittaro et al (2017), com o uso de emoções ligadas à morte. Ansiedade, relaxamento, medo e alegria foram as emoções mais frequentemente induzidas, aparecendo em 14,12, 12, e 11 pesquisas, respectivamente. Raiva, estresse e tristeza apareceram em poucos estudos, em 6 dos 61. Um estado neutro foi induzido em 4 pesquisas, sempre em conjunto com outros estados emocionais. A emoção menos induzida foi o nojo, aparecendo apenas em 2 estudos. 
30 pesquisas induziram mais de uma emoção específica, incluindo as que induziram ativação e valência afetiva. 18 destes 30 induziram mais de uma emoção combinada da lista acima. Alegria/felicidade e raiva foram comumente encontradas juntas com outras emoções, raramente sendo as únicas emoções induzidas. Nojo e estado neutro apareceram apenas em pesquisas que também induziram outras emoções.

\subsection{Equipamentos De Realidade Virtual}

Entre os equipamentos utilizados como mediador entre os participantes e os AVs, os óculos de RV (HMD), que consiste em um equipamento colocado no rosto e ligado a um computador foi o mais utilizado, aparecendo em 34 dos artigos revisados. $\mathrm{O}$ equipamento CAVE (Cave Automatic Virtual Environment), que consiste em uma sala com grandes telas no lugar das paredes ficou em segundo lugar de utilização, aparecendo em 10 artigos. Poucos estudos utilizaram videogames como AV para a indução de humor. O CAVE foi visto sendo particularmente utilizado na indução de estresse. Videogames foram utilizados para a indução de emoções como estresse e relaxamento, com alguns estudos utilizando para a indução de raiva e emoções positivas.

\subsection{Medidas Subjetivas}

Medidas subjetivas foram utilizadas para verificar a eficácia das induções de humor na RV, bem como outros constructos específicos de cada estudo. Diversas medidas subjetivas foram encontradas nos artigos analisados nesta revisão, com escalas e questionários variando de acordo com a emoção induzida. Parte dos estudos compilados nesta revisão não utilizaram medidas fisiológicas, sendo 26 artigos que mantiveram seu foco no uso de medidas subjetivas.

A State-Trait Anxiety Invetory (STAI), uma escala likert de 4 pontos em autorrelato, que avalia ansiedade como estado transitório ou como traço de característica, foi a escala mais utilizada, aparecendo em 16 artigos. A escala Visual Analogue Scale (VAS) foi o segundo instrumento mais utilizado, aparecendo em 12 artigos. A escala é usada para medir sentimentos, com participantes marcando em uma 
linha a representação dos seus estados subjetivos. A Positive And Negative Affect Scale (PANAS), utilizada para avaliar valência emocional esteve presente em 8 dos artigos analisados. A Self-Assessment Manikin (SAM), usada também em 8 artigos, é uma escala que mede valência, ativação e dominância para cada emoção induzida. O Beck Depression Inventory (BDI), usado para avaliar sintomas de depressão, apareceu em 7 pesquisas. Ansiedade, medo e estresse foram comumente avaliados subjetivamente pela escala STAI, bem como a escala VAS e algumas vezes pela escala SAM.

\subsection{Medidas Fisiológicas}

As medias fisiológicas foram utilizadas em menor número em comparação com as medidas subjetivas, aparecendo em 35 dos artigos analisados. Atividade eletrodérmica foi a medida mais utilizada, estando presente em 23 pesquisas. Em seguida se encontra o batimento cardíaco, que esteve presente em 21 estudos. Poucas pesquisas utilizaram eletromiografia e respiração para complementar seus achados. Entre os artigos revisados que não utilizaram medidas fisiológicas, as escalas VAS, STAI e BDI foram as mais frequentes das medidas de autorrelato. Medo e ansiedade foram comumente avaliados fisiologicamente por atividade eletrodérmica, enquanto alegria e relaxamento foram comumente avaliadas por batimento cardíaco. Apenas 3 estudos analisados utilizaram neuroimagem, sendo Ressonância Magnética Funcional (fMRI) e Eletroencefalograma (EEG).

\section{Discussão}

Resumindo, esta revisão sistemática reúne pesquisas que utilizaram Realidade Virtual VR como paradigma de indução de humor. Quatro bases de dados foram usadas (Web of Science, Science Direct, PsycInfo e PubMed), com um total de 61 artigos adequados aos critérios de inclusão. Grande parte das pesquisas foi realizada com participantes universitários. As emoções mais induzidas foram ansiedade, relaxamento, medo e alegria. Quanto aos equipamentos de RV, os mais utilizados foram os óculos de RV (Head Mounted Display), CAVE (Cave Automatic Virtual Environment - ambiente virtual automático em forma de caverna, em tradução livre), videogames e computadores, respectivamente. Grande parte das pesquisas (95\%) utilizou medidas 
subjetivas para a verificação de indução de humor, enquanto algumas pesquisas (57\%) também utilizaram medidas fisiológicas. Os achados sugerem que a RV é uma ferramenta efetiva na indução de humor em laboratório. Esses achados são discutidos em relação a lacunas na literatura, propondo uma base para futuras pesquisas neste campo.

O uso de voluntários universitários como participantes pode se dar pela facilidade de aceso, divulgação e logística. Porém, utilizar tal população pode reduzir a generalização das pesquisas, focando em amostras WEIRD (Henrich, Heine, \& Norenzayan, 2010), um acrônimo para "western, educated, industrialized, rich and democratic", que em tradução livre seriam grupos de população ocidentais, com acesso à educação e indústria, com alto poder econômico e em países democráticos. Quanto aos estudos com foco em estresse, grande parte das amostras era composta por participantes do sexo masculino. Completando, esses achados realçam a necessidade de maiores estudos com maior diversidade em idade, sexo, nível educacional e etnia, bem como pesquisas conduzidas em países em desenvolvimento, com o propósito de complementar os achados aqui presentes.

As pesquisas devem adequar procedimentos para os grupos utilizados nas pesquisas, como em Baños et al. (2012), que usou o computador como paradigma de $\mathrm{RV}$, com este sendo o equipamento de maior acessibilidade para idosos devido às restrições do uso da RV com questões cardíacas.

Ter estresse, relaxamento, medo e alegria como as emoções específicas mais induzidas, pode estar relacionado com a noção de que abordagens experimentais podem ser usadas para modelar fenômenos clínicos. Essas emoções são parte do cotidiano humano, tendo impacto nas relacões sociais, trabalho e vida pessoal. Alguns artigos não focaram em uma emoção específica, mas exploraram qualquer tipo resposta emocional, considerando ativação e valência. As razões pos trás da falta de foco em uma emoção específica pode se dar pela tentativa de utilizar a RV como indutor de humor em geral, com as respostas emocionais causadas por um AV específico ou pelo caráter exploratório das pesquisas. Estudos futuros podem auxiliar, criando uma "biblioteca" de estímulos na RV adequados para cada emoção/dimensão, como já foi realizado com indução por música (Västfjäll, 2001) e filme (Weisenberg, Raz, \& Hener, 1998). 
Os óculos de RV foram o paradigma mais comum, possivelmente por sua grande capacidade imersiva. Entretanto, comparando com computadores, é um equipamento mais caro. O paradigma CAVE também apresentou grande capacidade imersiva (Jönsson, Wallergård, Österberg, Hansen, Johansson, \& Karlson, 2010), porém é ainda mais caro, precisando também de adaptações no laboratório para seu uso. Videogames se tornam uma opção mais acessível para laboratórios com capacidade limitada, sendo usados especialmente para induzir estresse, relaxamento e medo. Pesquisas futuras sobre o desenvolvimento de novas tecnologias e metodologias de implementação da RV são necessárias, podendo ser bastante produtivas com a colaboração de psicólogos e cientistas computacionais.

Medidas de autorrelato usadas em cada estudo revisado se mostraram compatíveis para os propósitos de cada pesquisa. Como visto nos resultados, 26 artigos não utilizaram medidas fisiológicas para investigar a eficácia das induções de humor, confiando apenas nas escalas e questionários. Tais medidas são importantes para as pesquisas com emoção, já que possuem ontologia de primeira pessoa, sendo acessada apenas pelo experimentador (Searle, 1987). No entanto, escalas de autorrelato costumam ser criticadas por sua subjetividade, inclinação a exigir características e dificuldade de acesso em certos casos (por exemplo, emoções sutis) (Baumeister, Vohs, \& Funder, 2007). Estudos futuros podem se beneficiar do uso de medidas como a atividade eletrodérmica e as avaliações dos batimentos cardíacos. Em especial no caso de estudos que provocam ativação e valência emocional, mas também pode ser feito para estudos que exploram emoções específicas (Gross, 1998).

As características da RV dão ao pesquisador o controle de um estudo que não poderia ser controlado normalmente, permitindo a indução real de emoções nos AVs. Por exemplo, os tratamentos de fobias fazem com que o paciente enfrente seus medos com a intensidade do estímulo controlada, reduzindo o a ocorrência de comportamentos de evitamento e promovendo habituação do estímulo fóbico (Gorini, et al., 2009). A RV também pode ser usada para tratar estratégias de regulação emocional mal adaptativas, reduzindo os sintomas de transtornos (Wrzesien, et al., 2015).

O ambiente gerado na RV apresenta grande diversidade quanto sua utilização, sendo usada em arquitetura, treinamento médico e militar, educação e também em psicologia. Essa grande diversidade se dá com a interação gerada pelo estimulo dos 
muitos sentidos (Serrano, Baños, \& Botella, 2016). O avanço tecnológico trouxe novas interações em ambientes digitais. Tal fato indica a necessidade de uma adaptação tanto do humano com o virtual como do virtual para o humano para uma melhor utilização, tendo em consideração as reações humanas para com esse ambiente. Essa adaptação mútua tem enfoque especial na utilização das tecnologias digitais na área da saúde mental, na Terapia por Exposição em Realidade Virtual, que usam instrumentos para a modificação de expressões emocionais comprometidas (Peperkorn, Diemer, \& Mühlberger, 2015).

A demanda por tarefas que representem o funcionamento real do indivíduo em âmbito cognitivo vem crescendo. Pesquisadores e avaliadores apresentam dificuldade em avaliar construtos cognitivos específicos da forma em que o mesmo se apresenta em situações reais. A validade ecológica de ambientes virtuais na testagem neuropsicológica vem crescendo em aceitação a tratamentos e proximidade à realidade (Parsons, 2015).

A presença é um construto necessário no campo de atuação da RV. O usuário deve se sentir presente no AV. Este conceito está relacionado à qualidade gráfica das simulações utilizadas nos equipamentos: quanto maior a qualidade, maior será a presença, especialmente quando o AV não induz uma emoção específica. A imersão possui um papel importante nas classificações de presença e, assim, uma simulação imersiva se correlacionaria com a sensação de presença relatada (Diemer, Alpers, Peperkorn, Shiban, \& Mühlberger, 2015).

A experiência emocional na RV e a sensação de presença também possuem correlações reportadas em literatura. Alguns dos componentes da presença estão associados com o medo experimentado em simulações e a resposta do tratamento por exposição à RV (Price, Mehta, Tone, \& Anderson, 2011). A relação entre emoção e presença pode ser confrontada pela relação entre qualidade gráfica e presença nas simulações com conteúdo emocional neutro, que poderia indicar que a emoção não seria o fator mediador entre imersão e presença (Diemer, Alpers, Peperkorn, Shiban, \& Mühlberger, 2015). Estudos futuros devem investigar a relação entre emoção e imersão, bem como seu impacto na presença sentida pelo usuário, comparando estados neutros e induções de humor. 


\section{Referências Bibliogáficas}

Åhs, F., Dunsmoor, J. E., Zielinski, D., \& LaBar, K. S. (2015). Spatial proximity amplifies valence in emotional memory and defensive approach-avoidance. Neuropsychologia, 70, 476-485.

Åhs, F., Kragel, P. A., Zielinski, D. J., Brady, R., \& LaBar, K. S. (2015). Medial prefrontal pathways for the contextual regulation of extinguished fear in humans. Neuroimage, 122, 262-271.

Anderson, A. P., Mayer, M. D., Fellows, A. M., Cowan, D. R., Hegel, M. T., \& Buckey, J. C. (2017). Relaxation with immersive natural scenes presented using virtual reality. Aerospace medicine and human performance, $88(6), 520-526$.

Annerstedt, M., Jönsson, P., Wallergård, M., Johansson, G., Karlson, B., Grahn, P., ... \& Währborg, P. (2013). Inducing physiological stress recovery with sounds of nature in a virtual reality forest—Results from a pilot study. Physiology \& behavior, 118, 240-250.

Aymerich-Franch, L. (2010). Presence and emotions in playing a group game in a virtual environment: the influence of body participation. Cyberpsychology, Behavior, and Social Networking, 13(6), 649-654.

Baños, R. M., Etchemendy, E., Castilla, D., Garcia-Palacios, A., Quero, S., \& Botella, C. (2012). Positive mood induction procedures for virtual environments designed for elderly people. Interacting with Computers, 24(3), 131-138.

Baumeister, R. F., Vohs, K. D., \& Funder, D. C. (2007). Psychology as the science of self-reports and finger movements: Whatever happened to actual behavior?. Perspectives on Psychological Science, 2(4), 396-403.

Bradley, M. M., \& Lang, P. J. (1994). Measuring emotion: the self-assessment manikin and the semantic differential. Journal of behavior therapy and experimental psychiatry, 25(1), 49-59.

Brundage, S. B., Brinton, J. M., \& Hancock, A. B. (2016). Utility of virtual reality environments to examine physiological reactivity and subjective distress in adults who stutter. Journal of fluency disorders, 50, 85-95.

Canazei, M., Pohl, W., Bliem, H. R., Martini, M., \& Weiss, E. M. (2017). Artificial skylight effects in a windowless office environment. Building and Environment, 124, 69-77.

Cartaud, A., Ruggiero, G., Ott, L., Iachini, T., \& Coello, Y. (2018). Physiological response to facial expressions in peripersonal space determines interpersonal distance in a social interaction context. Frontiers in Psychology, 9.

Chirico, A., Ferrise, F., Cordella, L., \& Gaggioli, A. (2018). Designing awe in virtual reality: An experimental study. Frontiers in psychology, 8, 2351.

Chirico, A., Yaden, D. B., Riva, G., \& Gaggioli, A. (2016). The potential of virtual reality for the investigation of awe. Frontiers in psychology, 7, 1766. 
Chittaro, L. (2014). Anxiety induction in virtual environments: an experimental comparison of three general techniques. Interacting with Computers, 26(6), 528-539.

Chittaro, L., \& Sioni, R. (2014). Affective computing vs. affective placebo: Study of a biofeedbackcontrolled game for relaxation training. International Journal of Human-Computer Studies, 72(8-9), 663673.

Chittaro, L., Sioni, R., Crescentini, C., \& Fabbro, F. (2017). Mortality salience in virtual reality experiences and its effects on users' attitudes towards risk. International Journal of Human-Computer Studies, 101, 10-22.

Crescentini, C., Chittaro, L., Capurso, V., Sioni, R., \& Fabbro, F. (2016). Psychological and physiological responses to stressful situations in immersive virtual reality: Differences between users who practice mindfulness meditation and controls. Computers in Human Behavior, 59, 304-316.

Cuperus, A. A., Laken, M., van den Hout, M. A., \& Engelhard, I. M. (2016). Degrading emotional memories induced by a virtual reality paradigm. Journal of behavior therapy and experimental psychiatry, 52, 45-50.

Davidson, R. J. (2003). Affective neuroscience and psychophysiology: Toward a synthesis. Psychophysiology, 40(5), 655-665.

Dibbets, P., \& Schulte-Ostermann, M. A. (2015). Virtual reality, real emotions: a novel analogue for the assessment of risk factors of post-traumatic stress disorder. Frontiers in psychology, 6, 681.

Diemer, J., Alpers, G. W., Peperkorn, H. M., Shiban, Y., \& Mühlberger, A. (2015). The impact of perception and presence on emotional reactions: a review of research in virtual reality. Frontiers in psychology, 6, 26.

Ekman, P., Levenson, R. W., \& Friesen, W. V. (1983). Autonomic nervous system activity distinguishes among emotions. Science, 221(4616), 1208-1210.

Felnhofer, A., Kothgassner, O. D., Schmidt, M., Heinzle, A. K., Beutl, L., Hlavacs, H., \& Kryspin-Exner, I. (2015). Is virtual reality emotionally arousing? Investigating five emotion inducing virtual park scenarios. International journal of human-computer studies, 82, 48-56.

Fich, L. B., Jönsson, P., Kirkegaard, P. H., Wallergård, M., Garde, A. H., \& Hansen, Å. (2014). Can architectural design alter the physiological reaction to psychosocial stress? A virtual TSST experiment. Physiology \& behavior, 135, 91-97.

Gerrards-Hesse, A., Spies, K., Hesse, W.F. (1994). Experimental inductions of emotional states and their effectiveness: A review. British Journal of Psychology. 85 (1), 55-78.

Gordon, N. S., Merchant, J., Zanbaka, C., Hodges, L. F., \& Goolkasian, P. (2011). Interactive gaming reduces experimental pain with or without a head mounted display. Computers in Human Behavior, 27(6), 2123-2128. 
Gorini, A., Mosso, J. L., Mosso, D., Pineda, E., Ruíz, N. L., Ramíez, M., ... \& Riva, G. (2009). Emotional response to virtual reality exposure across different cultures: the role of the attribution process. Cyberpsychology \& behavior, 12(6), 699-705.

Gross, J. J. (1998). Antecedent-and response-focused emotion regulation: divergent consequences for experience, expression, and physiology. Journal of personality and social psychology, 74(1), 224.

Henrich, J., Heine, S. J., \& Norenzayan, A. (2010). The weirdest people in the world?. Behavioral and brain sciences, 33(2-3), 61-83.

Hildebrandt, L. K., McCall, C., Engen, H. G., \& Singer, T. (2016). Cognitive flexibility, heart rate variability, and resilience predict fine-grained regulation of arousal during prolonged threat. Psychophysiology, 53(6), 880-890.

Jackson, P. L., Michon, P. E., Geslin, E., Carignan, M., \& Beaudoin, D. (2015). EEVEE: The empathyenhancing virtual evolving environment. Frontiers in human neuroscience, 9, 112.

James, W. (1894). Discussion: The physical basis of emotion. Psychological Review, 1(5), 516.

Jönsson, P., Wallergård, M., Österberg, K., Hansen, Å. M., Johansson, G., \& Karlson, B. (2010). Cardiovascular and cortisol reactivity and habituation to a virtual reality version of the Trier Social Stress Test: a pilot study. Psychoneuroendocrinology, 35(9), 1397-1403.

Kwon, J. H., Powell, J., \& Chalmers, A. (2013). How level of realism influences anxiety in virtual reality environments for a job interview. International journal of human-computer studies, 71(10), 978-987.

Lin, J. H. T. (2017). Fear in virtual reality (VR): Fear elements, coping reactions, immediate and next-day fright responses toward a survival horror zombie virtual reality game. Computers in Human Behavior, 72 , 350-361.

Ma, K., Sellaro, R., Lippelt, D. P., \& Hommel, B. (2016). Mood migration: How enfacing a smile makes you happier. Cognition, 151, 52-62.

Madsen, K. E. (2016). The differential effects of agency on fear induction using a horror-themed video game. Computers in Human Behavior, 56, 142-146.

Maïano, C., Therme, P., \& Mestre, D. (2011). Affective, anxiety and behavioral effects of an aversive stimulation during a simulated navigation task within a virtual environment: A pilot study. Computers in Human Behavior, 27(1), 169-175.

Marschner, L., Pannasch, S., Schulz, J., \& Graupner, S. T. (2015). Social communication with virtual agents: The effects of body and gaze direction on attention and emotional responding in human observers. International Journal of Psychophysiology, 97(2), 85-92.

Matthias, H., \& Beckhaus, S. (2012). Adaptive generation of emotional impact using enhanced virtual environments. Presence: Teleoperators and Virtual Environments, 21(1), 96-116. 
McCall, C., Hildebrandt, L. K., Hartmann, R., Baczkowski, B. M., \& Singer, T. (2016). Introducing the Wunderkammer as a tool for emotion research: unconstrained gaze and movement patterns in three emotionally evocative virtual worlds. Computers in Human Behavior, 59, 93-107.

McEwen, B. S., \& Stellar, E. (1993). Stress and the individual: mechanisms leading to disease. Archives of internal medicine, 153(18), 2093-2101.

Mira, A., Campos, D., Etchemendy, E., Baños, R. M., \& Cebolla, A. (2016). Access to autobiographical memory as an emotion regulation strategy and its relation to dispositional mindfulness. Mindfulness \& Compassion, 1(1), 39-44.

Moghimi, M., Stone, R., Rotshtein, P., \& Cooke, N. (2016). Influencing human affective responses to dynamic virtual environments. Presence: Teleoperators and Virtual Environments, 25(2), 81-107.

Moher D, Liberati A, Tetzlaff J, Altman DG, The PRISMA Group (2009). Preferred Reporting Items for Systematic Reviews and Meta-Analyses: The PRISMA Statement.

Molet, M., Billiet, G., \& Bardo, M. T. (2013). Conditioned place preference and aversion for music in a virtual reality environment. Behavioural processes, 92, 31-35.

Mousas, C., Anastasiou, D., \& Spantidi, O. (2018). The effects of appearance and motion of virtual characters on emotional reactivity. Computers in Human Behavior, 86, 99-108.

Mühlberger, A., Wieser, M. J., \& Pauli, P. (2008). Darkness-enhanced startle responses in ecologically valid environments: a virtual tunnel driving experiment. Biological psychology, 77(1), 47-52.

Munyan III, B. G., Neer, S. M., Beidel, D. C., \& Jentsch, F. (2016). Olfactory stimuli increase presence in virtual environments. PloS one, 11(6), e0157568.

Murray, E. G., Neumann, D. L., Moffitt, R. L., \& Thomas, P. R. (2016). The effects of the presence of others during a rowing exercise in a virtual reality environment. Psychology of Sport and Exercise, 22, 328-336.

Nazry, N. N. M., \& Romano, D. M. (2017). Mood and learning in navigation-based serious games. Computers in Human Behavior, 73, 596-604.

Nogueira, P. A., Rodrigues, R., Oliveira, E., \& Nacke, L. E. (2015, January). Modelling human emotion in interactive environments: Physiological ensemble and grounded approaches for synthetic agents. In Web Intelligence (Vol. 13, No. 3, pp. 195-214). IOS Press.

Pallavicini, F., Cipresso, P., Raspelli, S., Grassi, A., Serino, S., Vigna, C., ... \& Riva, G. (2013). Is virtual reality always an effective stressors for exposure treatments? Some insights from a controlled trial. $B M C$ psychiatry, 13(1), 52.

Parsons, T. D. (2015). Virtual reality for enhanced ecological validity and experimental control in the clinical, affective and social neurosciences. Frontiers in human neuroscience, 9, 660. 
Peperkorn, H. M., Diemer, J., \& Mühlberger, A. (2015). Temporal dynamics in the relation between presence and fear in virtual reality. Computers in Human Behavior, 48, 542-547.

Price, M., Mehta, N., Tone, E. B., \& Anderson, P. L. (2011). Does engagement with exposure yield better outcomes? Components of presence as a predictor of treatment response for virtual reality exposure therapy for social phobia. Journal of anxiety disorders, 25(6), 763-770.

Riva, G., Mantovani, F., Capideville, C. S., Preziosa, A., Morganti, F., Villani, D., ... \& Alcañiz, M. (2007). Affective interactions using virtual reality: the link between presence and emotions. CyberPsychology \& Behavior, 10(1), 45-56.

Rodríguez, A., Rey, B., Clemente, M., Wrzesien, M., \& Alcañiz, M. (2015). Assessing brain activations associated with emotional regulation during virtual reality mood induction procedures. Expert Systems with Applications, 42(3), 1699-1709.

Ruggiero, G., Frassinetti, F., Coello, Y., Rapuano, M., Di Cola, A. S., \& Iachini, T. (2017). The effect of facial expressions on peripersonal and interpersonal spaces. Psychological research, 81(6), 1232-1240.

Schweizer, T., Schmitz, J., Plempe, L., Sun, D., Becker-Asano, C., Leonhart, R., \& Tuschen-Caffier, B. (2017). The impact of pre-existing anxiety on affective and cognitive processing of a Virtual Reality analogue trauma. PloS one, 12(12), e0190360.

Searle, J. R. (1987). Indeterminacy, empiricism, and the first person. The Journal of Philosophy, 84(3), 123-146.

Seinfeld, S., Bergstrom, I., Pomes, A., Arroyo-Palacios, J., Vico, F., Slater, M., \& Sanchez-Vives, M. V. (2016). Influence of music on anxiety induced by fear of heights in virtual reality. Frontiers in psychology, 6, 1969.

Serrano, B., Baños, R. M., \& Botella, C. (2016). Virtual reality and stimulation of touch and smell for inducing relaxation: A randomized controlled trial. Computers in Human Behavior, 55, 1-8.

Sharar, S. R., Alamdari, A., Hoffer, C., Hoffman, H. G., Jensen, M. P., \& Patterson, D. R. (2016). Circumplex model of affect: a measure of pleasure and arousal during virtual reality distraction analgesia. Games for health journal, 5(3), 197-202.

Shiban, Y., Diemer, J., Brandl, S., Zack, R., Mühlberger, A., \& Wüst, S. (2016). Trier social stress test in vivo and in virtual reality: Dissociation of response domains. International Journal of Psychophysiology, 110, 47-55.

Shin, D. (2018). Empathy and embodied experience in virtual environment: To what extent can virtual reality stimulate empathy and embodied experience?. Computers in Human Behavior, 78, 64-73.

Siamionava, K., Slevitch, L., \& Tomas, S. R. (2018). Effects of spatial colors on guests' perceptions of a hotel room. International Journal of Hospitality Management, 70, 85-94. 
Thimmesch-Gill, Z., Harder, K. A., \& Koutstaal, W. (2017). Perceiving emotions in robot body language: Acute stress heightens sensitivity to negativity while attenuating sensitivity to arousal. Computers in Human Behavior, 76, 59-67.

Toet, A., \& van Schaik, M. G. (2012). Effects of signals of disorder on fear of crime in real and virtual environments. Journal of Environmental Psychology, 32(3), 260-276.

Toet, A., van Welie, M., \& Houtkamp, J. (2009). Is a dark virtual environment scary?. CyberPsychology \& Behavior, 12(4), 363-371.

Tröger, C., Ewald, H., Glotzbach, E., Pauli, P., \& Mühlberger, A. (2012). Does pre-exposure inhibit fear context conditioning? A Virtual Reality Study. Journal of neural transmission, 119(6), 709-719.

Van Strien, T., Cebolla, A., Etchemendy, E., Gutierrez-Maldonado, J., Ferrer-Garcia, M., Botella, C., \& Baños, R. (2013). Emotional eating and food intake after sadness and joy. Appetite, 66, 20-25.

Vara, M. D., Baños, R. M., Rasal, P., Rodríguez, A., Rey, B., Wrzesien, M., \& Alcañiz, M. (2016). A game for emotional regulation in adolescents: The (body) interface device matters. Computers in Human Behavior, 57, 267-273.

Västfjäll, D. (2001). Emotion induction through music: A review of the musical mood induction procedure. Musicae Scientiae, 5(1_suppl), 173-211.

Verplaetse, J., \& De Smet, D. (2016). Mental beliefs about blood, and not its smell, affect presence in a violent computer game. Computers in Human Behavior, 63, 928-937.

Weisenberg, M., Raz, T., \& Hener, T. (1998). The influence of film-induced mood on pain perception. Pain, 76(3), 365-375.

Wrzesien, M., Rodríguez, A., Rey, B., Alcañiz, M., Baños, R. M., \& Vara, M. D. (2015). How the physical similarity of avatars can influence the learning of emotion regulation strategies in teenagers. Computers in Human Behavior, 43, 101-111.

Zhang, M., Dumas, G., Kelso, J. S., \& Tognoli, E. (2016). Enhanced emotional responses during social coordination with a virtual partner. International Journal of Psychophysiology, 104, 33-43.

Zlomuzica, A., Preusser, F., Totzeck, C., Dere, E., \& Margraf, J. (2016). The impact of different emotional states on the memory for what, where and when features of specific events. Behavioural brain research, 298, 181-187.

Zumbach, J., Seitz, C., \& Bluemke, M. (2015). Impact of violent video game realism on the self-concept of aggressiveness assessed with explicit and implicit measures. Computers in Human Behavior, 53, 278288. 
Indução De Humor Por Realidade Virtual $\mathrm{Na}$ Promoção De Autoconsciência - Um Estudo Piloto

Pedro Diniz Bernardo ${ }^{\mathrm{a}}$, Nicolly Marques ${ }^{\mathrm{a}}$, Daniel C. Mograbi ${ }^{\mathrm{a}, \mathrm{b}}$,

a Pontifícia Universidade Católica do Rio de Janeiro, Departamento de Psicologia, 22451 100, Gávea, Rio de Janeiro, Brazil b King's College London, Institute of Psychiatry, Psychology \& Neuroscience, De Crespigny Park, SE58AF, London, United Kingdom 


\section{RESUMO}

O presente estudo tem como objetivo verificar como a indução de humor por Realidade Virtual pode impactar na reatividade emocional e influenciar na melhora da consciência interoceptiva Introdução: O conceito de Indução de Humor engloba procedimentos para a alteração dos estados emocionais, que são categorizados de acordo com os estímulos usados para influenciar o humor do indivíduo. A Realidade Virtual (RV) é um ambiente gerado por um equipamento eletrônico que, unido a um computador, possibilita a emulação de diversas situações em meio virtual, permitindo que um indivíduo interaja com esse ambiente criado como se o mesmo estivesse em um ambiente real. A RV se mostra uma nova metodologia para estudos experimentais e a indução respostas de cunho emocional, fisiológico ou comportamental. Método: Participantes de ambos os sexos, com faixa etária entre 18 e 35 anos, foram divididos em dois grupos: o primeiro recebeu um estímulo neutro e o segundo grupo recebeu um estímulo emocional. Todos os estímulos foram apresentados por simulações no ambiente virtual, mediadas pelo aparelho de Óculos de Realidade Virtual. Foram utilizados os instrumentos Positive And Negative Affection Schedule (PANAS) para avaliar a reatividade emocional e uma tarefa de detecção de batimentos cardíacos (HBD Task) para avaliar a interocepção dos indivíduos testados. As respostas fisiológicas dos participantes, como frequência cardíaca e atividade eletodérmica, foram coletadas ao longo do experimento. Resultados: As análises indicaram efeito de interação entre tempo e grupo para atividade eletrodérmica. Tamanhos de efeito moderados a grandes foram observados para maior reatividade emocional negativa e melhor interocepção, sugerindo que esses efeitos poderiam ser significativos em maior amostra. Os resultados apresentados da atividade eletrodérmica indicam sucesso na indução de emoção. $O$ presente estudo se mostra relevante por trazer novos procedimentos e tecnologias para auxiliar nas pesquisas em psicologia, com a Realidade Virtual se mostrando eficaz em estudos de difícil aplicação. O caráter clínico do estudo é reforçado por sua a intenção em melhorar a capacidade cognitiva da interocepção, apresentando indícios da possibilidade de seu uso em tratamentos clínicos, ajudando o indivíduo em eventos com conteúdo emocional, onde a capacidade de identificar e discernir suas emoções e sensações corporais possibilitaria gerar respostas mais adaptativas.

\section{Palavras-chave:}

Indução; humor; emoção; consciência; realidade virtual; 


\section{ABSTRACT}

This study aims to investigate how mood induction via Virtual Reality can impact on emotional reactivity and influence the improvement of interoceptive awareness. Introduction: Mood Induction Procedures incorporate procedures for the manipulation of emotional states, which are categorized according to the stimuli used to elicit the subject's mood. Virtual Reality (VR) is an environment generated by an electronic equipment that, along with a computer, enables the emulation of several situations in a virtual environment, allowing an subject to interact with the environment created as if he/she were in a real environment. VR is a new methodology for conducting experiments and inducing emotional, physiological or behavioral responses. Method: Participants of both sexes, aged between 18 and 35 years, were assigned into two groups: the first received a neutral stimulus and the second group received an emotional stimulus. Simulations in the virtual environment, mediated by the Headmounted Display (HMD) equipment, presented all stimuli. Positive And Negative Affection Schedule (PANAS) instruments were used to assess emotional reactivity and a heartbeat detection task was used to assess the interoception of the individuals tested. Participants' physiological responses, such as heart rate and electodermal activity, were collected throughout the experiment. Results: The analyses indicated effect interaction between time and group and effect of time for electrodermal activity. Moderate to large effect sizes were observed for greater negative emotional reactivity and better interoception, suggesting that with a larger sample these effects could be significant. The heart rate results showed no significant differences. The results of the electrodermal activity indicate success in mood induction. The present study brings new procedures and technologies to assist in research in psychology, with Virtual Reality proving effective in studies of difficult application. The clinical character of the study is reinforced by its intent to improve the cognitive ability of interoception, presenting indications of the possibility of its use in clinical treatments, helping the individual in events with emotional content, where the ability to identify and discern their emotions and body sensations allow for more adaptive responses.

\section{Keywords:}

Mood; induction; emotion; awareness; virtual reality; 


\section{Introdução}

Os interesses da Psicologia nas emoções e suas influências nos processos psicológicos cresceram desde a década de 1980. Assim, os estados de humor se tornam uma variável independente na questão metodológica. Os procedimentos para a alteração dos estados emocionais são divididos em: classificação Pré-Experimental, onde se classificam os indivíduos de acordo com seu estado emocional inicial, avaliado no início da testagem. Comparação Entre Indivíduos Clínicos e Não Clínicos, onde ocorre comparação entre o estado emocional de pacientes em um estado clínico com o estado emocional de indivíduos "saudáveis". Emoções de Surgimento Natural, onde eventos de procedência natural são utilizados, como clima, passar por momentos de avaliação acadêmica, assistir eventos esportivos pela televisão ou mesmo uma cena onde uma emoção é apresentada. E por fim, a Indução Experimental de Humor, onde estados de humor são induzidos experimentalmente pelo uso de procedimentos de indução de humor especiais. O primeiro e o segundo procedimento listados não manipulam os estados de humor como variáveis independentes, sendo quase-experimentais. Quanto ao terceiro, não é possível padronizar as observações. O método experimental de indução de humor seria o mais rígido, seja aplicado em campo ou em laboratório. Os autores categorizam os procedimentos de indução do humor (PIH -em inglês MIP - Mood Induction Procedures) de acordo com os estímulos usados para influenciar o humor do indivíduo e também se a finalidade do procedimento é ou não anunciado ao indivíduo. (Gerrards-Hesse et al., 1994).

Quanto à eficácia dos procedimentos de indução de humor, a literatura aponta que os procedimentos utilizando filmes, músicas ou imaginação possuem maior taxa de efetividade, comparando com os métodos Velten (que consiste na leitura e reflexão de afirmações), que costuma ser mais efetivo com participantes mulheres, e expressão facial, que atua de formas diferentes caso o participante seja inclinado a reagir por ação emocional interna ou externa. Ainda assim, o conceito de sucesso dos procedimentos citados varia dependendo de sua operacionalidade. A literatura também aponta evidências de que cada indivíduo terá respostas diferentes para cada procedimento (Westermann, Spies, Stahl, \& Hesse, 1996).

Realidade Virtual (RV) é um ambiente gerado por um equipamento eletrônico que, unido a um computador, possibilita a emulação de diversas situações em meio virtual, permitindo que um indivíduo interaja com esse ambiente criado como se o 
mesmo estivesse em um ambiente real (Serrano, Baños \& Botella, 2016). Possuindo grande campo de atuação na Psicologia, a RV vem sido utilizada, no auxílio ao tratamento de fobias, transtornos de ansiedade, transtorno de estresse pós-traumático, bem como o espectro autista, transtornos alimentares e outras situações. A união de diversas tecnologias digitais permite a criação de um mundo virtual convincente onde o participante se percebe em um ambiente tridimensional. (Ribeiro \& Monteiro, 2015). Podemos enxergar nos ambientes virtuais uma nova metodologia para realizar experimentações e também perceber alterações dinâmicas ao refazer um ambiente real e, assim, podendo induzir respostas, sejam de cunho emocional, fisiológico ou comportamental. O avanço da tecnologia $3 D$, e consequentemente a melhora gráfica, vem permitindo a aproximação dos ambientes criados virtualmente enviados pela RV aos estímulos do cotidiano. A proximidade com a realidade dá ao ambiente virtual propriedade para a experimentação em laboratório (Riva et al., 2007). Estudos recentes indicam que, com o controle da interação e o aprimoramento da experiência do indivíduo testado fazem da RV um sistema de pesquisas avançado bastante eficaz para indução de humor, sendo similar à realidade (Monteiro et al., 2011).

Para maior aproveitamento do uso da RV, é necessário que o sujeito se perceba presente no ambiente virtual. O conceito de presença é relacionado à qualidade gráfica do programa de RV. Quanto maior a qualidade, mais presença é percebida, em especial nos programas em que o ambiente virtual não foi designado a induzir emoções precisas (Diemer et al., 2015). Ainda assim, presença e experiência emocional na terapia com $\mathrm{RV}$ possuem correlações reportadas em literatura. Diferentes componentes da presença são associados com a experiência do medo e a resposta do tratamento com RV. Entretanto a associação parece ser direcionada majoritariamente pela significante ligação entre o realismo da presença e classificações do medo durante a exposição (Price et al., 2011). A imersão também possui grande significância na presença. Um programa de RV com maior qualidade gráfica teria a sensação de presença aumentada em cenários neutros em relação à emoção, questionando a emoção como fator mediador entre imersão e presença no ambiente virtual (Diemer et al., 2015).

A influência da emoção na sensação de presença é vista em um estudo de Banõs, que comparou presença de participantes que receberam estímulos como tristeza, alegria, relaxamento em relação a participantes com estímulo virtual neutro, sem emoção, tendo aqueles que receberam estímulo emocional reportando maior presença (Baños, 2004). 
Giuseppe Riva utilizou o ambiente virtual para induzir relaxamento e ansiedade, encontrando resultados que também confirmaram a relação bidirecional entre a sensação de presença e a indução de emoções (Riva, 2007). Ainda que demostrem a eficácia do uso do ambiente virtual para induzir emoções e seu papel no aumento da sensação de presença, grande parte das pesquisas utilizam apenas estímulos audiovisuais em seus estudos (Serrano, Baños \& Botella, 2016). Assim, pesquisas em realidade virtual que utilizem outros sentidos, como tato e olfato, são raras, ainda que existam estudos que apresentam a melhora na experiência virtual quando há inserção desses estímulos extra, em conformidade com o ambiente virtual simulado (Tortell et al., 2007).

O ambiente virtual permite o estudo das emoções e seus impactos psicológicos e biológicos com maior controle de variáveis e validade ecológica (Parsons, 2015), além de permitir a criação de estratégias para tratamento de questões neuropsicológicas neste ambiente controlado (Monteiro et al., 2011). O uso da realidade virtual vem crescendo e estudos sobre seu potencial são necessários para melhor entendimento da ferramenta como método de pesquisas científicas e como método de terapia clínica. O presente estudo realizou manipulação experimental para verificar a relação da autoconsciência e como esta afeta o cotidiano de indivíduos saudáveis e assim, permitindo a criação de um conhecimento de base para um possível estudo sobre consciência emocional em população clínica e também possíveis formas de tratamento e/ou exercícios clínicos.

\section{Método}

\subsection{Participantes}

O recrutamento ocorreu por divulgação em redes sociais, por envio de email do banco de dados de participantes de pesquisas anteriores e também por divulgação nos departamentos da universidade em que o estudo foi realizado. A amostra consiste em estudantes universitários, contendo 27 indivíduos saudáveis de ambos os sexos, com idade entre 18 e 35 anos, que foram aleatorizados por código em um de dois grupos: controle e experimental, para testagem. Os critérios de exclusão foram: possuir menos de quatro anos de escolaridade, gravidez, condições neurológicas ou psiquiátricas e também condições que se agravem com o uso da Realidade Virtual (como labirintite, problemas cardíacos, acrofobia), deficiências visuais e auditivas. Uma entrevista de triagem foi realizada para verificar a existência de tais condições, bem como 
suscetibilidade a tonturas e enjoos, uso recente de substâncias psicoativas, com o intuito de filtrar a participação de indivíduos que não se adequassem a amostra pretendida.

\subsection{Equipamento}

Foram utilizados o equipamento de realidade virtual Oculus Rift DK 2 (Oculus VR; Menlo Park, California, EUA) e sensores de ativação autonômica: frequência cardíaca e atividade eletrodérmica, CAPTIV L7000 (Tech Ergo Appliquées; Technopôle Nancy-Brabois, Vandœuvre-lès-Nancy, França). Ambos tendo seus softwares instalados em um computador de sistema Microsoft Windows 7 (Microsoft Corporation; Redmond, Washington, EUA) 64bits, com disco rígido de 1tb e memória RAM de 8gb.

A simulação neutra utilizada consiste de fotos em 360 graus em áreas comuns de cidades europeias, como praças, fachadas de igrejas, pontes, etc., por Space WeaRV por $W_{e a V R}{ }^{\mathbf{T M}}$. Em grupos que receberam estimulo neutro mais de um momento na testagem foi utilizado um conjunto de fotos diferentes. As cidades representadas foram Basiléia, Zurique e Veneza. No estímulo emocional, Epic RollerCoasters (por B4T Games ${ }^{\mathbf{T M}}$ ) representa um passeio por uma montanha russa em um ambiente montanhoso e tropical.

\subsection{Instrumentos e tarefas}

Questionário de Ansiedade de Hamilton (HAM-A)

Utilizado para a verificação de sintomas de ansiedade. Possui 15 itens em escala likert de 5 pontos, sendo divididos em características psicológicas e somáticas. Maior pontuação no escore indica maior presença de sintomas de ansiedade. Suas propriedades psicométricas são bem estabelecidas (Kummer et al., 2010).

\section{Inventário de Depressão de Beck (BDI)}

Utilizado para verificação de sintomas depressivos. Possui vinte e um itens em escala likert de 4 pontos, indicando eventos de depressão leve, moderada ou grave. Maior pontuação no escore indica maior presença de sintomas de depressão. Suas propriedades psicométricas são bem estabelecidas (Gorenstein \& Andrade, 1998). 


\section{$\underline{\text { Avaliação Multidimensional da Consciência Interoceptiva (MAIA - VB2) }}$}

Utilizada para avaliar a consciência (sensibilidade) interoceptiva. Possui 32 itens em escala likert de 6 pontos. Possui 8 fatores, sendo eles percepção, não-distração, não preocupação, regulação da atenção, consciência emocional, autorregulação, escuta corporal e confiança. Maior pontuação no escore indica maior presença de sensibilidade interoceptiva. Suas propriedades psicométricas são bem estabelecidas (Mehling et al., 2012).

\section{Questionário de Regulação Emocional (ERQ)}

Utilizado para avaliar regulação emocional. Possui 10 itens em escala likert de 7 pontos, e os fatores reavaliação cognitiva e supressão emocional. A pontuação no escore irá indicar a estratégia de regulação emocional utilizada com maior frequência. Suas propriedades psicométricas são bem estabelecidas (Tavares Bastioni et al., 2013).

\section{Escala de Alexitimia de Toronto (TAS-20)}

Utilizada para avaliação de alexitimia. Contendo 20 itens em escala likert de 5 pontos e 3 fatores: a capacidade de distinguir sensações de sentimentos, pensamento concreto e capacidade de imaginação. A pontuação no escore irá indicar a presença ou ausência de sintomas de alexitimia. Suas propriedades psicométricas são bem estabelecidas (Yoshida, 2007).

\section{Escala de Afeto Positivo e Negativo (PANAS-3)}

Utilizada para avaliar valência afetiva. Possui 20 itens, que consistem em palavras relacionadas a afeto, e 2 fatores, sendo eles afeto positivo e afeto negativo. A pontuação no escore indicará os níveis de reatividade emocional positiva e/ou negativa. Suas propriedades psicométricas são bem estabelecidas (Zenon \& São, 2013).

\section{Questionário de Presença Igroup (IPQ)}

Utilizado para avaliar a sensação de presença do indivíduo no ambiente virtual. Possui 14 itens de 7 pontos, com os fatores de sensação de estar presente, presença espacial, envolvimento e realismo experimentado. Maior pontuação no escore indica maior sensação de presença percebida. Suas propriedades psicométricas são bem estabelecidas (Slater \& Usoh, 1994). 


\section{$\underline{\text { Tarefa de detecção de batimentos cardíacos (HBD Task) }}$}

Uma tarefa que consiste em contagem dos batimentos cardíacos para avaliação da precisão interoceptiva. No estudo foi utilizado um estímulo auditivo contínuo em Lá $440 \mathrm{~Hz}$ por 1 minuto, com as instruções para o indivíduo focar sua atenção para os processos corporais internos e contar os batimentos cardíacos sem contato tátil. Assim, o resultado obtido é a diferença entre o batimento relatado pelo participante e o batimento coletado pelos aparelhos de medida fisiológica (Brener, \& Kluvitse, 1988).

\subsection{Procedimento}

Foi realizado um estudo experimental, dividido em três etapas: pré-testagem, testagem e pós-testagem. Os participantes foram recebidos pelo pesquisador e colaboradores no laboratório, e assim, divididos em dois grupos distintos: grupo controle e grupo experimental. Na primeira etapa, os participantes foram recebidos na sala que antecede a sala experimental, onde preenchem o Termo de Consentimento Livre e Esclarecido. Ao chegarem à sala experimental, que é provida de ar condicionado e dimmer para a regulação da iluminação, foram conduzidos para a cadeira em frente ao computador onde o equipamento está instalado, estando a um metro de distância. Após a instalação dos aparelhos de medida fisiológica, os participantes de todos os grupos respondem questionários para verificação de ansiedade (HAM-A), depressão (BDI), consciência interoceptiva (MAIA-VB2), alexitimia (TAS-20) e avaliação da regulação emocional (ERQ). Nesse período, junto com o preenchimento dos questionários ocorre a habituação dos sensores.

Após o término do preenchimento das medidas subjetivas, é dado início à etapa de testagem, que é dividida em dois momentos. Iniciando o primeiro momento, o equipamento de realidade virtual é colocado e então, os indivíduos de ambos os grupos são expostos a uma simulação neutra, para coleta de medidas de base e aclimatação com o ambiente virtual. Após a simulação neutra, é realizada a tarefa de contagem de batimento cardíaco (HBD Task) para verificar a capacidade interoceptiva de base. Após, é realizado o preenchimento da escala para avaliar afeto positivo e negativo (PANAS) prévios a estímulos emocionais.

Seguindo para o segundo momento da etapa de testagem, cada um dos dois grupos, então, será apresentado a tipos diferentes de simulação no ambiente virtual 
gerado pelo equipamento de RV: O grupo controle é apresentado à segunda simulação neutra e o grupo experimental à simulação de estímulo emocional. Após as induções, ocorre novamente a tarefa de contagem de batimento cardíaco para verificar a capacidade interoceptiva, agora após a indução, seguida do uso da escala PANAS para avaliar novamente afeto positivo e negativo.

Ao fim das testagens, na última etapa, ocorreu a aplicação de um questionário de presença (IPQ) para avaliar a interação do indivíduo com o ambiente virtual.

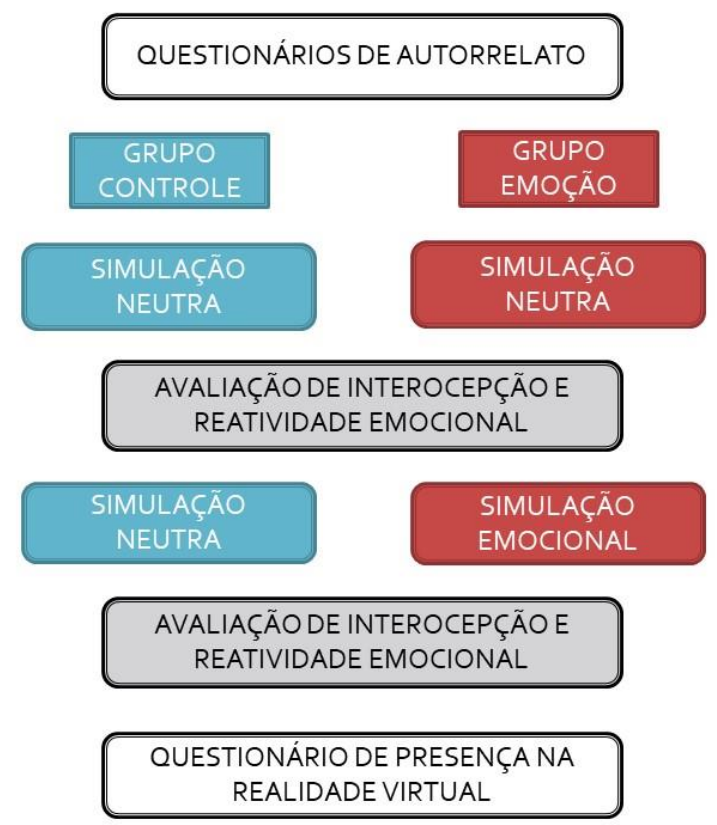

Figura 1: Modelo gráfico do procedimento de testagem

\subsection{Procedimentos Éticos}

As induções de humor, podendo ocorrer por meio de filmes, imagens, tarefas cognitivas, simulações virtuais, possibilitam a manipulação experimental do humor e emoções. Bastante utilizadas em pesquisa, permitem gerar estados emocionais transitórios e brandos que um indivíduo experimenta em seu cotidiano (Martin, 1990). O projeto foi aprovado pelo comitê de ética do Instituto Estadual do Cérebro Paulo Niemeyer (IEC). Os participantes assinaram o Termo de Consentimento Livre e Esclarecido, estando cientes que sua identidade permanece anônima, que os dados coletados foram utilizados para fins científicos, que poderiam interromper a testagem 
caso ocorresse algum desconforto e que foram esclarecidos quanto ao procedimento durante a testagem.

Nenhum dos 27 participantes relatou desconforto intenso ou retirou sua participação da pesquisa.

\subsection{Análise Estatística}

Estatísticas descritivas foram geradas ilustrando as características da amostra. Diferenças entre os grupos em variáveis sociodemográficas e clínicas foram investigadas com testes $\mathrm{T}$ de amostras independentes (idade, escolaridade) ou quiquadrado (sexo). Diferenças em reatividade emocional (auto-relato e medidas fisiológicas) e interocepção foram exploradas com análises de variância (ANOVA) de design misto $(2 \times 2)$ com tempo como fator de comparação intra-sujeito e grupo como fator de comparação entre-sujeitos.

\section{Resultados}

Características da amostra podem ser vistas na tabela 1. Não há diferença significativa entre os grupos para sexo $\left(\chi^{2}(1)=0.926, p=.336\right)$, idade $(t(25)=0.105, p$ $=.917)$ e escolaridade $(t(25)=0.480, p=.635)$. As medidas subjetivas utilizadas para verificação das capacidades dos participantes em linha de base para ansiedade (HAMA) $(t(25)=-0.541, p=.593)$, depressão (BDI) $(t(25)=-0.111, p=.913)$, sensibilidade interoceptiva (MAIA-VB2) $(t(25)=1.38, p=.178)$, Regulação emocional (QRE) $(t$ $(25)=-0.812, p=.424)$ e alexitimia (TAS-20) $(t(25)=0.159, p=.875)$ não apresentaram diferenças significativas entre os grupos controle e experimental. 
Tabela 1: Médias das variáveis sociodemográficas e clínicas

CONTROLE $(\mathbf{N}=9)$

\begin{tabular}{ccc} 
GRUPO & MÉDIA (DP) & MÉDIA (DP) \\
\hline SEXO (FEMININO/MASCULINO) & $5 / 4$ & $11 / 7$ \\
IDADE & $22,5(5,7)$ & $21,7(3,4)$ \\
ESCOLARIDADE & $15,2(2,4)$ & $15,1(1,6)$ \\
HAM-A & $10,7(3,8)$ & $12(6,5)$ \\
BDI & $11,5(9.0)$ & $11,9(8,4)$ \\
MAIA-VB2 & $92(20,5)$ & $81,2(18,2)$ \\
QRE & $39(9,6)$ & $42(8,8)$ \\
TAS-20 & $64(8,4)$ & $63,2(12,1)$ \\
\hline
\end{tabular}

HAM-A - Escala Hamilton de Ansiedade; BDI - Inventário de Depressão de Beck; MAIA-VB2 Avaliação Multidimensional de Consciência Interoceptiva; QRE - Questionário de Regulação Emocional; TAS-20 - Escala de Alexitimia de Toronto

\subsection{Frequência Cardíaca}

Não foram observados resultados significativos para interação tempo x grupo ( $F$ $\left.(1,25)=0.704 ; p=.409, \eta_{p}^{2}=.02\right)$, efeito principal de grupo $(F(1,25)=0.98 ; p=$ $\left..187, \eta_{p}{ }^{2}=.03\right)$ ou de tempo $\left(F(1,25)=0.112 ; p=.741, \eta_{p}{ }^{2}=.00\right)$.

Figura 2: Gráfico das médias de Frequência Cardíaca.

\section{FREQUÊNCIA CARDÍACA}

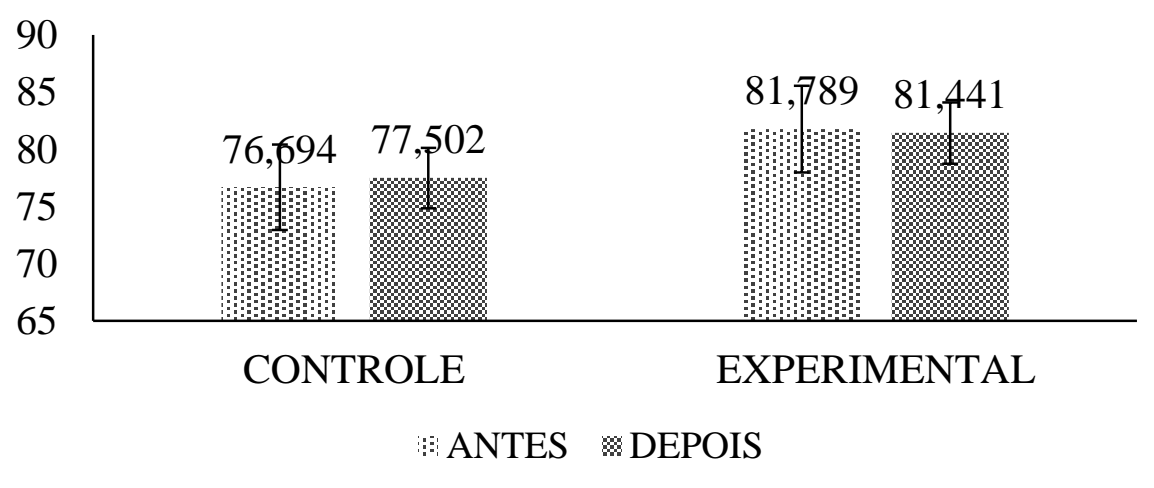




\subsection{Atividade Eletrodérmica}

A interação tempo x grupo apresentou efeito significativo $(F(1,25)=6.39 ; p$ $\left.=.018, \eta_{p}{ }^{2}=.20\right)$. Foi encontrado um efeito principal de Tempo $(F(1,25)=4.80 ; p=$ $\left..038, \eta_{p}{ }^{2}=.16\right)$. Não houve efeito de $\operatorname{Grupo}\left(F(1,25)=1.46 ; p=.238, \eta_{p}{ }^{2}=.05\right)$.

Figura 3: Gráfico das médias de Atividade Eletrodérmica.

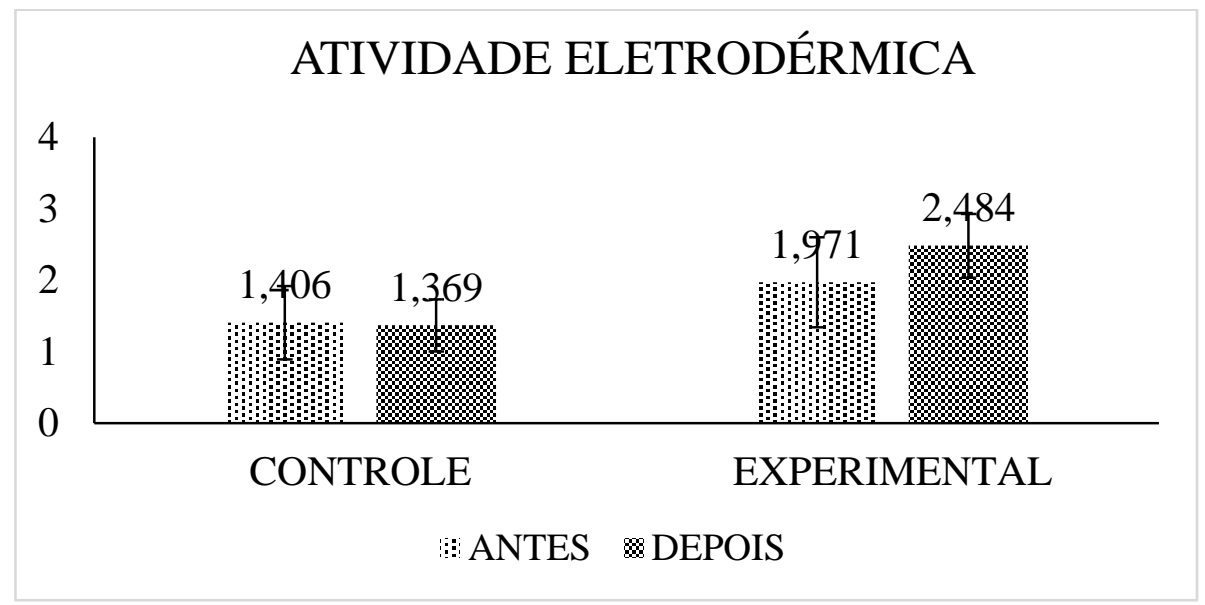

\subsection{Reatividade Emocional}

$\mathrm{Na}$ reatividade emocional negativa não foram encontrados resultados significativos para interação tempo x grupo $\left(F(1,25)=3.34 ; p=.079, \eta_{p}{ }^{2}=.11\right)$, efeito principal de tempo $\left(F(1,25)=1.68 ; p=.206, \eta_{p}{ }^{2}=.06\right)$ ou de grupo $(\mathrm{F}(1,25)=0.039$; $\left.\mathrm{p}=.844, \eta_{p}^{2}=.00\right)$.

Figura 4: Gráfico das médias de Reatividade Emocional Negativa.

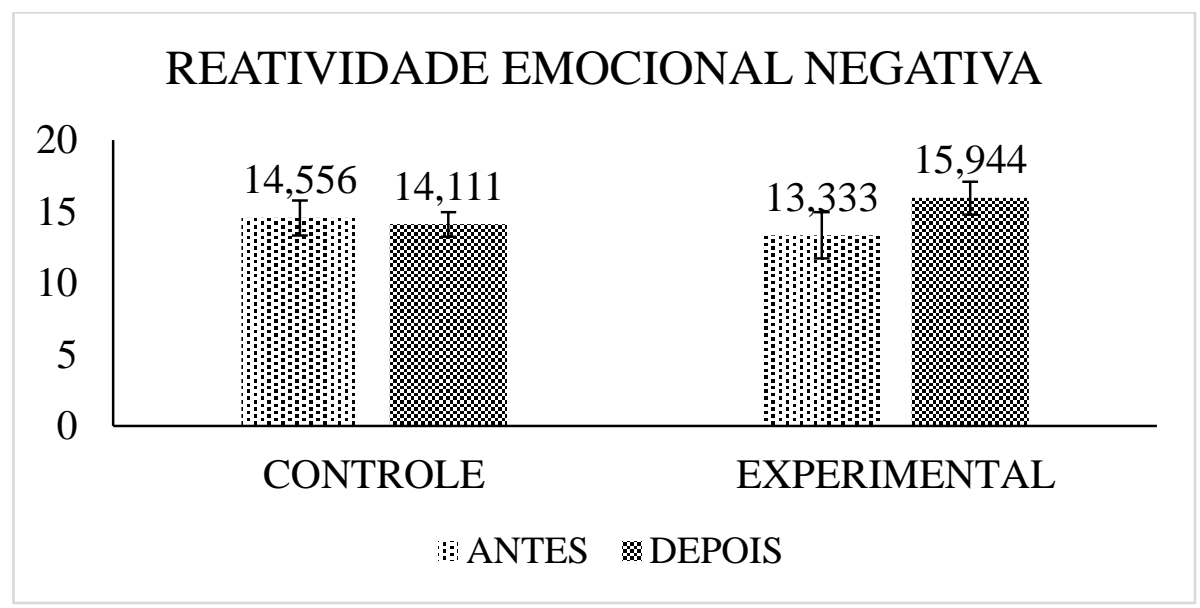


$\mathrm{Na}$ reatividade emocional positiva, não houve interação tempo $\mathrm{x}$ grupo significativa $\left(\mathrm{F}(1,25)<0.001 ; \mathrm{p}=1.00, \eta_{p}{ }^{2}<.001\right)$. Foram encontradas diferenças significativas quanto ao Tempo $\left(F(1,25)=7.35 ; p=.012, \eta_{p}{ }^{2}=.22\right)$, mas não quanto ao grupo $\left(F(1,25)=0.715 ; p=.406, \eta_{p}^{2}=.02\right)$.

Figura 5: Gráfico das médias de Reatividade Emocional Positiva.

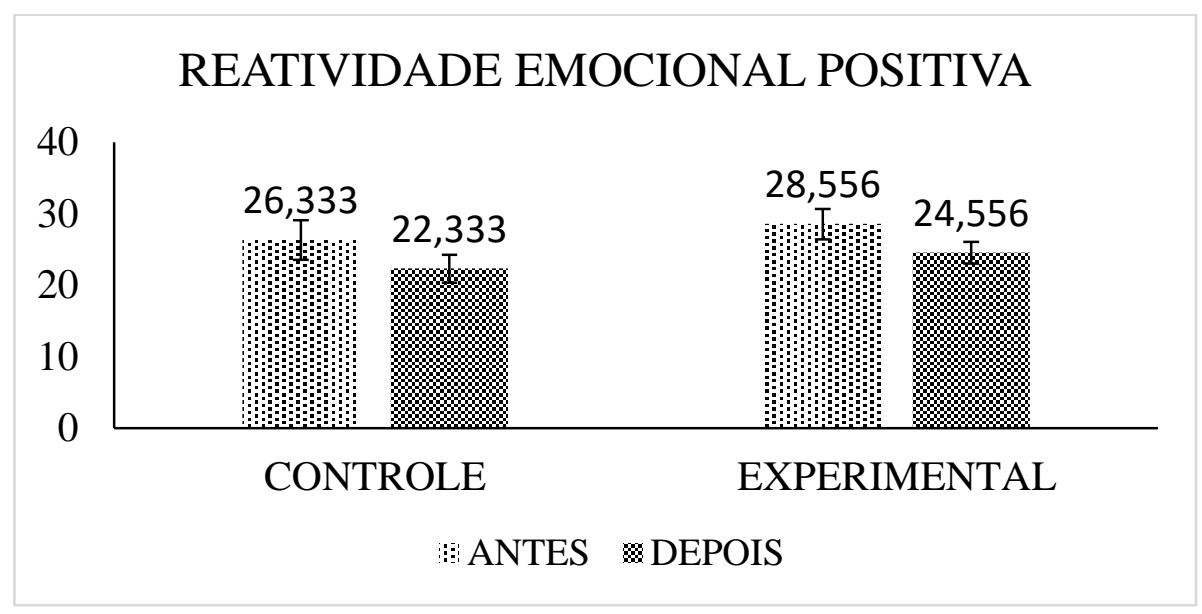

Na reatividade emocional total, a interação tempo x grupo $(F(1,25)=0.968 ; p$ $\left.=.335, \eta_{p}{ }^{2}=.03\right)$ e os efeitos principais de tempo $\left(F(1,25)=3.52 ; p=.072, \eta_{p}{ }^{2}=.12\right)$ e grupo $\left(F(1,25)=0.575 ; p=.456, \eta_{p}{ }^{2}=.02\right)$ não foram significativos.

Figura 6: Gráfico das médias de Reatividade Emocional Total.

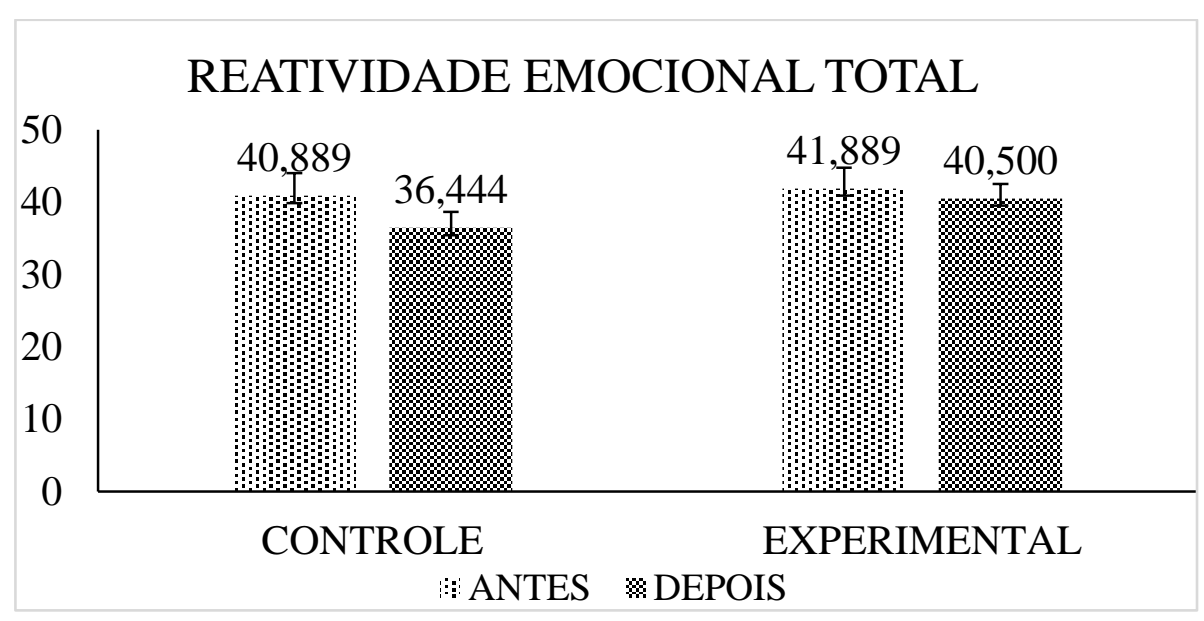




\subsection{Interocepção}

Não foi visto efeito significativo na interação tempo x grupo $(F(1,25)=3.85 ; p$ $\left.=.061, \eta_{p}{ }^{2}=.13\right)$. Não foi encontrado efeito quanto tempo $(F(1,25)=0.287 ; p=.597$, $\left.\eta_{p}{ }^{2}=.01\right)$ ou grupo $\left(\mathrm{F}(1,25)=1.84 ; p=.187, \eta_{p}{ }^{2}=.06\right)$.

Figura 7: Gráfico das médias de interocepção.

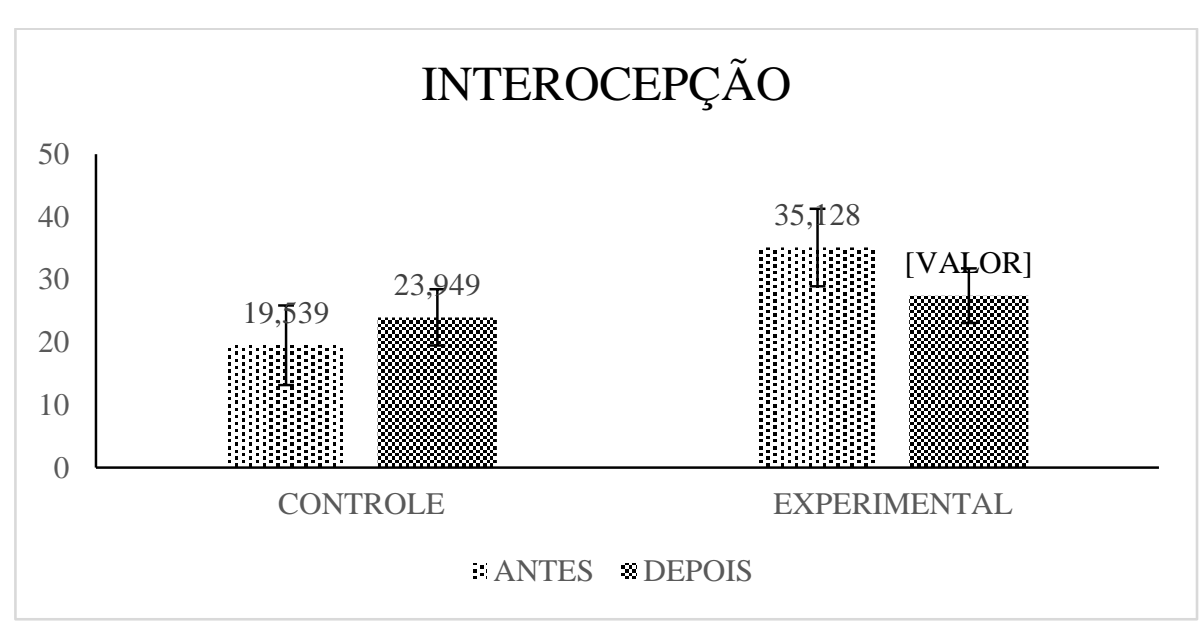

\subsection{Presença}

Não houve diferenças significativas de presença entre os grupos $(t(25)=-0.451, p=$ $.656)$.

Figura 8: Gráfico da média de Presença percebida pelos participantes

\section{PRESENÇA}

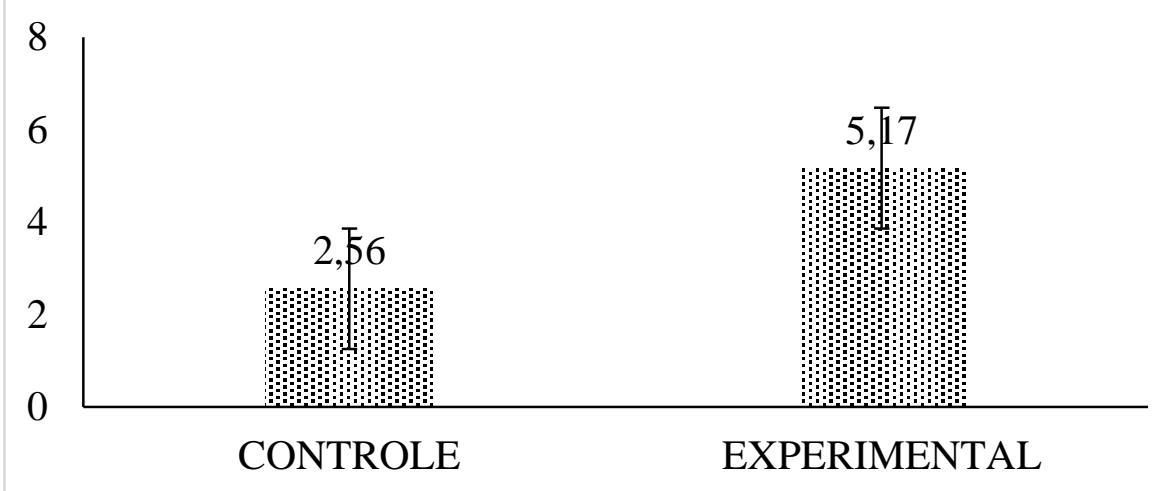




\section{Conclusões e Discussão}

O presente estudo utilizou o ambiente de RV como procedimento de indução de humor, com intuito de investigar as potencialidades da RV em testar a reatividade emocional e melhorar a interocepção, através da indução de ativação e valência emocional. Os participantes responderam questionários e escalas quanto à ansiedade, depressão, regulação emocional, alexitimia e sensibilidade interoceptiva. Ao longo da testagem, tiveram suas medidas de frequência cardíaca e atividade eletrodérmica coletadas. Entre os momentos das testagens realizaram a tarefa de contagem de batimentos cardíacos e preencheram a escala de afeto positivo e negativo. Ao final, preencheram o questionário sobre a sensação de presença durante o uso da RV.

A análise da atividade eletrodérmica indica que houve um efeito da interação tempo x grupo e efeito de tempo na testagem. A média das respostas de atividade eletrodérmica do grupo experimental aumentou ao longo do tempo. Tais resultados podem indicar sucesso na indução de ativação emocional. A análise da reatividade emocional positiva indica efeito de tempo, tendo ambos os grupos apresentando diminuição das médias. Uma possível explicação seria a habituação aos estímulos neutros por parte do grupo controle e, no grupo experimental, a inclinação da indução para a valência negativa citada acima. A análise de batimentos cardíacos mostrou que não houve efeito para a interação, tempo ou grupo. Como visto no gráfico dos resultados, a média dos dois momentos da testagem se manteve próxima em ambos os grupos. Tendências foram observadas quanto ao efeito da interação tempo x grupo na reatividade emocional negativa, e também no efeito de tempo no total da reatividade emocional, ambos tendo os resultados apresentando alto valor no tamanho de efeito. A análise da interocepção também apresentou tendência quanto à interação tempo x grupo, com seu tamanho de efeito indicando inclinação para uma melhora na interocepção (por se tratar da diferença entre as variáveis de detecção de batimento e batimento real, quanto menor o resultado, mais próximo do número exato). As tendências observadas podem vir a se tornar efeitos em um estudo com maior amostra. A tendência de efeito para interação tempo $\mathrm{x}$ grupo na reatividade negativa pode indicar uma possível inclinação à valência negativa, como uma indução de ansiedade.

A atividade eletrodérmica se mostrou uma medida bastante importante na checagem de manipulação na indução de ativação e valência afetiva. A média da 
atividade eletrodérmica está relacionada aos níveis de excitação (Lang, Greenwald, Bradley, \& Hamm, 1993). A prevalência desta medida no estímulo emocional pode indicar preparação corporal, comum nas ativações do sistema nervoso simpático. Nos participantes do grupo experimental, para enfrentar ansiedade causada pela simulação de montanha russa (Kreibig, 2010). Porém, seguindo a mesma linha de raciocínio, a frequência cardíaca deveria ter apresentado acréscimo por estar também ligada ao medo e ansiedade, o que direcionaria para uma indução de suspense, comumente relacionado à ansiedade, mas sem apresentar o crescimento da resposta de frequência cardíaca (Nomikos, Opton Jr, \& Averill, 1968).

Uma amostra de maior tamanho poderia ser utilizada para melhor generalização dos dados. Da mesma forma, a amostra obtida, sendo constituída por população universitária, apresenta características de uma amostra WEIRD (western, educated, industrialized, rich and democratic), (Henrich, Heine, \& Norenzayan, 2010), sendo grupos de população ocidentais, com acesso à educação e indústria, com alto poder econômico e em países democráticos, assim, também reduzindo a capacidade de generalização do estudo.

O uso de uma simulação para indução de humor com foco em ativação e valência afetiva pode ter enviesado os resultados. Estudos futuros que comparem a indução de uma emoção específica com indução de valência, ativação e suas influências na interocepção e reatividade emocional podem obter resultados mais conclusivos quanto à influência do tipo de emoção (Barrett, 1998). Estudos com maior número de amostra podem ser capazes de explorar a relação das tendências de melhora na capacidade interoceptiva e tendências quanto à reatividade emocional negativa, observadas neste artigo. A análise da sensação de presença também seria beneficiada em um estudo com maior amostra, já que não foram encontradas diferenças significativas entre as médias dos grupos.

O presente estudo se mostra relevante por trazer novos procedimentos e tecnologias para auxiliar nas pesquisas em psicologia, apresentando a Realidade Virtual como um equipamento com diversas possibilidades de uso, seja na Indução de Humor ou mesmo em estudos sobre transtornos diversos, como o Transtorno de Estresse Póstraumático, se mostrando eficaz em estudos de difícil aplicação. Como visto anteriormente, o ambiente virtual, representando uma situação real, permite a 
manipulação da intensidade e da duração dos estímulos, ao mesmo tempo em que verifica as respostas derivadas do estímulo. Assim, além de auxiliar em estudos científicos, essa ferramenta pode ser utilizada como tratamentos em psicologia clínica.

Para concluir, o resultado da medida de atividade eletrodérmica no estudo piloto indica que a RV é eficaz na indução de humor. O estudo piloto indica também uma inclinação para a melhora da interocepção com o uso da indução de humor na RV. 


\section{Referências Bibliográficas}

Baños, R. M., Botella, C., Alcañiz, M., Liaño, V., Guerrero, B., \& Rey, B. (2004). Immersion and emotion: their impact on the sense of presence. Cyberpsychology \& behavior, 7(6), 734-741.

Barrett, L. F. (1998). Discrete emotions or dimensions? The role of valence focus and arousal focus. Cognition \& Emotion, 12(4), 579-599.

Brener, J., \& Kluvitse, C. (1988). Heartbeat detection: judgments of the simultaneity of external stimuli and heartbeats. Psychophysiology, 25(5), 554-561.

Brundage, S. B., Brinton, J. M., \& Hancock, A. B. (2016). Utility of virtual reality environments to examine physiological reactivity and subjective distress in adults who stutter. Journal of fluency disorders, 50, 85-95.

Carvalho, H. W. D., Andreoli, S. B., Lara, D. R., Patrick, C. J., Quintana, M. I., Bressan, R. A., ... \& Jorge, M. R. (2013). Structural validity and reliability of the Positive and Negative Affect Schedule (PANAS): evidence from a large Brazilian community sample. Revista Brasileira de Psiquiatria, 35(2), 169-172.

Diemer, J., Alpers, G. W., Peperkorn, H. M., Shiban, Y., \& Mühlberger, A. (2015). The impact of perception and presence on emotional reactions: a review of research in virtual reality. Frontiers in psychology, 6, 26.

Garfinkel, S. N., Seth, A. K., Barrett, A. B., Suzuki, K., \& Critchley, H. D. (2015). Knowing your own heart: distinguishing interoceptive accuracy from interoceptive awareness. Biological psychology, 104, $65-74$.

Gerrards-Hesse, A., Spies, K., \& Hesse, F. W. (1994). Experimental inductions of emotional states and their effectiveness: A review. British journal of psychology, 85(1), 55-78.

Gorenstein, C., \& Andrade, L. H. S. G. (1998). Inventário de depressão de Beck: propriedades psicométricas da versão em português. Revista de Psiquiatria Clínica, 25(5), 245-250.

Henrich, J., Heine, S. J., \& Norenzayan, A. (2010). The weirdest people in the world?. Behavioral and brain sciences, 33(2-3), 61-83.

Kreibig, S. D. (2010). Autonomic nervous system activity in emotion: A review. Biological psychology, 84(3), 394-421.

Kummer, A., Cardoso, F., \& Teixeira, A. L. (2010). Generalized anxiety disorder and the Hamilton Anxiety Rating Scale in Parkinson's disease. Arquivos de neuro-psiquiatria, 68(4), 495-501.

Lang, P. J., Greenwald, M. K., Bradley, M. M., \& Hamm, A. O. (1993). Looking at pictures: Affective, facial, visceral, and behavioral reactions. Psychophysiology, 30(3), 261-273.

Martin, M. (1990). On the induction of mood. Clinical Psychology Review, 10(6), 669-697. 
Mehling, W. E., Price, C., Daubenmier, J. J., Acree, M., Bartmess, E., \& Stewart, A. (2012). The multidimensional assessment of interoceptive awareness (MAIA). PloS one, 7(11), e48230.

Monteiro, L. M. C. (2011). Manipulação da emoção em ambientes de realidade virtual: validação metodológica.

Nomikos, M. S., Opton Jr, E., \& Averill, J. R. (1968). Surprise versus suspense in the production of stress reaction. Journal of Personality and Social Psychology, 8(2p1), 204.

Parsons, T. D. (2015). Virtual reality for enhanced ecological validity and experimental control in the clinical, affective and social neurosciences. Frontiers in human neuroscience, 9, 660.

Price, M., Mehta, N., Tone, E. B., \& Anderson, P. L. (2011). Does engagement with exposure yield better outcomes? Components of presence as a predictor of treatment response for virtual reality exposure therapy for social phobia. Journal of anxiety disorders, 25(6), 763-770.

Ribeiro, A., \& Monteiro, L. (2015). A indução afetiva em cenários de realidade virtual: avaliação da sensação de presença. Psicologia Clínica, 27(1), 139-160.

Riva, G., Mantovani, F., Capideville, C. S., Preziosa, A., Morganti, F., Villani, D., ... \& Alcañiz, M. (2007). Affective interactions using virtual reality: the link between presence and emotions. CyberPsychology \& Behavior, 10(1), 45-56.

Serrano, B., Baños, R. M., \& Botella, C. (2016). Virtual reality and stimulation of touch and smell for inducing relaxation: A randomized controlled trial. Computers in Human Behavior, 55, 1-8.

Slater, M., \& Usoh, M. (1993). Representations systems, perceptual position, and presence in immersive virtual environments. Presence: Teleoperators \& Virtual Environments, 2(3), 221-233.

Tortell, R., Luigi, D. P., Dozois, A., Bouchard, S., Morie, J. F., \& Ilan, D. (2007). The effects of scent and game play experience on memory of a virtual environment. Virtual Reality, 11(1), 61-68.

Westermann, R., Spies, K., Stahl, G., \& Hesse, F. W. (1996). Relative effectiveness and validity of mood induction procedures: A meta-analysis. European Journal of social psychology, 26(4), 557-580.

Yoshida, E. M. P. (2007). Validade da versão em português da Toronto Alexithymia Scale-TAS em amostra clínica. Psicologia: Reflexão e Crítica, 20(3), 389-396.

Zanon, C., Bastianello, M. R., Pacico, J. C., \& Hutz, C. S. (2013). Desenvolvimento e validação de uma escala de afetos positivos e negativos. Psico-USF, 18(2), 193-201. 


\section{Discussão Geral}

Esta dissertação apresentou dois artigos, sendo o primeiro com caráter teórico e o segundo com caráter experimental, ambos com intuito de investigar as capacidades da RV em indução de humor e seus desdobramentos.

Com o primeiro artigo, é visto que os procedimentos de indução de humor são experimentos consolidados por décadas. No entanto, a revisão sistemática teve como objetivo suprir uma carência quanto a uma análise das pesquisas realizadas que utilizam a RV como método de indução de humor, catalogando os equipamentos mais utilizados, as emoções mais induzidas em experimentos, entendendo como é realizada a checagem de manipulação e verificando sua eficácia. Como visto nos resultados do primeiro artigo, a maior parte dos estudos apresentaram resultados sustentando a eficácia da RV como indutor de emoções, que pode ser embasada por seu potencial imersivo e facilidade de controle por parte do pesquisador, criando um setting propício para a pesquisa em laboratórios de Psicologia. Assim, os achados desta revisão contribuíram para uma base estrutural na elaboração do estudo experimental apresentado no segundo artigo desta dissertação.

Tendo por base a revisão sistemática, o estudo empírico foi realizado seguindo os resultados encontrados na revisão para estruturar o procedimento experimental de maneira mais adequada, buscando encontrar resultados fidedignos e válidos. Da seguinte forma, os Óculos de RV foram selecionados como equipamento para a apresentação do ambiente virtual, por sua alta capacidade imersiva em comparação com outros equipamentos listados, e também por sua maior acessibilidade e manipulação (Riva et al., 2007). As medidas fisiológicas mais comumente vistas na revisão, atividade eletrodérmica e frequência cardíaca, respectivamente, foram selecionadas de modo a melhor representar as ativações fisiológicas de cunho emocional (Lang, Greenwald, Bradley, \& Hamm, 1993), e então coletadas para complementar os achados das medidas subjetivas, tendo sua seleção realizada de modo a inferir consciência, reatividade e regulação emocional (Mauss, \& Robinson, 2009), bem como a presença do participante em um AV (Slater, \& Usoh, 1993).

A atividade eletrodérmica, medida fisiológica mais utilizada nos estudos revisados no primeiro artigo, apresentou crescimento durante as induções de humor que 
ocorreram no grupo experimental, como visto no segundo artigo, reforçando o grande papel dessa medida como meio de avaliação de emoção (Lang, Greenwald, Bradley, \& Hamm, 1993). Já a frequência cardíaca não apresentou alterações significativas em suas médias. Correlacionando com a literatura, isso pode indicar que o estímulo visual utilizado não foi intenso o suficiente para ativação cardíaca (Choi et al., 2017). A interocepção possui relações com a descrição de ativação emocional, onde indivíduos com melhor desempenho na tarefa de contagem de batimentos cardíacos apresentam melhor capacidade de descrição sobre as ativações e desativações referentes à experiência emocional (Barrett, Quigley, Bliss-Moreau, \& Aronson, 2004).

Futuros estudos podem investigar a comparação de paradigmas de RV, verificando como cada equipamento influencia na eficácia da indução de humor, na melhora da interocepção e na reatividade emocional dos participantes.

Concluindo, a proposta do estudo experimental em melhorar a interocepção representa o caráter clínico do estudo, que investigou a possibilidade de uso das novas tecnologias em ser utilizadas para a promoção de refinamento das habilidades cognitivas do indivíduo para auxílio do enfrentamento das psicopatologias, estas possuindo impacto no cotidiano, como a ansiedade. Dessa maneira, o estudo tem a intenção de melhorar a capacidade interoceptiva do indivíduo, de forma a ajudar na identificação de suas sensações corporais e diferenciação quanto as origens das atividades fisiológicas. $\mathrm{O}$ aumento da reatividade emocional tem o propósito de ajudar o indivíduo a melhor responder a um evento com conteúdo emocional. 


\section{Referências Bibliográficas}

Barreto, J. E. F., \& Silva, L. P. (2010). Sistema límbico e as emoções-uma revisão anatômica. Rev Neurocienc, 18(3), 386-94.

Barrett, L. F. (2006). Are emotions natural kinds?. Perspectives on psychological science, 1(1), 28-58.

Barrett, L. F., Gross, J., Christensen, T. C., \& Benvenuto, M. (2001). Knowing what you're feeling and knowing what to do about it: Mapping the relation between emotion differentiation and emotion regulation. Cognition \& Emotion, 15(6), 713-724.

Barrett, L. F., Quigley, K. S., Bliss-Moreau, E., \& Aronson, K. R. (2004). Interoceptive sensitivity and self-reports of emotional experience. Journal of personality and social psychology, 87(5), 684.

Burdea, G. C., \& Coiffet, P. (2003). Virtual reality technology. John Wiley \& Sons.

Cacioppo, J. T., Berntson, G. G., Larsen, J. T., Poehlmann, K. M., \& Ito, T. A. (2000). The psychophysiology of emotion. Handbook of emotions, 2, 173-191.

Chhatwal, J., \& Lane, R. D. (2016). A Cognitive-Developmental Model of Emotional Awareness and Its Application to the Practice of Psychotherapy. Psychodynamic psychiatry, 44(2), 305-325.

Choi, K. H., Kim, J., Kwon, O. S., Kim, M. J., Ryu, Y. H., \& Park, J. E. (2017). Is heart rate variability (HRV) an adequate tool for evaluating human emotions?-A focus on the use of the International Affective Picture System (IAPS). Psychiatry research, 251, 192-196.

Cruvinel, M., \& Boruchovitch, E. (2010). Regulação emocional: A construção de um instrumento e resultados iniciais. Psicologia em Estudo, 15(3), 537-545.

Damasio, A. (2003). Feelings of emotion and the self. Annals of the New York Academy of Sciences, 1001(1), 253-261.

Damasio, A. R. (1999). The feeling of what happens: Body and emotion in the making of consciousness. Houghton Mifflin Harcourt.

Freire, L. (2010). Alexitimia: dificuldade de expressão ou ausência de sentimento? Uma análise teórica. Psicologia: Teoria e Pesquisa, 26(1), 15.

Füstös, J., Gramann, K., Herbert, B. M., \& Pollatos, O. (2012). On the embodiment of emotion regulation: interoceptive awareness facilitates reappraisal. Social cognitive and affective neuroscience, 8(8), 911-917.

Glantz, K., Durlach, N. I., Barnett, R. C., \& Aviles, W. A. (1997). Virtual reality (VR) and psychotherapy: Opportunities and challenges. Presence: Teleoperators \& Virtual Environments, 6(1), 87105.

Gratz, K. L., \& Roemer, L. (2004). Multidimensional assessment of emotion regulation and dysregulation: Development, factor structure, and initial validation of the difficulties in emotion regulation scale. Journal of psychopathology and behavioral assessment, 26(1), 41-54.

Gross, J. J. (1998). Antecedent-and response-focused emotion regulation: divergent consequences for experience, expression, and physiology. Journal of personality and social psychology, 74(1), 224. 
Gross, J. J. (2002). Emotion regulation: Affective, cognitive, and social consequences. Psychophysiology, 39(3), 281-291.

James, W. (1894). Discussion: The physical basis of emotion. Psychological review, 1(5), 516.

Kreibig, S. D. (2010). Autonomic nervous system activity in emotion: A review. Biological psychology, 84(3), 394-421.

Lang, P. J., Greenwald, M. K., Bradley, M. M., \& Hamm, A. O. (1993). Looking at pictures: Affective, facial, visceral, and behavioral reactions. Psychophysiology, 30(3), 261-273.

Lucas, R. E., \& Baird, B. M. (2004). Extraversion and emotional reactivity. Journal of personality and social psychology, 86(3), 473.

Mauss, I. B., \& Robinson, M. D. (2009). Measures of emotion: A review. Cognition and emotion, 23(2), 209-237.

Miguel, F. K. (2015). Psicologia das emoções: uma proposta integrativa para compreender a expressão emocional. Psico-usf, 20(1), 153-162.

Payne, P., Levine, P. A., \& Crane-Godreau, M. A. (2015). Somatic experiencing: using interoception and proprioception as core elements of trauma therapy. Frontiers in Psychology, 6, 93.

Reeve, J. (2014). Understanding motivation and emotion. John Wiley \& Sons.

Riva, G. (2009). Virtual reality: an experiential tool for clinical psychology. British Journal of Guidance \& Counselling, 37(3), 337-345.

Sedeño, L., Couto, B., Melloni, M., Canales-Johnson, A., Yoris, A., Baez, S., ... \& Kichic, R. (2014). How do you feel when you can't feel your body? Interoception, functional connectivity and emotional processing in depersonalization-derealization disorder. PloS one, 9(6), e98769.

Sifneos, P. E. (1972). Is dynamic psychotherapy contraindicated for a large number of patients with psychosomatic diseases?. Psychotherapy and Psychosomatics, 21(1-6), 133-136.

Slater, M., \& Usoh, M. (1993). Representations systems, perceptual position, and presence in immersive virtual environments. Presence: Teleoperators \& Virtual Environments, 2(3), 221-233.

Stemmler, G. (2009). Somatoviszerale Aktivierung [Somatovisceral activation], In: Niels, B., Dieter, F., Julius, K., Stemmler, G. (Eds.), Psychologie der Emotion, Enzyklopädie der Psychologie [Psychology of emotion, encyclopedia of psychology]. Hogrefe, Göttingen, Germany, pp. 314-361 (Chapter 8).

Vincelli, F. (1999). From imagination to virtual reality: the future of clinical psychology. CyberPsychology and Behavior, 2(3), 241-248.

Yoris, A., Esteves, S., Couto, B., Melloni, M., Kichic, R., Cetkovich, M., ... \& Sedeño, L. (2015). The roles of interoceptive sensitivity and metacognitive interoception in panic. Behavioral and Brain Functions, 11(1), 14. 


\section{6 - Anexos}

ANEXO A

Escala de Hamilton para Ansiedade

\begin{tabular}{|c|c|c|c|c|c|}
\hline $\begin{array}{l}\text { Humor ansioso: inquietude, temor do pior, apreensão quanto } \\
\text { ao futuro ou presente, imitabilidade. }\end{array}$ & 0 & 1 & 2 & 3 & 4 \\
\hline $\begin{array}{l}\text { Tensão: sensação de tensão, fatigabilidade, tremores, choro fácil, } \\
\text { incapacidade de relaxar, agitação, reações de sobressalto. }\end{array}$ & 0 & 1 & 2 & 3 & 4 \\
\hline $\begin{array}{l}\text { Medo: de escuro, de desconhecidos, de multidão, de ser } \\
\text { abandonado, de animais grandes, de trânsito. }\end{array}$ & 0 & 1 & 2 & 3 & 4 \\
\hline $\begin{array}{l}\text { Insônia: dificuldade de adormecer, sonhos penosos, sono } \\
\text { intermompido, sono insatisfatório, fadiga ao acordar, pesadelos, } \\
\text { terrores noturnos. }\end{array}$ & 0 & 1 & 2 & 3 & 4 \\
\hline $\begin{array}{l}\text { Dificuldades intelectuais: dificuldade de concentração, distúrbios } \\
\text { de memória. }\end{array}$ & 0 & 1 & 2 & 3 & 4 \\
\hline $\begin{array}{l}\text { Humor depressivo: perda de interesse, humor variáuel, indiferença } \\
\text { às atividades de rotina, despertar precoce, depressão. }\end{array}$ & 0 & 1 & 2 & 3 & 4 \\
\hline $\begin{array}{l}\text { Sintomas somáticos musculares: dores e lassidão muscular, } \\
\text { rigidez muscular, mioclonias, ranger dos dentes, w0z insegura. }\end{array}$ & 0 & 1 & 2 & 3 & 4 \\
\hline $\begin{array}{l}\text { Sintomas somáticos sensoriais: visão turua, ondas de calor } \\
\text { ou trio, sensação de fraqueza, sensação de picada, zumbidos. }\end{array}$ & 0 & 1 & 2 & 3 & 4 \\
\hline $\begin{array}{l}\text { Sintomas cardiovasculares: taquicardia, palpitações, dores } \\
\text { pré-cordiais, batidas, pulsaçōes, sensação de desmaio. }\end{array}$ & 0 & 1 & 2 & 3 & 4 \\
\hline $\begin{array}{l}\text { Sintomas respiratórios: sensação de opressão, dispnéia, } \\
\text { constriçäo torácica, suspiros, bolo faŕngeo. }\end{array}$ & 0 & 1 & 2 & 3 & 4 \\
\hline $\begin{array}{l}\text { Sintomas gastrointestinais: dificuldade de engolir, aerofagia, } \\
\text { dispepsia, dor pré ou pós-prandial, queimações, empanzinamento, } \\
\text { náuseas, wômito, diaréias, constipação, perda de peso. }\end{array}$ & 0 & 1 & 2 & 3 & 4 \\
\hline $\begin{array}{l}\text { Sintomas geniturinários: micções freqüentes, urgência de } \\
\text { micção, frigidez, amenoméia, ejaculação precoce, impotência. }\end{array}$ & 0 & 1 & 2 & 3 & 4 \\
\hline $\begin{array}{l}\text { Sintomas do sistema nervoso autônomo: secura na boca, } \\
\text { ruboriz ação, palidez, sudorese, vertigens, cefaléia de tensão. }\end{array}$ & 0 & 1 & 2 & 3 & 4 \\
\hline $\begin{array}{l}\text { Comportamento na entrevista-geral : tenso, pouco à wortade, } \\
\text { agitação das mãos, dos dedos, tiques, inquietação, suspiros. }\end{array}$ & 0 & 1 & 2 & 3 & 4 \\
\hline $\begin{array}{l}\text { Fisiológico: enuctações, taquicardia em repouso, ritmo } \\
\text { respiratório }>20 \mathrm{pm}\end{array}$ & 0 & 1 & 2 & 3 & 4 \\
\hline Total de pontos: & & & & & \\
\hline
\end{tabular}


Inventário de Depressão de Beck (BDI)

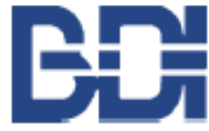

Data:

Nome: Estado Civil: Idade: Sexo:

Ocupação: Escolaridade

Este questionário consiste em 21 grupos de afirmações. Depois de ler cuidadosamente cada grupo, faça um círculo em tomo do número $(0,1,2$ ou 3$)$ próximo à afirmação, em cada grupo, que descreve melhor a maneira que você tem se sentido na última semana, incluindo hoje. Se várias afirmações num grupo parecerem se aplicar igualmente bem, faça um círculo em cada uma. Tome o cuidado de ler todas as afirmações, em cada grupo, antes de fazer a sua escollha.

1 Não me sinto triste.

1 Eu me sinto triste.

2 Estou sempre triste e não consigo sair disto.

3 Estou tão triste ou infeliz que não consigo suportar

2 Não estou especialmente desanimado quanto ao futuro.

1 Eu me sinto desanimado quanto ao futuro.

2 Acho que nada tenho a esperar.

3 Acho o futuro sem esperança e tenho a impressão de que as coisas não podem melhorar.

30 Não me sinto um fracasso.

1 Acho que fracassei mais do que uma pessoa comum.

2 Quando olho para trás, na minha vida, tudo o que posso ver é um monte de fracassos.

3 Acho que, como pessoa, sou um completo fracasso.

40 Tenho tanto prazer em tudo como antes.

1 Não sinto mais prazer nas coisas como antes.

2 Não encontro um prazer real em mais nada.

3 Estou insatisfeito ou aborrecido com tudo.

5 Não me sinto especialmente culpado.

1 Eu me sinto culpado grande parte do tempo.

2 Eu me sinto culpado na maior parte do tempo.

3 Eu me sinto sempre culpado.

6 Não acho que esteja sendo punido.

1 Acho que posso ser punido.

2 Creio que vou ser punido.

3 Acho que estou sendo punido.

7 Não me sinto decepcionado comigo mesmo.

1 Estou decepcionado comigo mesmo.

2 Estou enojado de mim.

3 Eu me odeio.
80 Não me sinto de qualquer modo pior que os outros.

1 Sou crítico em relação a mim por minhas fraquezas ou erros.

2 Eu me culpo sempre por minhas falhas.

3 Eu me culpo por tudo de mal que acontece.

90 Não tenho quaisquer idéias de me matar.

1 Tenho idéias de me matar, mas não as executaria.

2 Gostaria de me matar.

3 Eu me mataria se tivesse oportumidade.

10 Não choro mais que o habitual.

1 Choro mais agora do que costumava.

2 Agora, choro o tempo todo.

3 Costumava ser capaz de chorar, mas agora não consigo, mesmo que o queira.

11 Não sou mais irnitado agora do que já fui

1 Fico aborrecido ou initado mais facilmente do que costumava.

2 Agora, eu me sinto irritado o tempo todo.

3 Não me irrito mais com coisas que costumavam me initar.

12 Não perdi o interesse pelas outras pessoas.

1 Estoumenos interessado pelas outras pessoas do que costumava estar.

2 Perdi a maior parte do meu interesse pelas outras pessoas.

3 Perdi todo o interesse pelas outras pessoas.

13 Tomo decisões tão bem quanto antes.

1 Adio as tomadas de decisões mais do que costumava.

2 Tenho mais dificuldades de tomar decisões do que antes.

3 Absolutamente não consigo mais tomar decisões. 
14 Não acho que de qualquer modo pareço pior do que antes.

1 Estou preocupado em estar parecendo velho ou sem atrativo.

2 Acho que há mudanças permanentes na minha aparência, que me fazem parecer sem atrativo.

3 Acredito que pareço feio.

15 Posso trabalhar tão bem quanto antes.

1 É preciso algum esforço extra para fazer alguma coisa.

2 Tenho que me esforçar muito para fazer alguma coisa.

3 Não consigo mais fazer qualquer trabalho.

16 Consigo dormir tão bem como o habitual

1 Não durmo tão bem como costumava.

2 Acordo 1 a 2 horas mais cedo do que habitualmente e acho dificil voltar a dormir.

3 Acordo vánas horas mais cedo do que costumava e não consigo voltar a dormir.

17 Não fico mais cansado do que o habitual.

1 Fico cansado mais facilmente do que costumava.

3 Estou cansado demais para fazer qualquer coisa.

180 meu apetite não está pior do que o habitual

1 Meu apetite não é tão bom como costumava ser.

2 Meu apetite é muito pior agora.

3 Absolutamente não tenho mais apetite.
19 Não tenho perdido muito peso se é que perdi algum recentemente.

1 Perdi mais do que 2 quilos e meio.

2 Perdi mais do que 5 quilos.

3 Perdi mais do que 7 quilos.

Estou tentando perder peso de propósito, comendo menos: Sim Não

20 Não estou mais preocupado com a minha saúde do que o habitual.

1 Estou preocupado com problemas físicos, tais como dores, indisposição do estômago ou constipação.

2 Estou muito preocupado com problemas físicos e é dificil pensar em outra coisa.

3 Estou tão preocupado com meus problemas físicos que não consigo pensar em qualquer outra coisa.

21 Não notei qualquer mudança recente no meu interesse por sexo.

1 Estou menos interessado por sexo do que costumava.

2 Estou muito menos interessado por sexo agora.

3 Perdi completamente o interesse por sexo. 
ANEXO C

Avaliação Multidimensional da Consciência Interoceptiva (MAIA - VB2)

Nome: Data:

Abaixo você encontrará uma lista de situações. Por favor indique a frequência com que cada situação se aplica a sua vida, no dia a dia.

\begin{tabular}{|c|c|c|c|c|c|c|}
\hline \multirow[b]{2}{*}{ 1. Quando estou tenso percebo no meu corpo onde a tensåo se localza. } & \multicolumn{3}{|c|}{ Nunca } & \multicolumn{3}{|c|}{ Sempre } \\
\hline & 0 & 1 & 2 & 3 & 4 & 5 \\
\hline 2. Eu perceso quando sinto desconforto em meu corpo. & 0 & 1 & 2 & 3 & 4 & 5 \\
\hline 3. Eu perceso no meu corpo aonde estou confortavel. & 0 & 1 & 2 & 3 & 4 & 5 \\
\hline $\begin{array}{l}\text { 4. Eu perceso mudanças na minha respiraç̧a, por exemplo, quando ela } \\
\text { diminul cu aumenta de velocidade. }\end{array}$ & 0 & 1 & 2 & 3 & 4 & 5 \\
\hline $\begin{array}{l}\text { 5. Eu nåo percebo (ou lgnoro) a tensăo fislca ou desconforto ate que eles se } \\
\text { tornem mals graves. }\end{array}$ & 0 & 1 & 2 & 3 & 4 & 5 \\
\hline 6. Eu procuro me distrair de sensaçbes de desconforto. & 0 & 1 & 2 & 3 & 4 & 5 \\
\hline 7. Quando eu sinto dor ou desconforto, eu tento supera-los. & 0 & 1 & 2 & 3 & 4 & 5 \\
\hline 8. Quando eu sinto dor fisica, eu flco chateado. & 0 & 1 & 2 & 3 & 4 & 5 \\
\hline $\begin{array}{l}\text { 9. Eu comę̧o a ficar preocupado de que alguma colsa nå esta bem quando } \\
\text { sinto qualquer descontorto. }\end{array}$ & 0 & 1 & 2 & 3 & 4 & 5 \\
\hline $\begin{array}{l}\text { 10. Eu posso perceber uma sensaçá desagradável no meu corpo, sem me } \\
\text { preocupar com ela }\end{array}$ & 0 & 1 & 2 & 3 & 4 & 5 \\
\hline $\begin{array}{l}\text { 11. Eu posso prestar atençá na minha respiraçăo sem me distralr com colsas } \\
\text { acontecendo ao meu redor. }\end{array}$ & 0 & 1 & 2 & 3 & 4 & 5 \\
\hline $\begin{array}{l}\text { 12. Eu posso manter a conscléencla das minhas sensaç̧es corporals Internas } \\
\text { mesmo quando multas colsas estäo acontecendo ao meu redor. }\end{array}$ & 0 & 1 & 2 & 3 & 4 & 5 \\
\hline 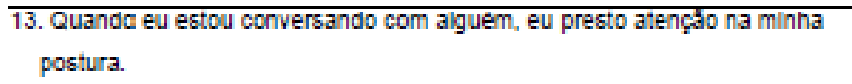 & 0 & 1 & 2 & 3 & 4 & 5 \\
\hline $\begin{array}{l}\text { 14. Eu consigo voltar a prestar atenç̧ăo ao meu corpo mesmo se estiver } \\
\text { distraldo. }\end{array}$ & 0 & 1 & 2 & 3 & 4 & 5 \\
\hline $\begin{array}{l}\text { 15. Eu posso resgatar minha atençăo, Indo do pensamento para as } \\
\text { sensaçbes que ocorrem em meu corpo. }\end{array}$ & 0 & 1 & 2 & 3 & 4 & 5 \\
\hline
\end{tabular}


Circule um numero em cada llnha

\begin{tabular}{|c|c|c|c|c|c|c|}
\hline & Nunc: & & & & & pre \\
\hline $\begin{array}{l}\text { 16. Eu sou capaz de manter a atençăo em todo o meu corpo mesmo } \\
\text { quando uma parte de mim esta com dor ou desconforto. }\end{array}$ & 0 & 1 & 2 & 3 & 4 & 5 \\
\hline $\begin{array}{l}\text { 17. Eu sou capaz de intenclonaimente prestar a atenç5̆o em meu corpo } \\
\text { como un todo. }\end{array}$ & 0 & 1 & 2 & 3 & 4 & 5 \\
\hline 18. Eu percebo como meu corpo muda quando eu estou zangado (bravo). & 0 & 1 & 2 & 3 & 4 & 5 \\
\hline $\begin{array}{l}\text { 19. Quando alguma colsa năo esta bem em minha vida, posso sentir lsso no } \\
\text { meu corpo. }\end{array}$ & 0 & 1 & 2 & 3 & 4 & 5 \\
\hline $\begin{array}{l}\text { 20. Eu percebo que o meu corpo flca diferente depols de uma experlencla } \\
\text { tranqulla. }\end{array}$ & 0 & 1 & 2 & 3 & 4 & 5 \\
\hline $\begin{array}{l}\text { 21. Eu percebo que minha respiraçăo se torna Ivire e facll quando eu me } \\
\text { sinto confortavel. }\end{array}$ & 0 & 1 & 2 & 3 & 4 & 5 \\
\hline 22. Eu percebo como meu corpo muda quando eu me sinto feliz/contente. & 0 & 1 & 2 & 3 & 4 & 5 \\
\hline $\begin{array}{l}\text { 23. Quando me sinto multo estressado, consigo encontrar a calma e a paz } \\
\text { dentro de mim. }\end{array}$ & 0 & 1 & 2 & 3 & 4 & 5 \\
\hline $\begin{array}{l}\text { 24. Quando eu trago a minha consclencla para o meu corpo eu sinto uma } \\
\text { sensaç̧o de caima. }\end{array}$ & 0 & 1 & 2 & 3 & 4 & 5 \\
\hline 25. Eu uso minha respiraçăo para reduzir a tensăo. & 0 & 1 & 2 & 3 & 4 & 5 \\
\hline $\begin{array}{l}\text { 26. Quando eu sou "pego" por meus pensamentos, eu posso acaimar minha } \\
\text { mente focando em meu corpoirespiraçăo. }\end{array}$ & 0 & 1 & 2 & 3 & 4 & 5 \\
\hline $\begin{array}{l}\text { 27. Eu presto atenç̧o as Informaçbes vindas do meu corpo sobre o meu } \\
\text { estado emocional. }\end{array}$ & 0 & 1 & 2 & 3 & 4 & 5 \\
\hline $\begin{array}{l}\text { 28. Quando estou chateado, eu levo um tempo para perceber como meu } \\
\text { corpo se sente. }\end{array}$ & 0 & 1 & 2 & 3 & 4 & 5 \\
\hline $\begin{array}{l}\text { 29. Eu presto atençtáo no meu corpo para dar Informaçbes sobre o que devo } \\
\text { fazer. }\end{array}$ & 0 & 1 & 2 & 3 & 4 & 5 \\
\hline 30. Eu me sinto bem no meu corpo. & 0 & 1 & 2 & 3 & 4 & 5 \\
\hline 31. Eu sinto que meu corpo e um lugar seguro. & 0 & 1 & 2 & 3 & 4 & 5 \\
\hline 32. Eu conflo nas sensaçס̄es do meu corpo. & 0 & 1 & 2 & 3 & 4 & 5 \\
\hline
\end{tabular}




\section{ANEXO D}

Questionário de Regulação Emocional (QRE)

$$
\text { l }
$$

Voluntário $\mathrm{N}^{\circ}$

\section{QRE}

Gostaríamos de te fazer algumas perguntas sobre sua vida emocional, em particular, sobre como você se controla (isto é, regula e administra) suas emoções. Estamos interessados em 2 aspectos da sua vida emocional. Um é a sua experiência emocional, ou o que você sente dentro de si. O outro é a sua expressão emocional, ou como você demonstra suas emoções na fala, gestos e comportamentos. Embora algumas das perguntas seguintes possam parecer similares umas as outras, elas se diferem em aspectos importantes. Para cada item, por favor responda usando a escala seguinte

$\begin{array}{lll}\begin{array}{l}\text { Discordo } \\ \text { fortemente }\end{array} & \text { neutro } & -5 \\ \text { fortemente }\end{array}$

1. Quando eu quero sentir emoções mais positivas (tais como alegria e diversão), eu mudo o que eu estou pensando.

2. Eu guardo minhas emoções para mim mesmo.

3. _uando eu quero sentir emoções menos negativas (tais como tristeza e raiva), eu mudo o que eu estou pensando.

4. ___ Quando eu estou sentindo emoções positivas, eu tomo o cuidado de não demonstrá-las.

5. _uando eu me deparo com uma situação estressante, eu tento pensar nela de forma a me ajudar a ficar calmo.

6. Eu controlo as minhas emoções não as expressando.

7. Quando eu quero sentir emoçōes mais positivas, eu mudo a forma como eu estou pensando na situação.

8. Eu controlo minhas emoções mudando a forma como eu penso a respeito da situação em que estou.

9. ___ Quando eu estou sentindo emoções negativas, eu não as expresso.

10. Quando eu quero sentir emoções menos negativas, eu mudo a forma como eu estou pensando na situação. 
ANEXO E

Escala de Alexitimia de Toronto (TAS - 20)

Escala de Alexitimia De Toronto - TAS -20

Nome: Sexo: Idade:

Data Escolaridade:

Profissão:

Usando a escala fornecida como guia, indique o seu grau de concordância com cada uma das seguintes afirmações fazendo um círculo à volta do número correspondente. Dê só uma resposta por cada afirmação.

Use a seguinte chave:

1. Discordo totalmente

2. Discordo em parte

3. Nem discordo nem concordo

4. Concordo em parte

5. Concordo totalmente

1. Fico muitas vezes confuso sobre qual a emoção que estou a sentir

$$
\begin{array}{lllll}
1 & 2 & 3 & 4 & 5
\end{array}
$$

2. Tenho dificuldade em encontrar as palavras certas para descrever os meus sentimentos

$\begin{array}{lllll}1 & 2 & 3 & 4 & 5\end{array}$

3. Tenho sensações físicas que nem os médicos compreendem

$$
\begin{array}{lllll}
1 & 2 & 3 & 4 & 5
\end{array}
$$

4. Sou capaz de descrever facilmente os meus sentimentos $\begin{array}{lllll}1 & 2 & 3 & 4 & 5\end{array}$

5. Prefiro analisar os problemas a descrevê-los apenas

$$
\begin{array}{lllll}
1 & 2 & 3 & 4 & 5
\end{array}
$$


6. Quando estou aborrecido, não sei se me sinto triste, assustado ou zangado $\begin{array}{lllll}1 & 2 & 3 & 4 & 5\end{array}$

7. Fico muitas vezes intrigado com sensações do meu corpo $\begin{array}{lllll}1 & 2 & 3 & 4 & 5\end{array}$

8. Prefiro simplesmente deixar as coisas acontecer a compreender por que acontecem assim

$\begin{array}{lllll}1 & 2 & 3 & 4 & 5\end{array}$

9. Tenho sentimentos que não consigo identificar bem

$\begin{array}{lllll}1 & 2 & 3 & 4 & 5\end{array}$

10. É essencial estar em contato com as emoções

$\begin{array}{lllll}1 & 2 & 3 & 4 & 5\end{array}$

11. Acho difícil descrever o que sinto em relação às pessoas

$\begin{array}{lllll}1 & 2 & 3 & 4 & 5\end{array}$

12. As pessoas dizem-me para falar mais dos meus sentimentos

$\begin{array}{lllll}1 & 2 & 3 & 4 & 5\end{array}$

13. Não sei o que se passa dentro de mim

$\begin{array}{lllll}1 & 2 & 3 & 4 & 5\end{array}$

14. Muitas vezes não sei porque estou zangado

$\begin{array}{lllll}1 & 2 & 3 & 4 & 5\end{array}$

15. Prefiro conversar com as pessoas sobre as suas atividades diárias do que sobre os seus sentimentos

$\begin{array}{lllll}1 & 2 & 3 & 4 & 5\end{array}$

16. Prefiro assistir a espetáculos ligeiros do que a dramas psicológicos

$$
\begin{array}{lllll}
1 & 2 & 3 & 4 & 5
\end{array}
$$


17. É-me difícil revelar os sentimentos mais íntimos mesmo a amigos próximos $\begin{array}{lllll}1 & 2 & 3 & 4 & 5\end{array}$

18. Posso sentir-me próximo de uma pessoa mesmo em momentos de silêncio $\begin{array}{lllll}1 & 2 & 3 & 4 & 5\end{array}$

19. Considero o exame dos meus sentimentos úteis na resolução de problemas pessoais

$\begin{array}{lllll}1 & 2 & 3 & 4 & 5\end{array}$

20. Procurar significados ocultos nos filmes e peças de teatro distrai do prazer que proporcionam

$\begin{array}{lllll}1 & 2 & 3 & 4 & 5\end{array}$


ANEXO F

Positive And Negative Affect Schedule (PANAS-3)

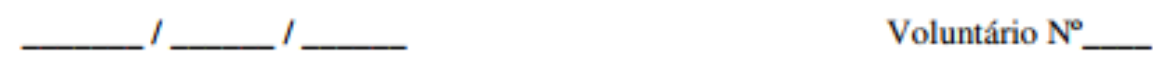

PANAS-3

Essa escala consiste de palavras que descrevem diferentes sentimentos e emoçōes. Leia cada item e então marque a resposta apropriada no espaço ao lado da palavra. Indique o quanto você se sente assim NO MOMENTO.

\begin{tabular}{llllll}
\hline & $\begin{array}{c}\text { Muito pouco ou } \\
\text { nada }\end{array}$ & Um pouco & Moderadamente & Muito & Excessivamente \\
\hline Interessado & $\square$ & $\square$ & $\square$ & $\square$ & $\square$ \\
\hline Aflito & $\square$ & $\square$ & $\square$ & $\square$ & $\square$ \\
\hline Empolgado & $\square$ & $\square$ & $\square$ & $\square$ & $\square$ \\
\hline Chateado & $\square$ & $\square$ & $\square$ & $\square$ & $\square$ \\
\hline Forte & $\square$ & $\square$ & $\square$ & $\square$ & $\square$ \\
\hline Culpado & $\square$ & $\square$ & $\square$ & $\square$ & $\square$ \\
\hline Com medo & $\square$ & $\square$ & $\square$ & $\square$ & $\square$ \\
\hline Hostil & $\square$ & $\square$ & $\square$ & $\square$ & $\square$ \\
\hline Entusiasmado & $\square$ & $\square$ & $\square$ & $\square$ & $\square$ \\
\hline Orgulhoso & $\square$ & $\square$ & $\square$ & $\square$ & $\square$ \\
\hline Irritável & $\square$ & $\square$ & $\square$ & $\square$ & $\square$ \\
\hline Alerta & $\square$ & $\square$ & $\square$ & $\square$ & $\square$ \\
\hline Envergonhado & $\square$ & $\square$ & $\square$ & $\square$ & $\square$ \\
\hline Inspirado & $\square$ & $\square$ & $\square$ & $\square$ & $\square$ \\
\hline Nervoso & $\square$ & $\square$ & $\square$ & $\square$ & $\square$ \\
\hline Determinado & $\square$ & $\square$ & $\square$ & $\square$ & $\square$ \\
\hline Atento & $\square$ & $\square$ & $\square$ & $\square$ & $\square$ \\
\hline Agitado & $\square$ & $\square$ & $\square$ & $\square$ & $\square$ \\
\hline Ativo & $\square$ & $\square$ & $\square$ & $\square$ & $\square$ \\
\hline Apavorado & $\square$ & $\square$ & $\square$ & $\square$ & $\square$ \\
\hline
\end{tabular}


ANEXO G

Igroup Presence Questionnaire (IPQ)

\section{Questionario sobre Realldade Virtual - IPQ}

Responda as perguntas ababxo em relaçăo a experiencla pela qual passou. Marque um $X$ sobre o quadrado que responde mals adequadamente as perguntas.

1- 0 quanto voce estava clente do entomo do mundo real enquanto navegava no mundo virtual (sons, temperatura da sala, outras pessoas etc)?

\begin{tabular}{c|c|c|c|c|c|c|}
\hline-3 & -2 & -1 & 0 & +1 & +2 & +3 \\
\hline
\end{tabular}

2- Qudo real o mundo virtual pareceu para voce?

\begin{tabular}{c|c|c|c|c|c|c|}
\hline-3 & -2 & -1 & 0 & +1 & +2 & +3 \\
\hline
\end{tabular}

3- Eu tive a sensaçăo de agir dentro do espaço virtual, ao inves de operar algo pelo lado de fora.

\begin{tabular}{|c|c|c|c|c|c|c|}
\hline-3 & -2 & -1 & 0 & +1 & +2 & +3 \\
\hline
\end{tabular}

4- Quanto a sua experiencla no mundo virtual pareceu consistente com sua expertencla no mundo real?

\begin{tabular}{|c|c|c|c|c|c|c|}
\hline-3 & -2 & -1 & 0 & +1 & +2 & +3 \\
\hline năo consistente
\end{tabular}

5- Quáo real o mundo virtual pareceu para voce?

\begin{tabular}{|c|c|c|c|c|c|c|}
\hline-3 & -2 & -1 & 0 & +1 & +2 & +3 \\
\hline
\end{tabular}

6- Eu năo me sentl presente no espaço virtual.

\begin{tabular}{|c|c|c|c|c|c|c|}
\hline-3 & -2 & -1 & 0 & +1 & +2 & +3 \\
\hline
\end{tabular}


7- Eu náo estava clente do meu amblente real.

\begin{tabular}{|c|c|c|c|c|c|c|}
\hline-3 & -2 & -1 & 0 & +1 & +2 & +3 \\
\hline
\end{tabular}

8- No mundo gerado por computador eu twe a sensaçăo de "estar la".

\begin{tabular}{|c|c|c|c|c|c|c|}
\hline-3 & -2 & -1 & 0 & +1 & +2 & +3 \\
\hline
\end{tabular}

9- De alguma forma eu sent que o mundo virtual me envolveu.

\begin{tabular}{|c|c|c|c|c|c|c|}
\hline-3 & -2 & -1 & 0 & +1 & +2 & +3 \\
\hline dscordo totalmente & & \multicolumn{5}{c|}{ concordo totalmente }
\end{tabular}

10- Eu me senti presente no espaço vitual.

\begin{tabular}{|c|c|c|c|c|c|c|}
\hline-3 & -2 & -1 & 0 & +1 & +2 & +3 \\
\hline discordo totalmente & & & & concordo totamente
\end{tabular}

11- Eu contnuava prestando atençăo ao amblente real.

\begin{tabular}{|c|c|c|c|c|c|c|}
\hline-3 & -2 & -1 & 0 & +1 & +2 & +3 \\
\hline
\end{tabular}

12- O mundo virtual pareceu mals realista que o mundo real.

\begin{tabular}{|c|c|c|c|c|c|c|}
\hline-3 & -2 & -1 & 0 & +1 & +2 & +3 \\
\hline
\end{tabular}

13- Eu sent como se eu estivesse apenas percebendo magens.

\begin{tabular}{|c|c|c|c|c|c|c|}
\hline-3 & -2 & -1 & 0 & +1 & +2 & +3 \\
\hline
\end{tabular}

14- Eu estava completamente capturado pelo mundo virual.

\begin{tabular}{|c|c|c|c|c|c|c|}
\hline-3 & -2 & -1 & 0 & +1 & +2 & +3 \\
\hline dscordo totalmente & \multicolumn{5}{c|}{ concordo totalmente } \\
\end{tabular}




\author{
ANEXO H \\ Termo de Consentimento Livre e Esclarecido \\ TERMO DE CONSENTIMENTO LIVRE E ESCLARECIDO
}

Nome:

$\mathrm{RG}$ :

Matrícula

Assinatura:

Título do projeto: "A Indução de humor por realidade virtual na promoção de consciência interoceptiva e emocional" (Estudo sobre geração de emoção e sua influência na autoconsciência).

Pesquisador responsável pelo projeto: Dr. Daniel Mograbi.

Departamento: Departamento de Psicologia da Pontifícia Universidade Católica do Rio de Janeiro (PUC-Rio)

Contatos: Pedro Diniz - pedrodinizbernardo@gmail.com (21) 981215155.

Dr. Daniel Mograbi - danielmograbi@puc-rio.br (21) 3527-2086/2075.

Você está sendo convidado (a) a participar de um projeto de pesquisa que pretende investigar a relação entre a geração de emoções pelo equipamento de realidade virtual e suas contribuições para a autoconsciência. O estudo será dividido em três momentos. Desta forma, primeiramente, sua participação como voluntário (a) será responder algumas perguntas relativas a características individuais, hábitos e comportamentos na forma de questionários, e também assistir um filme interativo (simulação virtual) para que se acostume com o equipamento. Já no segundo momento, sua tarefa será participar de outro filme interativo (simulação virtual). O pesquisador lhe dará as instruções em detalhes antes do teste começar e será dado o início. Os vídeos interativos representam situações que podem ser vividas normalmente no cotidiano, ainda assim, caso ocorra algum desconforto, os testes poderão ser interrompidos imediatamente. Durante a atividade serão registradas medidas fisiológicas, mais especificamente a frequência cardíaca, sudorese e temperatura corporal. Estas são medidas não invasivas, não causam dor, choques ou qualquer outro desconforto. No terceiro momento, será conduzida uma entrevista na qual será pedido dados relacionados à simulação virtual em que participou e sobre o quanto se sentiu 
envolvido. É importante mencionar que você não terá nenhum custo financeiro decorrente da participação neste estudo. Quanto aos riscos, há a possibilidade de desconforto como náusea e dores de cabeça, relacionada ao uso dos óculos de realidade virtual. Caso possua condições que se agravem com o uso da Realidade Virtual (como labirintite, problemas cardíacos, acrofobia) não poderá participar do estudo. Como dito acima, os aparelhos de captação das medidas fisiológicas não são invasivos, não dão choque ou qualquer outro desconforto. Os questionários não apresentam riscos, mas alguns podem conter perguntas pessoais sobre o cotidiano dos participantes. Também não existem benefícios diretos da participação na pesquisa, entretanto, os resultados podem ter importantes implicações clínicas, como por exemplo, para as práticas clínicas, e esclarecimento de fatores que podem ser melhor prevenidos ou gerenciado em diferentes quadros patológicos. Além disso, pode servir para orientar esforços teóricos na investigação dos temas em questão. Nenhuma das informações coletadas será divulgada de forma a permitir sua identificação, garantindo o anonimato. Logo, os dados pessoais obtidos serão separados dos dados de pesquisa, ou seja, você terá o seu anonimato assegurado. Você também é livre para encerrar sua participação voluntária e retirar seu consentimento a qualquer momento, durante ou após o experimento, o que não acarretará em prejuízo algum a você.

Agradecemos sua participação e estamos à disposição para esclarecer quaisquer dúvidas sobre a pesquisa.

Como participante dessa pesquisa, estou ciente:

- Que recebi respostas ou esclarecimentos a quaisquer dúvidas acerca dos procedimentos, riscos, benefícios e outros assuntos relacionados com a pesquisa;

- Da liberdade de retirar meu consentimento a qualquer momento e deixar de participar do estudo sem razão específica e sem nenhuma consequência;

- Que se manterá o caráter confidencial das informações relacionadas ao meu desempenho;

- Que obterei informações atualizadas durante o estudo, ainda que isto possa afetar a minha vontade de continuar participando dele;

- Que os resultados aqui obtidos deverão ser levados a Congressos e publicados em revistas científicas, sempre mantendo o anonimato dos dados coletados.

$\mathrm{Eu}$, acredito

ter sido suficientemente informado a respeito do estudo acima citado. Ficaram claros 
para mim quais são os procedimentos a serem realizados, as garantias de confidencialidade e de esclarecimentos permanentes. Concordo voluntariamente em participar deste estudo e poderei retirar o meu consentimento a qualquer momento, antes ou durante o mesmo, sem penalidades ou prejuízos de qualquer espécie.

Rio de Janeiro, de de 20 .

Assinatura:

Pesquisador: 